OSTEOLOGY OF THE MIDDLE EOCENE

CERATOMORPH HYRACHYUS MODESTUS

(MAMMALIA, PERISSODACTYLA)

BIN BAI, JIN MENG, YUAN-QING WANG, HAI-BING WANG, AND LUKE HOLBROOK

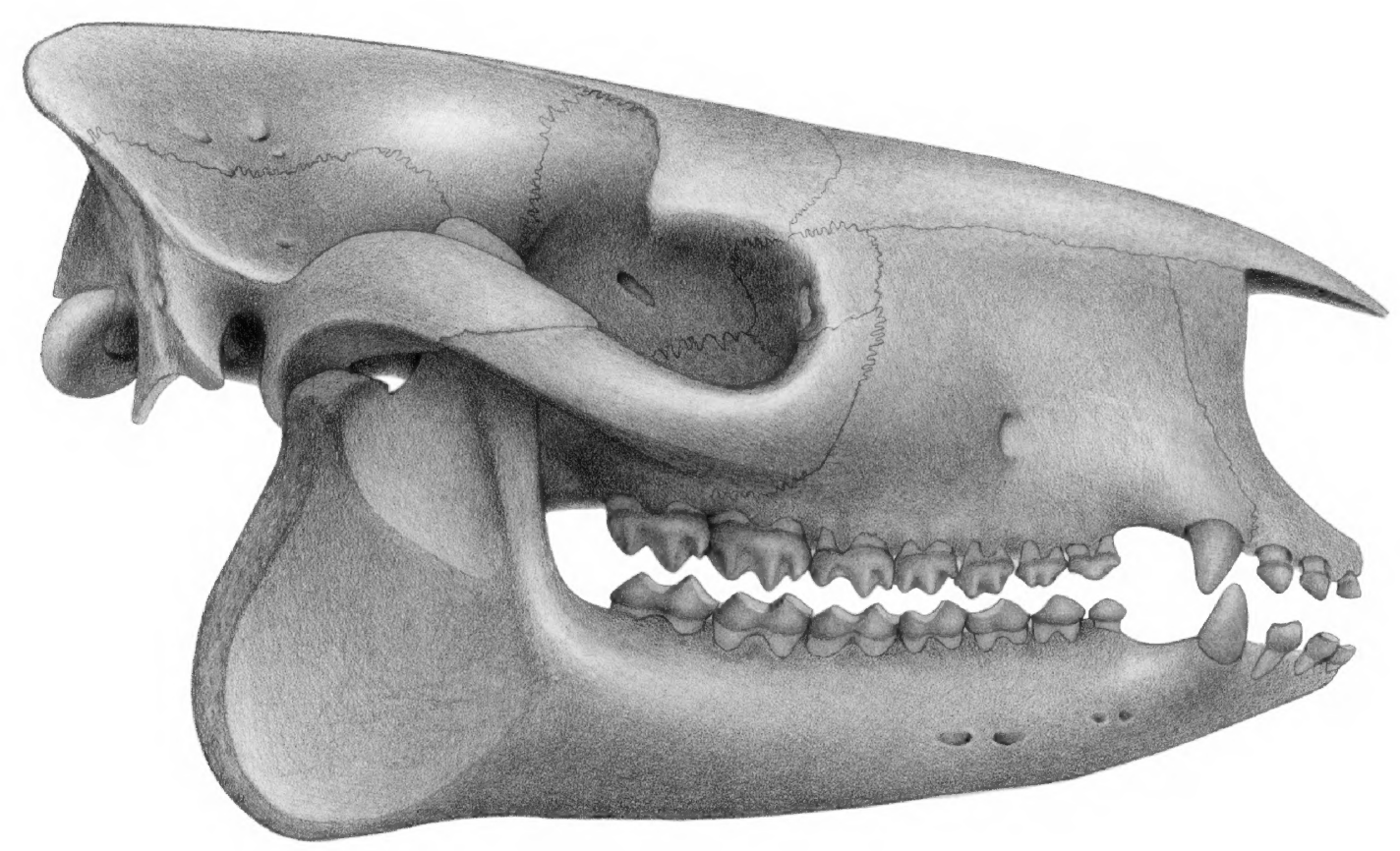

BULLETIN OF THE AMERICAN MUSEUM OF NATURAL HISTORY 


\title{
OSTEOLOGY OF THE MIDDLE EOCENE CERATOMORPH HYRACHYUS MODESTUS (MAMMALIA, PERISSODACTYLA)
}

\author{
BIN BAI
}

Key Laboratory of Vertebrate Evolution and Human Origins of Chinese Academy of Sciences, Institute of Vertebrate Paleontology and Paleoanthropology, CAS, Beijing; and State Key Laboratory of

Palaeobiology and Stratigraphy, Nanjing Institute of Geology and Palaeontology, CAS, Nanjing

\section{JIN MENG}

Key Laboratory of Vertebrate Evolution and Human Origins of Chinese Academy of Sciences, Institute of Vertebrate Paleontology and Paleoanthropology, CAS, Beijing; and Division of Paleontology, American Museum of Natural History, New York

\section{YUAN-QING WANG}

Key Laboratory of Vertebrate Evolution and Human Origins of Chinese Academy of Sciences, Institute of Vertebrate Paleontology and Paleoanthropology, CAS, Beijing; and College of Earth Science, UCAS, Beijing

\section{HAI-BING WANG}

Key Laboratory of Vertebrate Evolution and Human Origins of Chinese Academy of Sciences, Institute of Vertebrate Paleontology and Paleoanthropology, CAS, Beijing; and UCAS, Beijing

\section{LUKE HOLBROOK}

Department of Biological Sciences, Rowan University, Glassboro, NJ; Division of Paleontology, American Museum of Natural History; and Department of Vertebrate Zoology, Academy of Natural Sciences of Drexel University, Philadelphia

BULLETIN OF THE AMERICAN MUSEUM OF NATURAL HISTORY

Number 413, 68 pp., 34 figures, 22 tables

Issued June 9, 2017 


\section{CONTENTS}

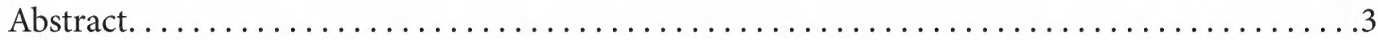

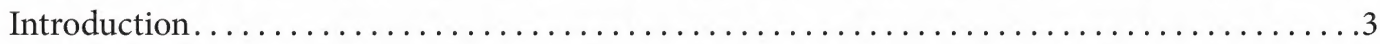

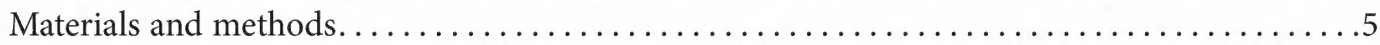

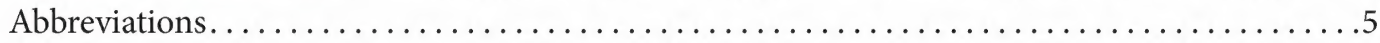

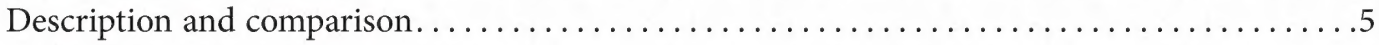

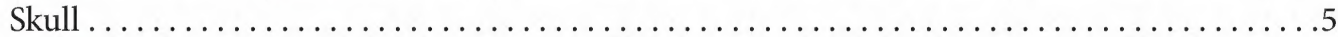

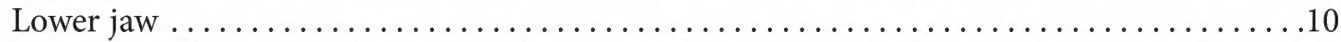

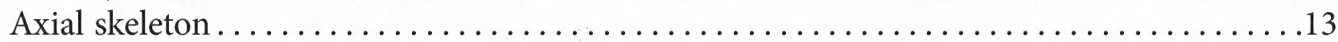

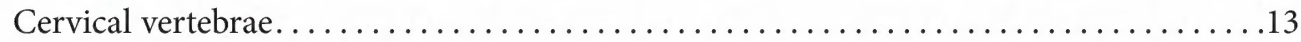

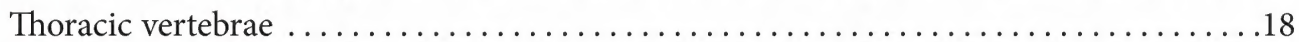

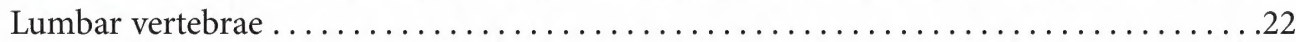

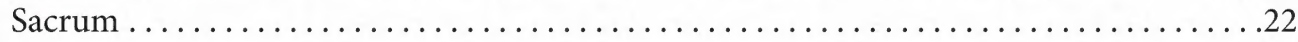

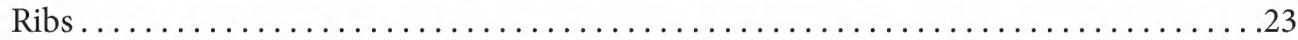

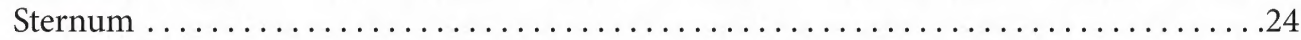

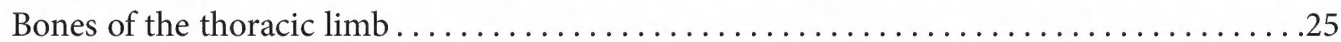

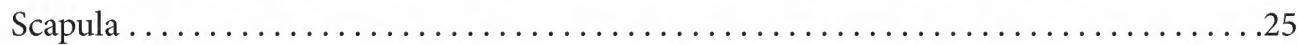

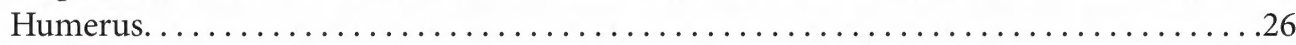

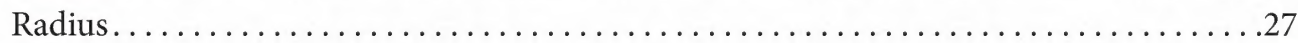

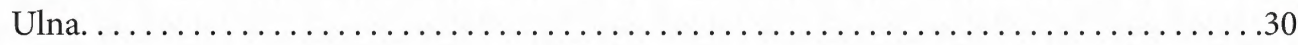

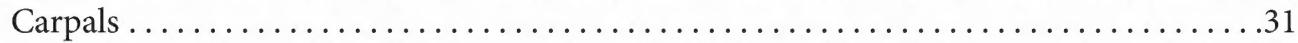

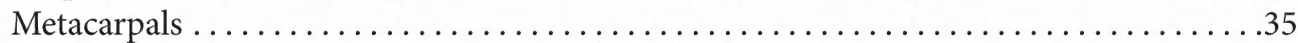

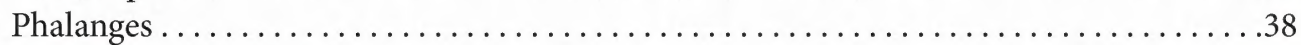

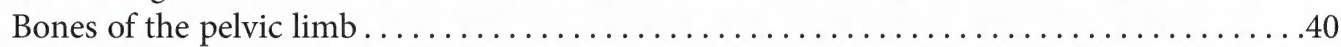

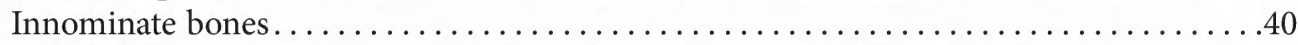

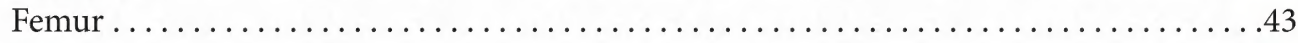

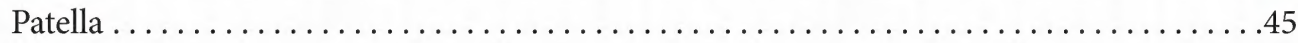

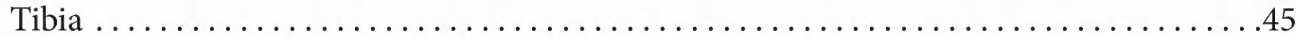

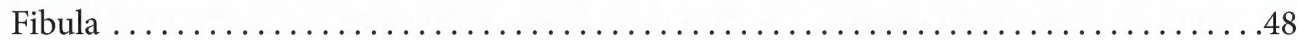

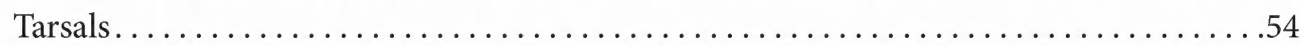

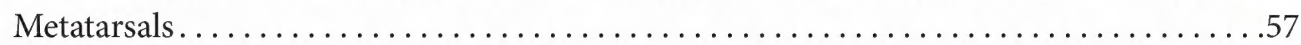

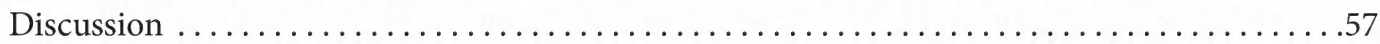

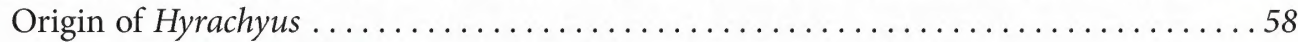

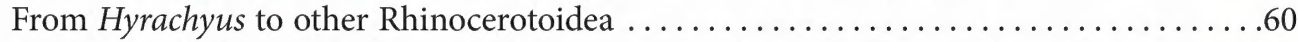

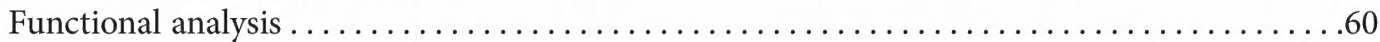

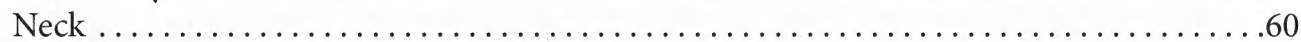

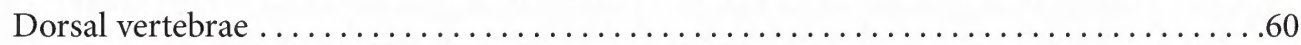

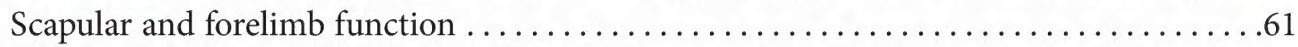

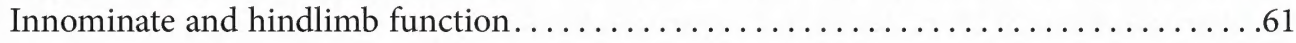

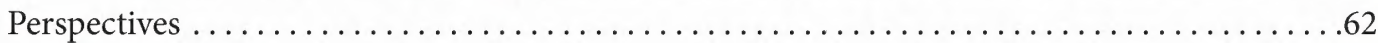

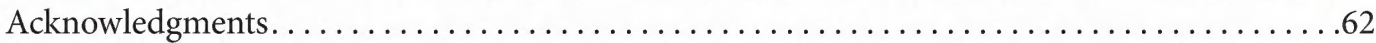

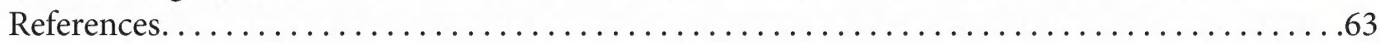

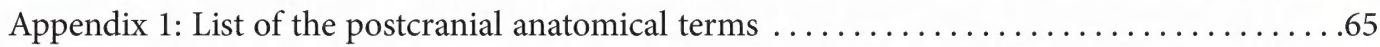




\begin{abstract}
The middle Eocene ceratomorph Hyrachyus has been considered a pivotal genus in ceratomorph evolution, either as a transitional form from tapiroids to rhinocerotoids, giving rise to all later rhinocerotoids, or else as the sister taxon to other rhinocerotoids. Thus, Hyrachyus has been commonly chosen as an outgroup in phylogenetic analyses of rhinocerotoids. However, little has been published on the osteology of Hyrachyus, even though well-preserved craniodental and postcranial specimens of this taxon have been in collections for decades. Here, we describe and illustrate the cranial and postcranial osteology of Hyrachyus modestus, based mainly on the exceptionally preserved specimens housed at the American Museum of Natural History, specifically AMNH FM 12664. Our bone-by-bone description provides detailed information on the osteological morphology of Hyrachyus, which should be useful for phylogenetic analyses of both rhinocerotoids and perissodactyls in general, because it provides one of the more complete and best-preserved examples of the skeleton of an earlier Eocene perissodactyl.

The cranial morphology of Hyrachyus modestus shows a shallow narial notch, a lacrimal contacting the nasal, and a sphenorbital fissure closely situated to the anterior opening of the alisphenoid canal. In the basicranial region, there is a mastoid exposure of the petrosal between the occipital and the squamosal, and the posttympanic process and paracondylar process are partly fused. The postcranial morphology of Hyrachyus modestus includes the following features: The cervical region of the vertebral column is relatively short compared to the rest of the vertebral column. The lumbar vertebrae have concave-convex embracing prezygapophyses and postzygapophyses. The scapula has a distinct acromion process. The humerus has a greater tubercle that does not elevate above the head, and the deltoid tuberosity and deltopectoral crest are weak. The scaphoid and lunar facets of the radius are confluent. The olecranon of the ulna extends posteroproximally. The manus is functionally tetradactyl, with a complete fifth manual digit. The innominate bone has a long, narrow coxal tuberosity. The greater trochanter of the femur is elevated proximally above the head. The femur has a long, narrow, and symmetric trochlea. The patella has a moderately anteroposteriorly deep base. The intercondyloid eminences of the tibia are equal in height, and the extensor sulcus of the tibia is relatively deep. The fibula has a relatively slender shaft with expanded ends. The pes has three functional digits. The calcaneus does not contact the navicular, nor does the Mt III contact the cuboid.

Comparisons between the skeleton of Hyrachyus modestus and those of the early tapiroid Heptodon, the hyracodontid Triplopus, the paraceratheriid Juxia, and the rhinocerotid Uintaceras were also investigated. These results indicate that Hyrachyus probably did not derive from Heptodon, but from a more basal group of ceratomorphs. Furthermore, distinct differences between the skeletons of Hyrachyus and Triplopus (the earliest representative of Hyracodontidae) suggest that hyracodontids were not descended from Hyrachyus. However, Hyrachyus-like ancestors probably gave rise to other non-hyracodontid rhinocerotoids. Like that of other Eocene perissodactyls, the postcranial morphology of Hyrachyus modestus exhibits adaptations that suggest that cursorial locomotion was already present early in perissodactyl evolution.
\end{abstract}

\section{INTRODUCTION}

The genus Hyrachyus is a common ceratomorph in the late early Eocene and middle Eocene in North America and Asia, and plays a pivotal role in understanding the origin of rhinocerotoids (Radinsky, 1967b; Prothero et al., 1986). Wood (1934), in his revision of the
Hyrachyidae, recognized four genera and 12 species; however, Radinsky (1967b) recognized only one genus and two species as valid in North America. The two species, Hyrachyus modestus and Hyrachyus eximius, mainly differ in size, and Radinsky (1967b) suggested that they gave rise to the hyracodontids Triplopus and Fostercooperia, respectively. As suggested 
by Schoch (1984), Wood's (1934) revision probably oversplit the Hyrachyidae, and yet Radinsky (1967b) probably oversynonymized the taxa. Emry (1990) suggested the validity of $H$. affinis based mainly on its smaller size. Other authors have recognized as many as eight species of Hyrachyus from China (Radinsky, 1965b; Chow and Qi, 1982; Huang and Qi, 1982; Qi, 1987; Huang and Wang, 2002). Huang and Wang (2002) briefly reviewed Hyrachyus from China in addition to a description of a new species, H. tongi. European Hyrachyus was less common and represented by two species: $H$. modestus $(=H$. stehlini) and $H$. minimus (Savage et al., 1966; Radinsky, 1967b; Franzen, 1981; Hellmund, 2016). The taxonomy of the Hyrachyidae thus needs further revision (Schoch, 1984), especially in light of the fact that Hyrachyus has often been chosen as an outgroup in studies of the phylogeny of the Rhinocerotoidea (Prothero et al., 1986; Cerdeno, 1995; Antoine, 2002; Prothero, 2005; Deng and Chen, 2016).

Cranial and postcranial specimens of Hyrachyus, including complete skeletons, are abundant, particularly from the Bridger Basin of North America. Two complete skeletons of Hyrachyus eximius (AMNH FM 5065) and Hyrachyus affinis (YPM 11170; = H. modestus) were reported by Cope (1884) and Troxell (1922), respectively. Cope (1884) described the famous skeleton of Hyrachyus eximius (see also Osborn, 1898; Wood, 1934: fig. 50), mounted in the $A M N H$, in relative detail; however, the specimen lacks the skull anterior to the occipital region, and Cope's description and illustrations were brief. Troxell (1922) only mentioned a few postcranial characters, although his specimen is nearly complete and has been mounted in the Peabody Museum of Yale University. Holbrook (2001) described many skeletal features of Hyrachyus as part of a broader survey of tapiromorph osteology. However, there has been no detailed description of the skeleton of Hyrachyus since the research of Cope (1884). Wood (1934: 221) mentioned a specimen of Hyrachyus modestus (AMNH FM 12664) as "a fine skull and skeleton, which deserves monographic treatment." AMNH FM 12664 is a well-preserved skeleton, missing the humeri and pes and with some vertebrae and ribs broken. A comprehensive bone-by-bone description of this specimen is valuable for future phylogenetic analyses of perissodactyls, especially when rhinocerotoids are included.

Most postcranial material from the Bridgerian (North American Land Mammal Age) in general, and from the Bridger Basin in particular, has been assigned to Hyrachyus without associated skulls or teeth, so the attribution of these specimens are not certain, especially given the existence of perissodactyl taxa overlapping in size with species of Hyrachyus (Holbrook and Lapergola, 2011). The description of AMNH FM 12664 helps to provide morphological criteria beyond size for identifying isolated postcrania of Hyrachyus.

This work is part of a larger systematic review of perissodactyls, and here we focus on description and comparison of the skeletal morphology of Hyrachyus modestus, based mainly on AMNH FM 12664 and several other specimens housed at the AMNH. The phylogenetic position of Hyrachyus within the Perissodactyla by means of the cladistic analysis will be conducted in future research. Wood (1934) originally assigned AMNH FM 12664 to Hyrachyus affinis. Radinsky (1967b) considered Hyrachyus affinis as a junior synonym of Hyrachyus modestus, though he allowed for the possibility that there were three species of this genus in North America: $H$. modestus in the Bridger $\mathrm{B}$, and two species in the Bridger $\mathrm{C}$ and $\mathrm{D}$, one slightly smaller than $H$. modestus (to which Radinsky assigned it) and a distinctly larger species, $H$. eximius. For this study, we follow Radinsky (1967b) in referring AMNH FM 12664 to $H$. modestus, pending a more thorough revision of Hyrachyidae.

In order to investigate the origin of Hyrachyus and its relationships to other rhinocerotoids, comparisons were made between the cranial 
and postcranial skeletal anatomy of Hyrachyus modestus and that of other early perissodactyls, including Heptodon, Triplopus, Juxia, and Uintaceras. The helaletid Heptodon was regarded as an early representative of Tapiroidea with a close affinity to Hyrachyus (Radinsky, 1963; Radinsky, 1966). Radinsky (1965a) described a nearly complete skeleton of Heptodon posticus in detail. The Uintan Triplopus cubitalis (AMNH FM 5095) is the earliest known member of Hyracodontidae and is known in terms of postcrania from the forelimb and a few vertebrae (Cope, 1884; Radinsky, 1967a). Osborn (1890) described the manus and pes of Triplopus obliquidens (YPM VPPU 10397). The Sharamurunian (Asian Land Mammal Age) rhinocerotoid Juxia is considered to be an early indricothere and possibly as the ancestor of the later giant paraceratheres. Qiu and Wang (2007) thoroughly described Juxia based on a nearly complete skeleton (IVPP V 2891). Wang et al. (2016) described a complete cranium of a basal paraceratheriid Pappaceras meiomenus, with which we also compared. The Uintan rhinocerotoid Uintaceras was regarded as a sister group to Rhinocerotidae and includes much of the postcranial skeleton, as well as a fairly complete but crushed skull (Holbrook and Lucas, 1997). Wang et al. (2016), however, suggested that Uintaceras is closer to paraceratheriids. We also briefly compared the skeleton of $H$. modestus with that of $H$. eximius, because they are almost indistinguishable in morphology beyond the larger size of $H$. eximius. Ultimately, a revision of the family Hyrachyidae may be needed but is beyond the scope of the present paper.

\section{MATERIALS AND METHODS}

The description of Hyrachyus modestus was based mainly on AMNH FM 12664, which was collected by Miller from Grizzly Buttes (Horizon B), Bridger Basin (Wyoming) in 1905. Some other postcranial specimens of $H$. modestus were also studied to compensate for missing elements in AMNH FM 12664, includ- ing the humerus of AMNH FM 12361 (associated with dentitions) from Henry's Fork (Horizon C), Bridger Basin; the innominate, tibia, fibula, cuboid, and ectocuneiform of AMNH FM 11662 from Millersville (Horizon B), Bridger Basin; the astragalus, calcaneus, and mesocuneiform of AMNH FM 1643c from the Bridgerian of the Bridger Basin, Wyoming; and the entocuneiform and metatarsals of AMNH FM 1612 from the Bridgerian of the Bridger Basin, Wyoming. The locality and stratigraphic record of the third metacarpal of AMNH FM 91775 are missing.

For cranial terminology, we follow Wible (2003). For postcranial terminology, we use the combination of Nomina Anatomica Veterinaria (NAV 2005; Sisson et al., 1975; Constantinescu and Schaller, 2007; Evans and de Lahunta, 2013) and Flower (1885) (appendix 1). Measurements were taken using digital calipers and are given in millimeters. Measurements of bones and ratios follow Qiu and Wang (2007) and Gromova (1959).

\section{ABBREVIATIONS}

Institutions: AMNH FM, American Museum of Natural History, Fossil Mammals, New York; CM, Carnegie Museum of Natural History, Pittsburgh; IVPP, Institute of Vertebrate Paleontology and Paleoanthropology, Beijing; YPM, Peabody Museum of Natural History, Yale University, New Haven.

AnATomies: fac., facet; med., medial; lat., lateral; pro., process. Others are listed in the caption of the figures.

\section{DESCRIPTION AND COMPARISON}

\section{SKULL}

The skull is preserved in a relatively good condition with many distinct sutures visible; however, the skull was slightly laterally compressed and the premaxillae, nasals, frontals, and the zygomatic processes of the squamosals were partially broken off (table 1). 


\section{TABLE 1}

Measurements of skulls and lower jaws of Hyrachyus modestus and Hyrachyus eximius (mm) $\mathrm{L}=$ length; $\mathrm{D}=$ distance.

\begin{tabular}{|c|c|c|}
\hline & $\begin{array}{l}\text { Hyrachyus modestus } \\
\text { (AMNH FM 12664) }\end{array}$ & $\begin{array}{r}\text { Hyrachyus eximius } \\
\text { (Qiu and Wang, 2007) }\end{array}$ \\
\hline \multicolumn{3}{|l|}{ Skull } \\
\hline 1. Basilar L & 208.3 & $?$ \\
\hline 2. Premaxilla-condyle, $\mathrm{L}$ & 211.0 & 340 \\
\hline 3. Vertex L & $228.5^{\mathrm{a}}$ & 335 \\
\hline 4. Occipital condyle-postorbital process, L & 98.2 & 140 \\
\hline 5. Premaxilla-postorbital process, $\mathrm{L}$ & 128.3 & 200 \\
\hline 6. P1-condyle, L & 180.3 & 268 \\
\hline 7. Postglenoid process-condyle, D & 38.8 & 36 \\
\hline 8. Nasal notch, L & 21.1 & 46 \\
\hline 9. Orbit-nasal notch, D & 71.3 & 96 \\
\hline 10. Width at condyles & 38.6 & $?$ \\
\hline 11. Width at posttympanic process & 56.6 & $?$ \\
\hline 12. Width at zygomatic arch & $83.0^{\mathrm{a}}$ & 177 \\
\hline 13. Occiput height & 60.5 & 66 \\
\hline 14. Condyle, height $\times$ width & $21.85 \times 10.16$ & $?$ \\
\hline 15. Paracondylar-posttympanic process, L & 18.8 & 18 \\
\hline 16. I1-M3, L & 123.7 & 199.2 \\
\hline 17. Diastema I1-P1 & 41.0 & 62.6 \\
\hline 18. P1-M3, L & 84.3 & 109.8 \\
\hline \multicolumn{3}{|l|}{ Ratio (\%) } \\
\hline $12: 1$ & 40 & $?$ \\
\hline $12: 2$ & 39.4 & 52.2 \\
\hline $4: 5$ & 76.6 & 70 \\
\hline $7: 6$ & 21.5 & 13.4 \\
\hline $17: 18$ & 48.6 & 57 \\
\hline \multicolumn{3}{|l|}{ Mandibles } \\
\hline 1. Total L & 190.1 & 296 \\
\hline 2. p1-angular process, $\mathrm{L}$ & 150.9 & 240 \\
\hline 3. p1-m3 L & 83.9 & 111.4 \\
\hline 4. Height at $\mathrm{p} 2$ & 30.4 & 37.1 \\
\hline 5. Height at $\mathrm{m} 1$ & 36.1 & 44 \\
\hline 6. Coronoid process, height & 93.5 & 160 \\
\hline 7. Condylar process, height & 76.7 & 126 \\
\hline \multicolumn{3}{|l|}{ Ratio (\%) } \\
\hline $3: 1$ & 44.1 & 37.6 \\
\hline $5: 1$ & 19.0 & 14.9 \\
\hline $6: 1$ & 49.2 & 54 \\
\hline $7: 1$ & 40.4 & 42.6 \\
\hline
\end{tabular}

a Approximate measurements. 
Occipital view (fig. 1): The outline of the occipital is roughly a high and narrow rectangle with the middle part constricted and the ventral part slightly expanded. The supraoccipital is deeply concave transversely, so the middle part of the nuchal crest is posteriorly concave, and its lateral part extends anteroventrally to join the weak temporal crest at approximately the middle of the height of the occipital (fig. 2). The exoccipital is convex transversely and anteriorly slanted above the foramen magnum, which is bordered by the occipital condyles. The dorsal apices of the occipital condyles are widely separated, whereas the ventral parts are separated by a narrow notch. The lateroventral border of the condyle (linea divisa condyli) is a somewhat blunt ridge, separating posterior and ventral articular surfaces.

Lateral View (fig. 2): The skull is moderately high and long (table 1). We follow Qiu and Wang (2007) in placing the border between the cranium and the face at the transverse plane through the postorbital processes of the frontals, not at the anterior borders of the orbits (Sisson et al., 1975). The face $(12.0 \mathrm{~cm})$ is longer than the cranium $(10.5 \mathrm{~cm})$. The supraoccipital overhangs the occipital condyles, and is slightly more posteriorly extended than the latter. The linea divisa condyli forms an angle of about $60^{\circ}$ with the long axis of the skull. A number of postparietal foramina (nutrient foramina) are present on the posterior skull surface above the parietal-squamosal suture. The paracondylar process (= paroccipital process) is slender, and extends distally and slightly posteriorly, tapering distally and anteroposteriorly compressed at its distal extremity. The anterior surface of the paracondylar process is excavated, whereas the posterior side is divided by a longitudinal ridge into a flat, narrow posterolateral surface and a concave posterior surface, forming the anterior border of the condyloid fossa. The posttympanic process is separated from the exoccipital by a rather narrow mastoid exposure (mastoid process) on its dorsal half, whereas distally the posttympanic process likely fuses with the para-

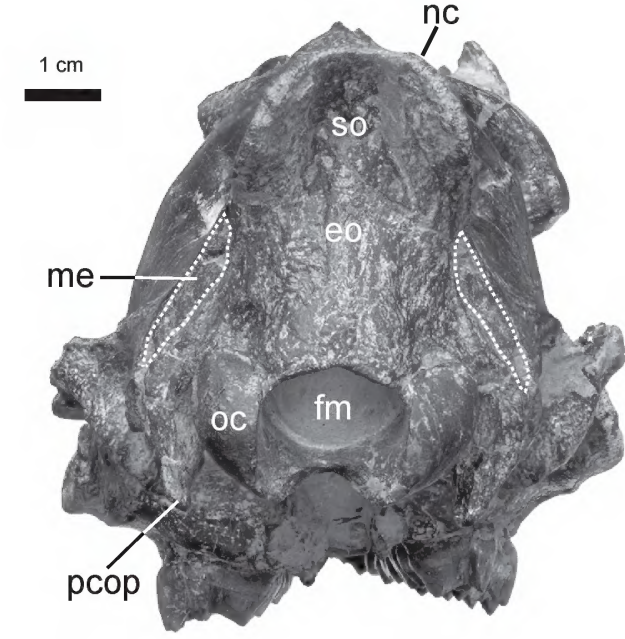

FIG. 1. Occipital region of the skull of Hyrachyus modestus (AMNH FM 12664). Abbreviations: eo, exocciptial; fm, foramen magnum; me, mastoid exposure of petrosal; nc, nuchal crest; oc, occipital condyle; pcop, paracondylar process; so, supraoccipital.

condylar process and extends anteroventally. Above the fused part there is a small mastoid foramen between the mastoid exposure and the posttympanic process. The paracondylar process extends slightly more distally than the occipital condyle but considerably more distally than the posttympanic process. The posttympanic process is widely separated from the postglenoid process.

The squamous bone articulates with the parietal anterodorsally, and with the alisphenoid ventrally and partially on its anteroventral portion. The pterygoid process of the alisphenoid extends anteroventrally with an oval posterior opening of the alisphenoid canal placed at the posterodorsal side. The pterygoid crest is a relatively sharp ridge, and at least three foramina are discernable on the anteromedial side of the pterygoid crest. The most anterodorsal one is the oval optic foramen with a nearly vertical long axis. Between the optic foramen and the pterygoid crest there is a large foramen filled by matrix. Based on the left side, this contains a 

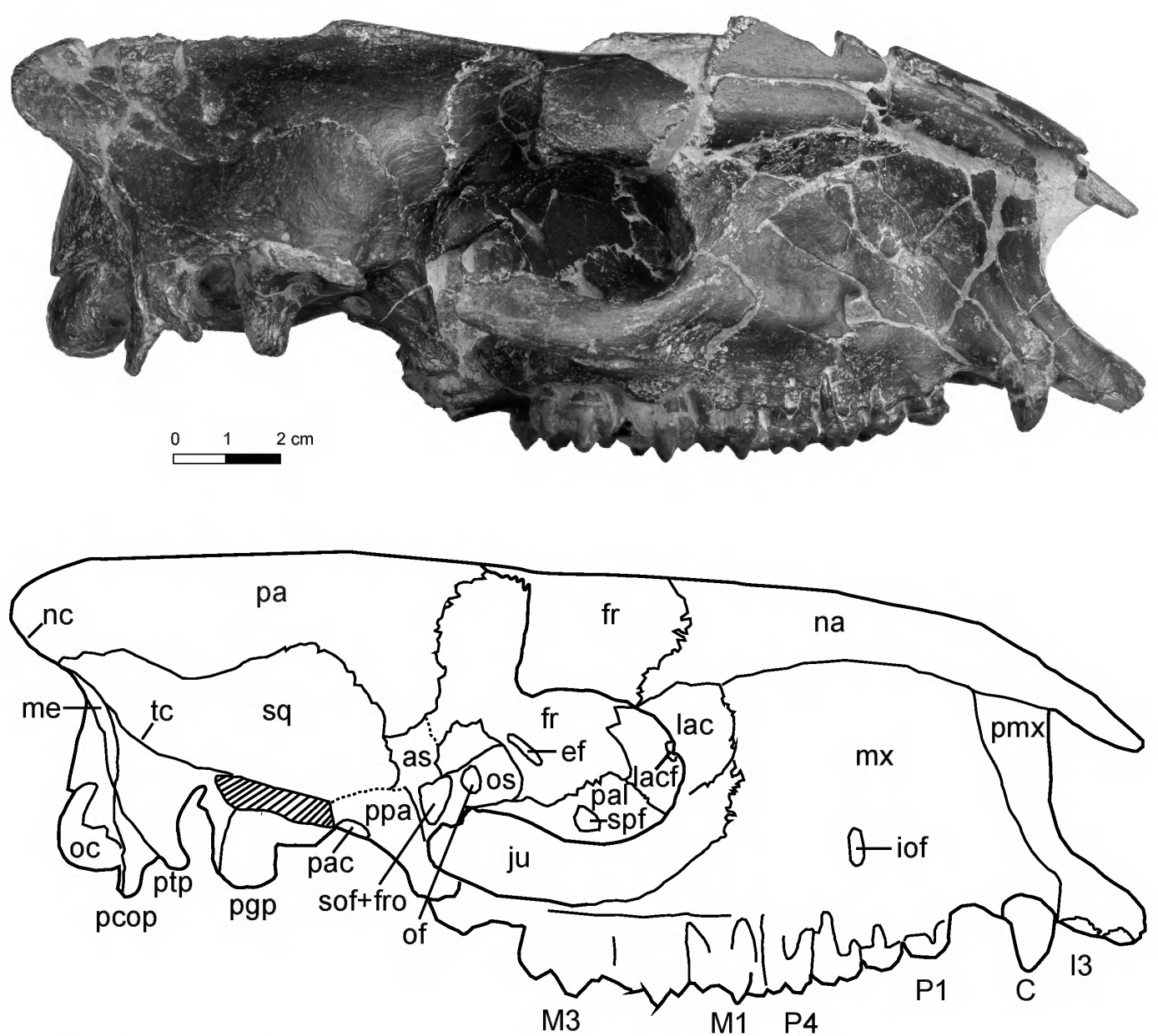

FIG. 2. Lateral view of the skull of Hyrachyus modestus (AMNH FM 12664). Abbreviations: as, alisphenoid; ef, ethmoid foramen; fr, frontal; fro, foramen rotundum; iof, infraorbital foramen; ju, jugal; lac, lacrimal; lacf, lacrimal foramen; me, mastoid exposure of petrosal; mx, maxilla; na, nasal; nc, nuchal crest; oc, occipital condyle; of, optic foramen; os, orbitosphenoid; pa, parietal; pac, posterior opening of the alisphenoid canal; pal, palatine; pcop, paracondylar process; pgp, postglenoid process; pmx, premaxilla; ppa, pterygoid process of alisphenoid; ptp, posttympanic process; sof, sphenorbital fissure; spf, sphenopalatine foramen; sq, squamosal; tc, temporal crest.

dorsal sphenorbital fissure and a ventral foramen rotundum separated by a thin plate. The anterior opening of the alisphenoid canal presumably opens in common with the foramen rotundum, as in other early perissodactyls (Radinsky, 1965a; Holbrook, 2001). A short ridge extends anterodorsally above the sphenorbital fissure and optic foramen, terminating just posterior to an ethmoidal foramen that extends anteroventrally into a narrow and deep groove. About $1.0 \mathrm{~cm}$ posterodorsally to the ethmoidal foramen, there is another small foramen.

The dorsal profile is nearly straight and horizontal, but the anterior part of the nasal slopes downward to some extent, though this may be affected by distortion. The orbit is round and relatively large. The postorbital process of the frontal bone is stout, lying approximately above 

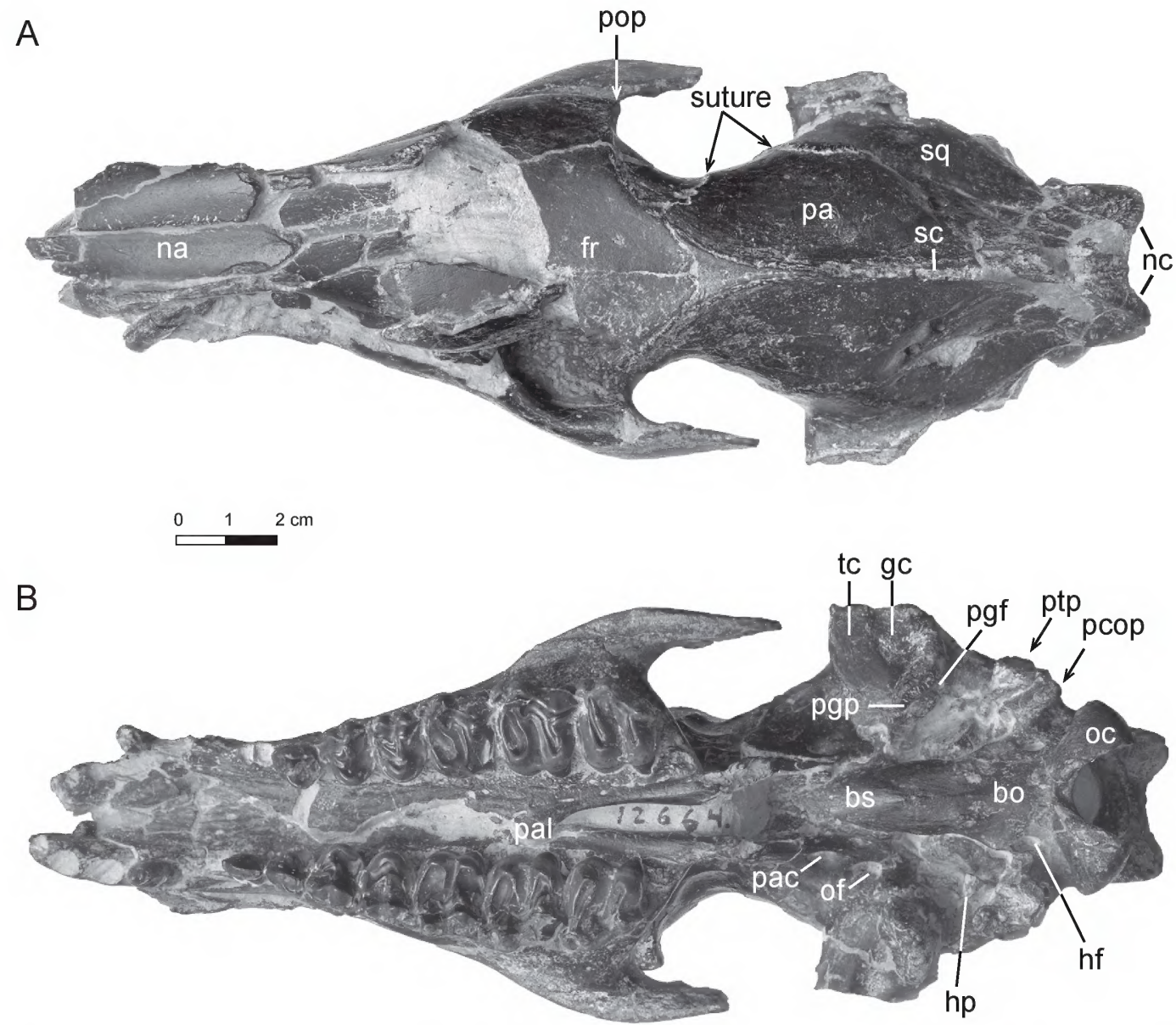

FIG. 3. Skull of Hyrachyus modestus (AMNH FM 12664). A, dorsal; and B, ventral views. Abbreviations: bo, basioccipital; bs, basisphenoid; fr, frontal; gc, glenoid cavity; hf, hypoglossal foramen; hp, hyoid process; na, nasal; nc, nuchal crest; oc, occipital condyle; of, oval foramen; pa, parietal; pac, posterior opening of the alisphenoid canal; pal, palatine; pcop, paracondylar process; pgf, postglenoid foramen; pgp, postglenoid process; pop, postorbital process; ptp, posttympanic process; sc, sagittal crest; sq, squamosal; tc, temporal condyle.

the posterior border of M3. The facial part of the lacrimal bone is moderately large, articulating with the nasal bone on the dorsal side, thus separating the frontal and maxilla. The orbital part of the lacrimal is larger than the facial part, and a lacrimal foramen is present along the anterior border of the orbit, which is situated approximately at the level of the anterior border of M2. The lacrimal tuberosity is essentially absent. The jugal forms the rough, concave ventral border of the orbit. The maxilla housing M2 and M3 (i.e., the tuber maxillae) forms the ventral surface of the orbital medially.

The tip of the nasal overhangs the premaxilla. The narial notch is shallow and ends above the canine. The maxilla is large and somewhat concave in its anterior portion, a condition probably attributable to postmortem transverse compression. The infraorbital foramen is situated above the anterior half of P3, nearly at the same horizontal level as the ventral border of the orbit. The premaxilla is long and slen- 
der, articulating with the nasal dorsally and maxilla posteriorly. The body of the premaxilla extends anteroventrally.

Dorsal VIEW (fig. 3A): Although the sagittal crest is partially broken, it is long and splits posteriorly into two diverging ridges, which are continuous with the nuchal crest. The sagittal crest bifurcates into two frontal ridges anteriorly, which curve anteroventrally and lead to the postorbital processes of the frontals, at the level of the anterior border of the temporal condyle. The posterior border of the nasal is transversely extended, and the frontal intrudes between the nasals medially (based on the specimen of AMNH FM 13756, cast of YPM 17580).

Ventral View (fig. 3B): The condyloid fossa between the occipital condyle and the paracondylar process is deeply concave. The paracondylar process is situated posteromedial to the posttympanic process, and a hyoid process is situated anteromedial to the posttympanic process. On the medial side of the paracondylar process there is an oval hypoglossal foramen. The suture between the basioccipital and basisphenoid is obliterated on AMNH FM 12664, whereas on AMNH FM 13756 this suture is present approximately at the level of the postglenoid process. A weak median ridge is present on the anterior half of the ventral side of the basioccipital with two tubercles on either side in the middle of the basioccipital. The basisphenoid is smooth and laterally convex. The detailed characters of the petrosal are obscured by matrix. The temporal condyle is flat, curving onto the anteromedial surface of the postglenoid process. Posterior to the temporal condyle is the moderately concave glenoid cavity. The postglenoid process is oriented anterolaterally at an angle of about $45^{\circ}$ from the long axis of the skull, with a small postglenoid foramen on the posteromedial side. A relatively large foramen ovale is present on the medial side of the temporal condyle, and the posterior opening of the alisphenoid (alar) canal is situated a short distance anteromedial to the foramen ovale. The posterior border of the palate is situated approximately at the level of the pos- terior border of M2 based on the specimen of AMNH FM 13756.

\section{LOWER JAW}

The lower jaw was broken into right and left mandibles, and the left condylar process and the tips of coronoid processes on both sides are not complete (table 1). The mandible is long and slender (fig. 4). The body is procumbent anteriorly with the posterior border of the symphysis situated at the level of p2 (fig. 4C). The lingual surface of the body is long, narrow, and relatively deep. The mental surface is convex with several small nutrient foramina.

The ventral border of the horizontal ramus is nearly straight with a shallow vascular impression. The alveolar border ascends slightly posteriorly. On the left side, two equal-sized mental foramina are present below the middle of $\mathrm{p} 3$ and the anterior border of $\mathrm{p} 4$, respectively. On the right side, only one medium-sized mental foramen is present below the anterior border of p4. There are three small foramina, probably nutrient foramina, present below the diastema and $\mathrm{p} 1$ and $\mathrm{p} 2$, respectively.

The angular process of the mandible is rounded and somewhat posteriorly extended with rough borders; thus, the anterior border of the vertical ramus (= coronoid crest) is nearly vertical, whereas the posterior border (= condyloid crest) slants anterodorsally. The lateral surface of the angle is flat with slightly reticulated impressions for attachment of the superficial masseter muscle, whereas the masseteric fossa above the level of the alveolar border is more concave for the attachment of the deep masseter muscle (fig. 4A). The medial surface of the angular process is concave, especially on the posterior side, for the attachment of internal pterygoid muscle (fig. 4B), where the posterior border of the angular process curves medially forming a flange. A relatively large mandibular foramen is present just above the level of the alveolar border.

The condylar process is relatively high (about $44 \mathrm{~mm}$ higher than the alveolar border), trans- 


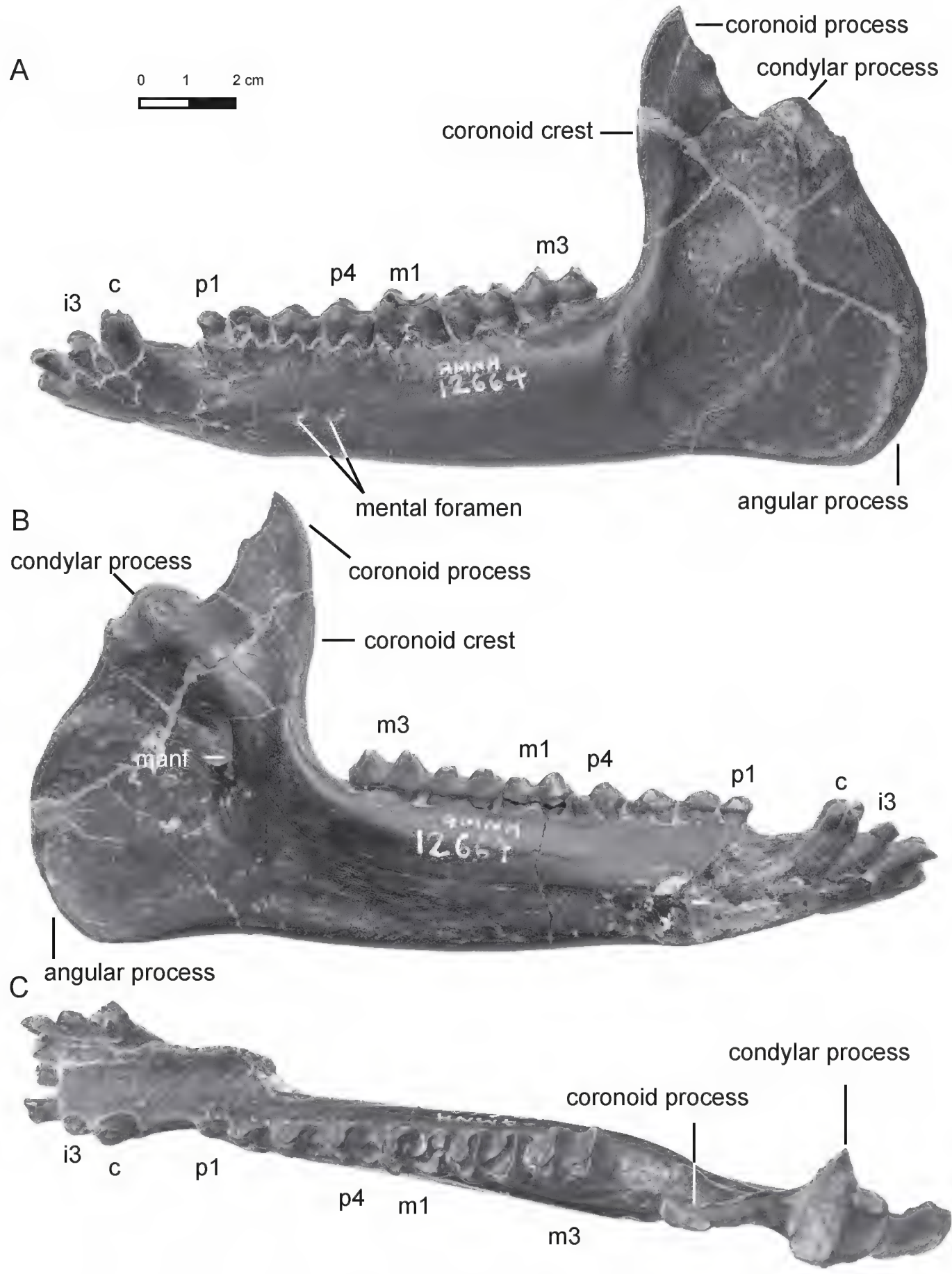

FIG. 4. Left mandible of Hyrachyus modestus (AMNH FM 12664). A, lateral; B, medial; and C, occlusal views. Abbreviation: manf, mandibular foramen. 
versely elongated, slightly convex anteroposteriorly and inclined medially, facing dorsally on the lateral side and curving posteroventrally on the medial side. In posterior view, below the articular surface there is a narrow, transverse groove on the posteromedial side. Lateroventral to the groove is a convex rugose postcotyloid process (Osborn, 1898: 117). The tip of the coronoid process is broken off; however, it was probably inclined posteriorly. The mandibular incision between the coronoid process and the condylar process is relatively narrow and shallow.

COMPARISON OF THE SKULL: The skull of Hyrachyus modestus is different from that of Heptodon posticus, in retaining the following primitive characters: a shallow narial notch retracting at the level of the canine instead of the postcanine diastema, a nasal in contact with the lacrimal bone, and a sphenorbital fissure closely situated to the anterior opening of the alisphenoid canal instead of widely separate. The skull of $H$. posticus further differs from that of Hyrachyus modestus by a nuchal crest more notched in dorsal view, incisors more widely placed and separated from the canine by a diastema, an angular process of the mandible more posteriorly expanded, and by the absence of the postcotyloid process of the mandible.

A juvenile skull of Triplopus cubitalis (AMNH FM 5095) has been described and figured by Cope (1884). Two juvenile and adult skulls of T. obliquidens (CM 11957, 3201) provide additional cranial features of Triplopus, although the CM 3201 is heavily crushed. The cranium of Triplopus is similar to that of $H$. modestus in having a shallow narial notch retracted to the level of the canine, and a lacrimal bone in contact with the nasal. However, due to a large tympanic bulla, the posttympanic process of Triplopus cubitalis is widely separated from the postglenoid process and distally extended beyond the level of the latter. Furthermore, the posttympanic process of T. cubitalis is also posteriorly separated from the paracondylar process by an open shallow groove, which is probably bottomed by the mastoid as suggested by Cope (1884: 680); a similar condition can be also observed in the cranium of Hyracodon. By contrast, the posttympanic and paracondylar processes are partially fused in Hyrachyus modestus, although a mastoid exposure was present. The condyle of the mandible in Hyrachyus modestus possesses a postcotyloid process, which is absent in Triplopus and Hyracodon but present in other non-hyracodontid rhinocerotoids (Wang et al., 2016).

Recently, Wang et al. (2016) described a primitive paracerathere Pappaceras meiomenus from the Arshanto Formation of the Erlian Basin in China. The species represents the earliest known unequivocal rhinocerotoid and the basal taxon to Paraceratheriidae (giant rhinoceroses), which form a sister group with Amynodontidae based on their cladistic analysis. The skull of Pappaceras shows some similarities with that of Hyrachyus modestus in having a naso-premaxilla contact, the tip of nasal bending ventrally, facial part of the lacrimal bone relatively large and contacting the nasal, a prominent sagittal crest, and a posttympanic process fused with the paracondylar process. However, the skull of Pappaceras has some derived or rudimentary characters shared with those of later Fostercooperia and Juxia, but different from that of $H$. modestus, namely the possession of a relatively deep narial notch retracting posterior to the canine, widely placed incisors and canine, a larger canine, a cranium as long as the facial part, the anterior border of the orbit above the M2/3 border, a massive postglenoid process with two facets, and rudimentary coalescence and enlargement of the posttympanic and paracondylar processes. Qiu and Wang (2007) further compared skull of Juxia with that of Hyrachyus in detail.

A reconstruction of the skull of Uintaceras was based on laterally distorted crania (Holbrook and Lucas, 1997; Radinsky, 1967a; Wang et al., 2016). The skull of Uintaceras is similar to that of $H$. modestus in having a naso-pre- 
A

B

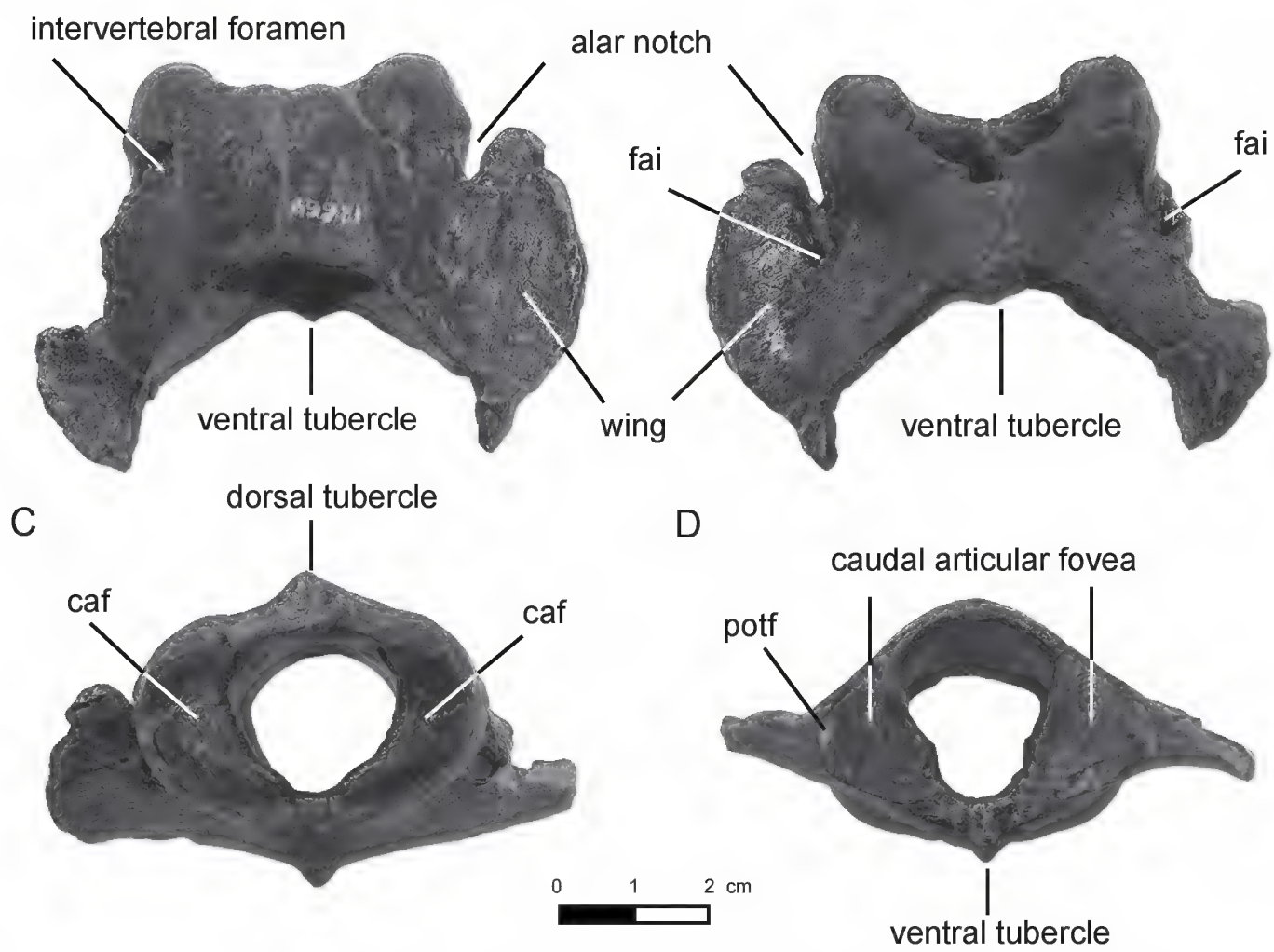

FIG. 5. Atlas of Hyrachyus modestus (AMNH FM 12664). A, dorsal; B, ventral; C, cranial; and D, caudal views. Abbreviations: caf, cranial articular fovea; fai, foramen alare inferior; potf, posterior orifice of the transverse foramen.

maxilla contact, a canine appressed to the third incisor, the facial part longer than the cranial part, an anterior border of the orbit above the M1/M2 border, a prominent sagittal crest, and a posttympanic process fused with the paracondylar process. The skull of Uintaceras differs from that of Hyrachyus modestus in having a deeper narial notch above $\mathrm{P} 1$ and a more massive postglenoid process.

\section{Axial Skeleton}

The specimen of AMNH FM 12664 preserves partial vertebrae from the first cervical to the first sacral. The cervical vertebrae and the anterior thoracic vertebrae (T1-T11) are more complete than other preserved vertebrae.

\section{Cervical Vertebrae}

Atlas (fig. 5; table 2): This bone is nearly complete except for an anterior part of the left wing and a posterior border of the right wing. The cranial articular foveae are deeply concave and reniform; they are separated by a wide notch dorsally and a narrow one ventrally (fig. $5 \mathrm{~A}, \mathrm{~B})$. The anterior border of the dorsal arch is obtusely rounded, whereas that of the ventral arch forms a narrow and square median notch. The caudal articular foveae are flat, triangular in outline, widely separated above and closely apposed below.

The dorsal arch is greatly bowed, bearing a median dorsal tubercle on the anterior half. The intervertebral foramen is large and situated at 
TABLE 2

Measurements of atlas and axis of Hyrachyus modestus (mm)

\begin{tabular}{lr}
\hline \hline & \\
& \\
\hline Atlas & 12664 \\
1. Maximum length & 51.1 \\
2. Dorsal sagittal length & 21.8 \\
3. Ventral sagittal length & 15.5 \\
4. Maximum width & $70.0^{\mathrm{a}}$ \\
5. Cranial articular foveae, width & 40.8 \\
6. Caudal articular facets, width & 40.2 \\
7. Caudal articular facet, Height $\times$ width & $19.9 \times 17.6$ \\
Ratio (\%) & \\
1:4 & 73.0 \\
3:4 & 22.1 \\
5:4 & 58.2 \\
7H:7W & 113.0 \\
\hline Axis & \\
1. Maximum length & 59.03 \\
2. Maximum height & 64.09 \\
3. Body and dens, length & 59.03 \\
4. Body, length & $18.9 \times 19.8$ \\
5. Cranial articular facets, width & \\
7. Fossa, height×width & \\
\hline
\end{tabular}

a Approximate measurements.

the level of the anterior process of the wing. The alar notch is very deep, connecting the intervertebral foramen by a wide, transverse groove on the dorsal side, and the foramen alare inferior by a narrow, longitudinal groove on the ventral side (fig. $5 \mathrm{~A}, \mathrm{~B}$ ). The foramen alare inferior is situated anterior to the transversely middle line of the wing, and on its median side there is a rather shallow alar fossa (fig. 5B). The ventral arch is much shorter and narrower than the dorsal arch, and bears a ridgelike ventral tubercle on its posterior side and a transversely concave fovea dentis on its dorsal side.

The lateral wing has a rounded anterior process and a pointed posterior process, extending laterally and slightly ventrally. Between the posterior process of the wing and the caudal articular fovea there is a posterior orifice for the transverse foramen (fig. 5C).

Axis (fig. 6; table 2): The axis is nearly complete, except for the partially broken free border of the spinous process and the left postzygapophysis. The body (= centrum) is the longest among the cervical vertebrae. The dens (= odontoid process) is long and shaped like a truncated cone, with a convex ventral surface for the articulation with the atlas, above which there are longitudinal grooves on either side. The dorsal surface of the dens is also transversely convex. The paired cranial articular facets are roughly triangular in outline with the apex toward the medial side, and slightly saddle shaped (fig. 6A). The vertebral fossa is slightly concave, subcordate with a straight dorsal border, and slanting anteriorly (fig. 6B). The ventral crest is very sharp and long, nearly extending from the dens posteroventrally to the level of the vertebral fossa, where it forms a ventrally pointed tubercle.

The neural arch has a wide and moderately deep anterior notch and a relatively shallow posterior notch. The postzygapophysis (= caudal articular process) is roughly oval in outline, anteroposteriorly elongated, flat, and directed more ventrally than laterally. Its posterior extremity is placed at the level between the dorsal and ventral borders of the vertebral fossa.

The transverse process is single, projecting posterolaterally at the level of the dorsal border of the caudal extremity (fig. 6C). The transverse foramen is short and situated at the posterior half of the body. Its anterior opening is slightly larger than the posterior opening.

The spinous process is large, high, and slightly depression anteriorly and swollen posteriorly (fig. 6C). Its free border is straight, sharp, and posterodorsally extended (at an angle of about $40^{\circ}$ ) to the posterior end nearly at the level of the posterior border of the postzygapophysis, where it becomes slightly thickened and rough; then, it extends ventrally 


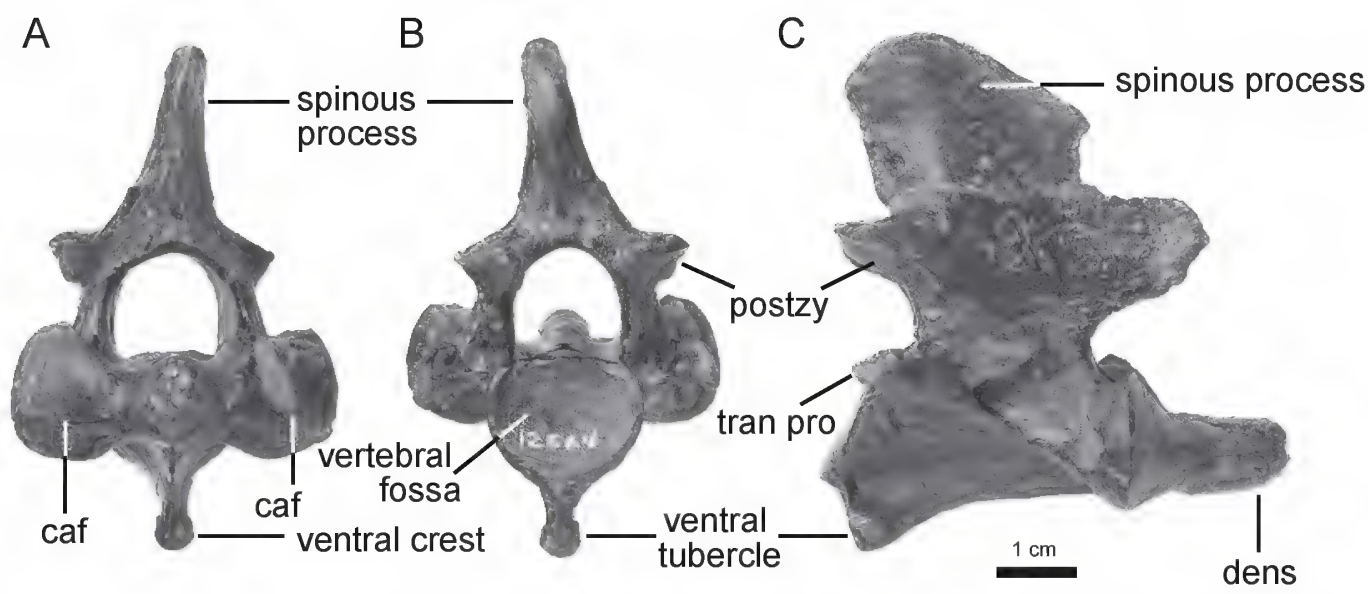

FIG. 6. Axis of Hyrachyus modestus (AMNH FM 12664). A, cranial; B, caudal; and C, lateral views. Abbreviations: caf, cranial articular facet; postzy, postzygapophysis; tran pro, transverse process.

and slightly anteriorly as a sharp ridge. The spinous process connects the postzygapophyses by two short ridges.

C3-C5 (figs. 7, 8; table 3): The body of the third cervical vertebra is long, only slightly shorter than the axis (figs. 7A, 8C). The ventral crest is very sharp and ends as a ventrally pointed tubercle on its posterior end (fig. 8C). On either side of the ventral crest the body is deeply excavated. The head is slightly convex, pentagonal in outline with vertical lateral borders, and anteriorly inclined (fig. 8A). The vertebral fossa is articulated with the head of the fourth cervical vertebra, and its characters are unclear.

The neural arch is large and perforated by a transverse foramen on either side. The pedicle of the arch is vertical, whereas the lamina is nearly horizontal (fig. 8A).

The prezygapophyses (= cranial articular process) are flat, roughly oval in outline, directed dorsomedially, and extending anteriorly at the level of the head. The prezygapophyses are divided by a wide U-shaped notch (fig. 7B). The postzygapophyses, at the same horizontal level as the prezygapophyses but slightly wider than the latter, are directed ventrolaterally and divided by a relatively shallowly U-shaped notch (fig. 7B). In dorsal view, the two pairs of articular processes are considerably longer than wide (fig. 7B).
The transverse processes are platelike and divided into anterior and posterior branches. The parapophysis (ventral tubercle of transverse process) becomes narrow and slightly thickened anteriorly, and extends beyond the level of the head (figs. 7A, 8C). The diapophysis (dorsal tubercle of transverse process) is relatively shorter, wider, and slightly higher than the parapophysis (fig. 7A). The transverse foramen is long and forms a vertically elongated oval in cross section (fig. 8A). The spinous process is a very low crest.

The fourth cervical vertebra is nearly as long as the third cervical vertebra and very similar to the latter (figs. 7, 8B, C). It mainly differs from the third cervical vertebra in having (1) a slightly weaker ventral tubercle of the ventral crest, (2) prezygapophyses that are wider than the postzygapophyses, which are divided by a rounded V-shaped notch (fig. 7B), (3) the two pairs of zygapophyses slightly longer than wide in dorsal view, (4) parapophysis more ventrally directed and expanded, (5) diapophysis higher than the parapophysis and more laterally extended, and (6) a more rounded transverse foramen. Although the spinous process is broken off, it appears to be more prominent and higher. The vertebral fossa is slightly concave and roughly circular in outline (fig. 8B). 


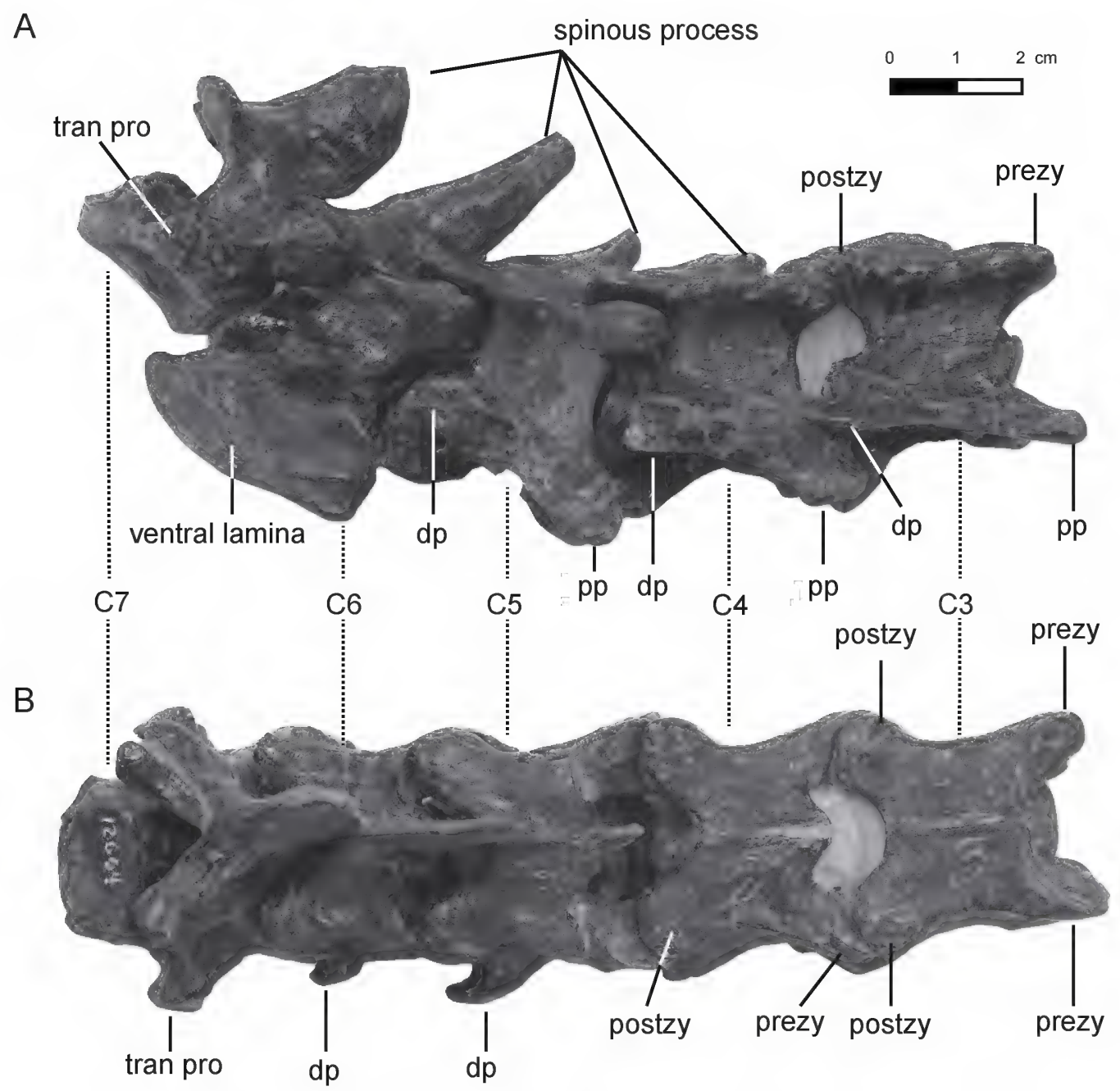

FIG. 7. The third (C3), fourth (C4), fifth (C5), sixth (C6), and seventh (C7) cervical vertebrae of Hyrachyus modestus (AMNH FM 12664). A, lateral; and B, dorsal views. Abbreviations: dp, diapophysis; postzy, postzygapophysis; pp, parapophysis; prezy, prezygapophysis; tran pro, transverse process. 
A

A

C
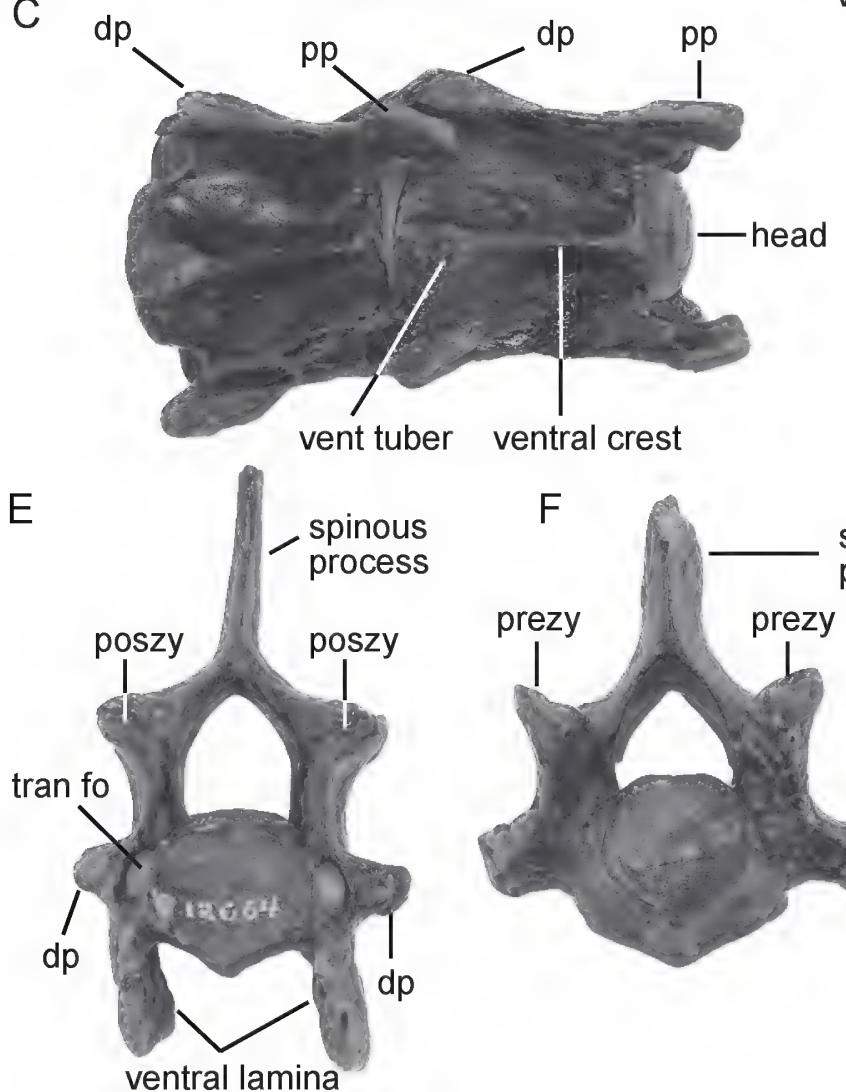

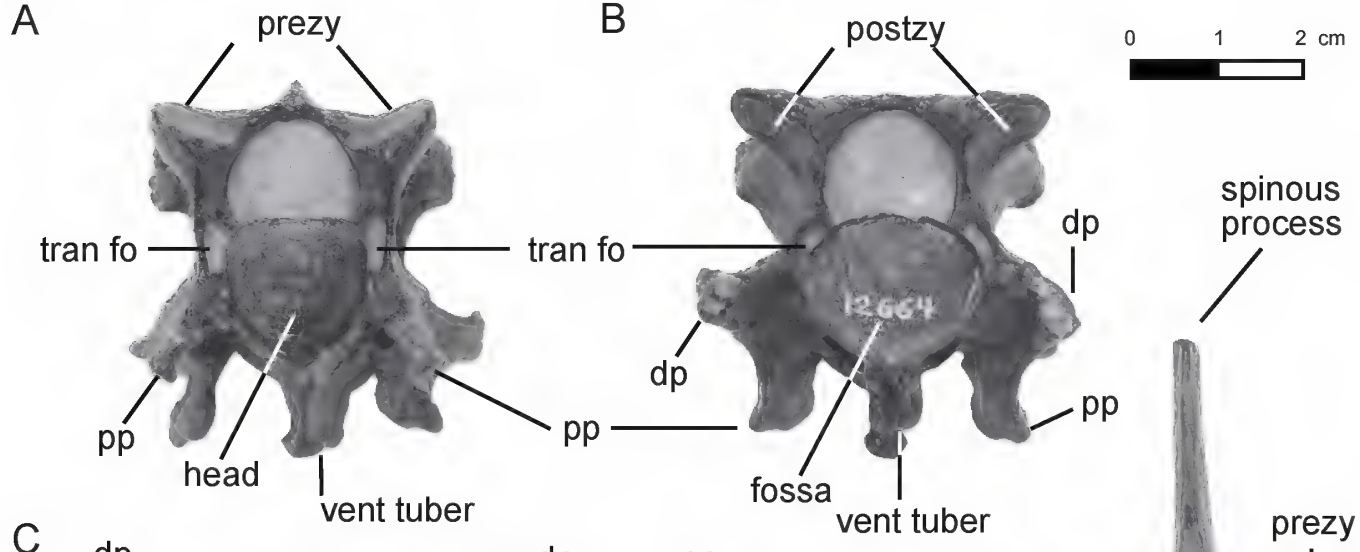

B

$2 \mathrm{~cm}$
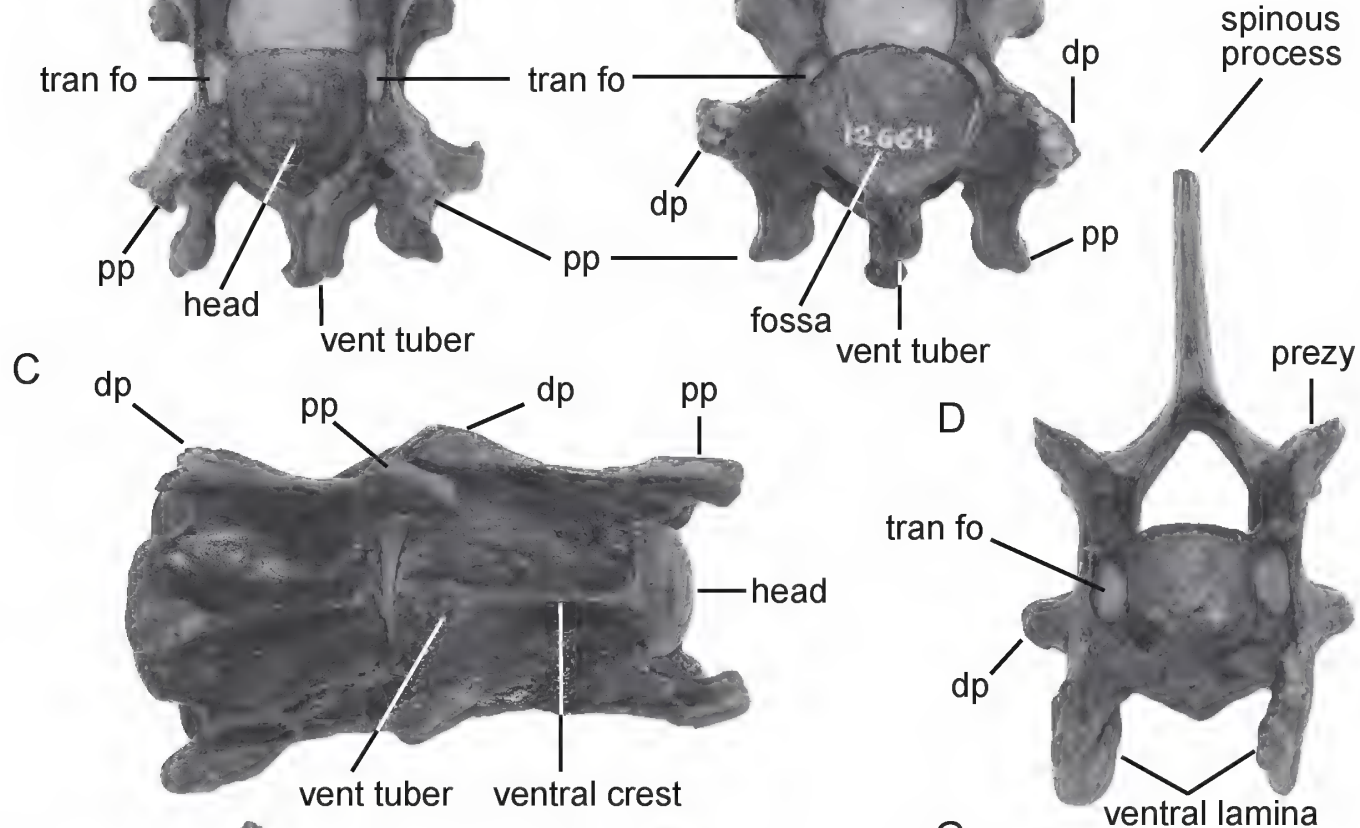

G
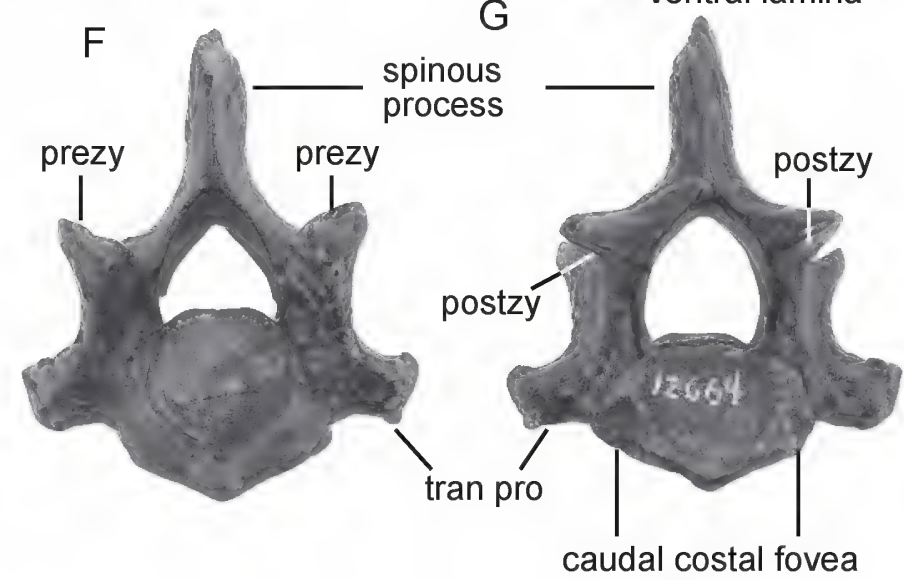

FIG. 8. Partial cervical vertebrae of Hyrachyus modestus (AMNH FM 12664). A-C, articulated C3 and C4. A, C3 in cranial view; B, C4 in caudal view; C, ventral view. D-E, C6. D, cranial; and E, caudal views. F-G, C7. F cranial; and G, caudal views. Abbreviations: dp, diapophysis; postzy, postzygapophysis; pp, parapophysis; prezy, prezygapophysis; tran fo, transverse foramen; tran pro, transverse process; vent tuber, ventral tubercle. 
TABLE 3

Measurements of C3, and C5-C7 of Hyrachyus modestus (AMNH FM 12664) (mm) Postzy. $=$ postzygapophysis; Prezy. $=$ prezygapophysis.

\begin{tabular}{lcccc}
\hline \hline & C3 & C5 & C6 & C7 \\
\hline 1. Body, Length & 29.4 & 26.9 & 24.2 & 21.7 \\
2. Head, Width & 16.4 & 15.3 & 14.7 & 17.4 \\
3. Head, Height & 18.0 & 18.0 & 18.3 & 17.8 \\
4. Prezy., Width & 31.7 & 37.1 & 35.6 & 35.2 \\
5. Postzy., Width & 35.2 & 34.7 & $33.6^{\mathrm{a}}$ & 32.3 \\
6. Maximum Length, pre- and postzy. & 40.1 & 39.0 & 35.3 & 36.3 \\
7. Vertebral foramen, Height×Width & $13.6 \times 18.7$ & $11.6 \times 17.8$ & $14.2 \times 14.0$ & $13.6 \times 13.6$ \\
\hline Ratio (\%) & & & & \\
4:6 & 78.9 & 95.0 & 100.7 & 97.2 \\
5:6 & 87.6 & 88.9 & 95.1 & 89.1 \\
3:2 & 110.1 & 117.7 & 124.7 & 102.2 \\
7:8 & 72.9 & 65.4 & 101.7 & 100.1 \\
\hline
\end{tabular}

a Approximate measurements.

The fifth cervical vertebra is slightly shorter than the fourth cervical vertebra (fig. 7). It differs from the latter in having a low, triangular rough area on the posterior half of the ventral crest, a more ventrally directed parapophysis, a more laterally extended diapophysis that is pointed on the posterior side, and a spinous process elevated and anteriorly inclined.

C6 (figs. 7, 8D, E; table 3): The body of the sixth cervical vertebra is slightly shorter than that of the fifth cervical vertebra. The most conspicuous character of the sixth vertebrae is the large, flangelike, and nearly vertical parapophyses (i.e., ventral lamina in figures) of the transverse processes, and small, short, and tuberculate diapophyses (fig. 8D, E). The sixth cervical vertebra is also characterized by a relatively weak (but still sharp) ventral crest, dorsomedially inclined laminae of the neural arch, and the spinous process greatly enlarged, elongated, and anteriorly inclined.

C7 (figs. 7, 8F, G; table 3): The body of the seventh cervical vertebra is slightly shorter than that of the sixth cervical vertebra. It is distinguished from other cervical vertebrae by the following characters: a blunt ventral crest with tubercles in the middle, an oval-shaped vertebral fossa with a facet on each side for articulation with part of the head (= capitulum) of the first rib (i.e., caudal costal fovea in fig. 8G), slender prezygapophyses relatively lower than postzygapophyses, a transverse process short and undivided without transverse foramina, and a stout and nearly vertically extended spinous process. It is interesting to note that the dorsal surface of the body of the seventh cervical vertebra has two grooves on the either side, which are connected in the middle, where it is overhung by a slender, bridgelike lamina. A similar "bridge" on the dorsal surface of the body of the sixth cervical vertebra was probably broken off.

\section{Thoracic Vertebrae}

There are 18 thoracic vertebrae preserved in Hyrachyus modestus. T1-T4 are well preserved, whereas T5-T11 are less well preserved, often with broken spinous processes. T12-T18 are poorly preserved with only bodies and partial transverse processes. Generally, the right sides of the thoracic vertebrae are better preserved than the left sides. 


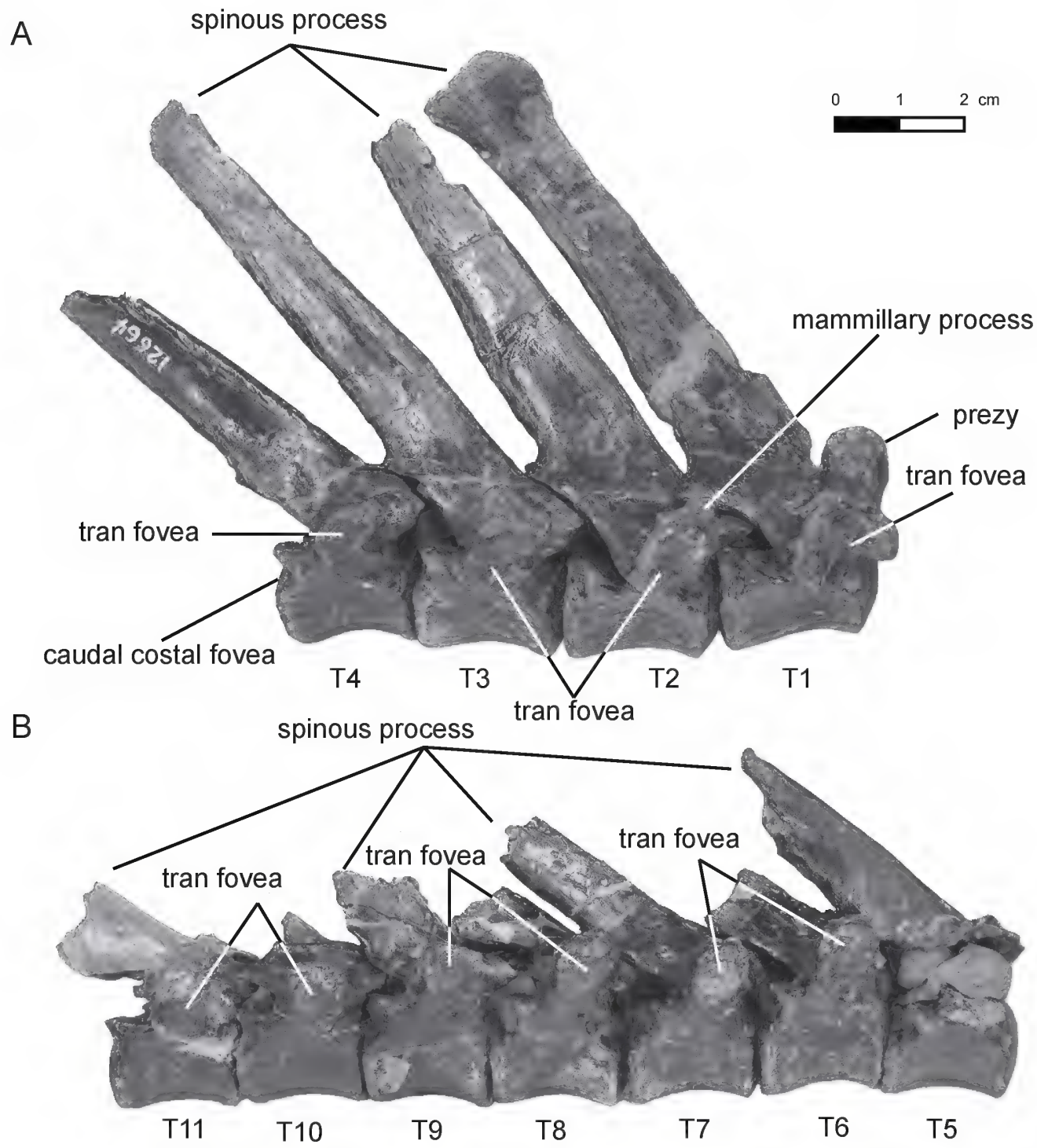

FIG. 9. The first 11 thoracic vertebrae in lateral view. A, the first thoracic vertebra (T1) to the fourth thoracic vertebra (T4); B, the fifth thoracic vertebra (T5) to the 11th thoracic vertebra (T11). Abbreviations: prezy, prezygapophysis; tran fovea, transverse fovea.

T1 (figs. 9A, 10A, B; table 4): T1 is well preserved; however, the left transverse process is broken off. The body is nearly as long as that of C7. The head is slightly convex, pentagonal in outline with a distal apex, and nearly perpendicular to the long axis of the body (fig. 10A). The fossa is moderately concave and oval (fig.
10B). On the middle part of either side of the head are concave cranial costal facets, which are transversely elongated ovals in outline and face anteroventrally (fig. 10A). On the upper part of either side of the fossa are nearly rounded caudal costal facets, which face posterolaterally and are more concave than the cranial costal facets 

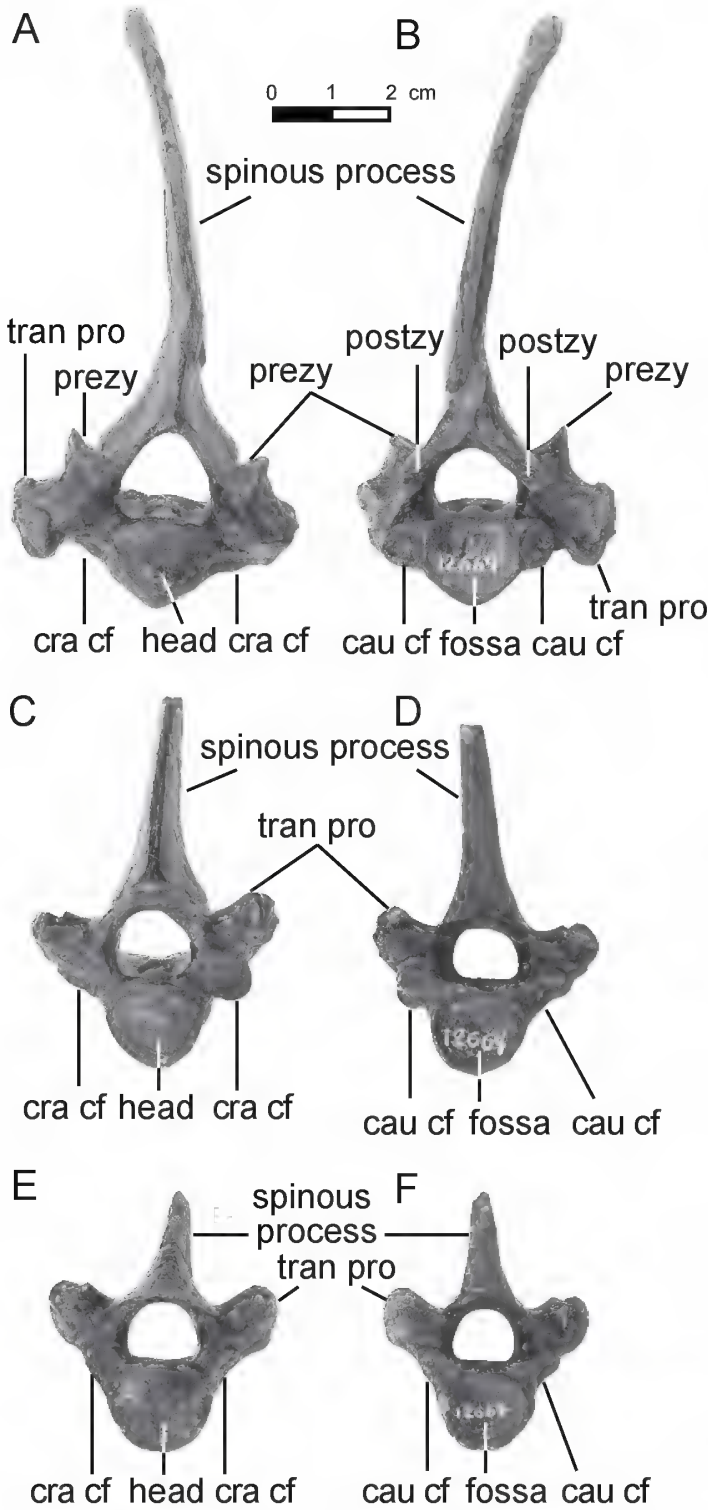

FIG. 10. Partial thoracic vertebrae of Hyrachyus modestus (AMNH FM 12664). A-B, T1. A, cranial; and $\mathbf{B}$, caudal views. $\mathbf{C}-\mathrm{D}, \mathrm{T} 4$. C, cranial; and $\mathbf{D}$, caudal views. E-F, T7. E, cranial; and F, caudal views. Abbreviations: cau cf, caudal costal facet; cra cf, cranial costal facet; postzy, postzygapophysis; prezy, prezygapophysis; tran pro, transverse process. (fig. 10B). The ventral crest is blunt with a prominent ridge in the middle and two ridges on either side on the anterior half.

The vertebral foramen is large and triangular in outline with rounded corners (fig. 10A). The prezygopophyses are less anteriorly extended compared with those of $\mathrm{C} 7$, bearing two large and flat (or slightly concave) facets directed dorsomedially (fig. 9A). On each side of the posterior base of the spinous process are the postzygapophyses, which are oval, slightly concave, facing ventrally and slightly medially, and widely separated dorsally. The transverse processes are stout, bearing deeply concave and ventrolaterally directed transverse foveae for articulation with the tubercles of the first ribs. The transverse fovea is nearly confluent with the cranial costal facet, separated by a narrow groove.

The spinous process is partially distorted toward the right side (figs. 9A, 10A, B). It is long and slants posteriorly with an expanded, rugose summit. Both the anterior and posterior borders of the spinous process are sharp, although the posterior border is slightly wider and more rounded with a wide base.

T2 (fig. 9A): T2 is almost complete. The body is as long as that of $\mathrm{T} 1$, but has a more concave lateral surface on either side of the ventral crest. The head is pentagonal in outline as in T1, but the fossa is more rounded. The cranial costal facets are displaced on the upper part of the lateral side of the head, and the caudal costal facets are transversely elongated oval in outline with the dorsal borders nearly in line with the dorsal border of the fossa. The prezygapophyses are widely separated, bearing flat, oval, and dorsomedially oriented facets. The postzygapophyses, situated at the posterior base of the spinous process, are elongated ovals in outline, slightly concave, and face posteroventrally and slightly medially. The postzygapophses are closely placed dorsally and diverge distally. The transverse processes are relatively smaller and have less concave and more anteriorly facing transverse foveae for articulation with the tubercle of the second rib. Above the facet for the tubercle of the rib is a prominent, anterodorsally projecting 


\section{TABLE 4}

Measurements of T1, T4, T7, and T11 of Hyrachyus modestus (AMNH FM 12664) (mm) $\mathrm{H}=$ height; $\mathrm{L}=$ length; pro. = process; Verte. = vertebral; $\mathrm{W}=$ width.

\begin{tabular}{|c|c|c|c|c|}
\hline & $\mathrm{T} 1$ & $\mathrm{~T} 4$ & T7 & $\mathrm{T} 11$ \\
\hline Body, L & 19.4 & 19.8 & 19.0 & 18.3 \\
\hline Head, $\mathrm{H} \times \mathrm{W}$ & $16.32 \times 17.3$ & $15.74 \times 16.34$ & $14.92 \times 18.29$ & $13.86 \times 16.34$ \\
\hline Verte. fossa, $\mathrm{H} \times \mathrm{W}$ & $15.47 \times 16.32$ & $15.88 \times 17.32$ & $14.98 \times 17.95$ & $14.62 \times 17.17$ \\
\hline Maximum W & $48.8^{\mathrm{a}}$ & 40.6 & $39.3^{\mathrm{a}}$ & $36.8^{\mathrm{a}}$ \\
\hline Verte. foramen, $\mathrm{H} \times \mathrm{W}$ & $13.26 \times 15.32$ & $10.33 \times 12.74$ & $9.94 \times 12.16$ & $9.71 \times 11.8$ \\
\hline Spinous pro., anterior $\mathrm{H}$ & 80.6 & $?$ & $?$ & $?$ \\
\hline Spinous pro., basal L & 19.8 & 19.8 & 18.1 & 22.3 \\
\hline Spinous pro,, basal W & 15.8 & 11.4 & 8.0 & $?$ \\
\hline
\end{tabular}

a Approximate measurements.

mammillary process. The spinous process is long and similar to that of $\mathrm{T} 1$, although the summit has been broken off.

T3 (fig. 9A): T3 is similar to T2. Compared with $\mathrm{T} 2, \mathrm{~T} 3$ has a more rounded head, cranial and caudal costal facets more dorsally extended, prezygapophses situated on the anterior part of the neural arch with narrow oval outlines separated by a V-shaped notch, a more rounded vertebral foramen, mammillary processes with two small processes on each side, and a narrower spinous process.

T4 (figs. 9A, 10C, D; table 4): The mammillary process and the summit of the spinous process of T4 have been broken off. T4 is similar to T3, and mainly differs from the latter in having a body with a smooth ventral surface, transverse processes with small and slightly concave transverse foveae for articulation with the tubercles of the ribs, and a spinous process narrower and more posteriorly slanting.

T5-T11 (figs. 9B, 10E, F; table 4): The fifth through 11th thoracic vertebrae show few differences among them. The heads and fossae are more or less rounded in outline and are perpendicular to the long axes of the bodies. The bodies are almost the same length and have smooth ventral surfaces. The cranial and caudal costal facets are oval and concave, extending dorsolaterally from the upper parts of each side of the heads and fossae, respectively, although the caudal costal facets are more concave. The prezygapophyses and postzygapophyses are similar to those of T4. The transverse processes are short and stout, with slightly concave transverse foveae for the articulations with the tubercles of the ribs on T5-7, whereas these facets are nearly flat, smaller, and more separated from the cranial costal facets on T8-11. The mammillary processes are often broken off on T5-10, but they are probably nodulelike as deduced from T5 and T10. The spinous processes are not complete, but they are probably equally posteriorly extended as deduced from relatively complete spinous processes on T5, T6, and T11.

T12-18: These thoracic vertebrae were preserved in a much poorer condition, and only bodies, partial transverse processes and neural arches were preserved. The bodies of T12-15 are similar to those of preceding thoracic vertebrae, but with more prominent yet obtuse ventral crests. The heads and fossae are more dorsoventrally compressed on T13-15. The transverse foveae for the articulations of the tubercles of the ribs tend to adjoin the cranial costal facets on T13-14. The body of T16 is slightly longer and wider than that of T15, whereas those of T17-18 are considerably longer and wider than the preceding thoracic vertebrae with sharp ventral crests. The heads and fossae are more dorsoventrally compressed with reduced costal facets, and the last thoracic vertebra lacks caudal costal facets. 


\section{Lumbar Vertebrae}

Five lumbar vertebrae are preserved in AMNH FM 12664, and probably L1 and L5 are missing based on the gradual changes of the outlines of the heads and fossae and the fit between articulated lumbar vertebrae. Thus, there should be seven lumbar vertebrae in Hyrachyus modestus. Generally only bodies are preserved, which bear sharp ventral crests on all lumbar vertebrae except for the last. The head and fossa are roughly cordiform on L2, and they gradually become kidneylike and oval in outline posteriorly. The last lumbar vertebra preserves a partial transverse process, bearing an oval and concave facet on the posterior side for the articulation of the wing of sacrum.

Four lumbar vertebrae are preserved in AMNH FM 11662. They are similar to the specimen of AMNH FM 12664 in having sharp ventral crests. Furthermore, the lumbar vertebrae have concave-convex embracing prezygapophyses and postzygapophyses, transverse processes anterolaterally extended, and the spinous processes slightly anteriorly slanted.

\section{Sacrum}

The specimen of AMNH FM 12664 preserves only the first sacral vertebra, which is partially broken off and not fused with the rest of the sacrum. The body is nearly flat and smooth on the ventral surface. The head is a dorsoventrally compressed oval in outline. The prezygapophyses extend anterodorsally beyond the head, bearing a small triangular, concave, and dorsomedially oriented facet. Only the partial right wing was preserved. The wing extends laterally and slightly anteriorly, bearing a convex and oval-shaped facet on the anterior border for the articulation with the transverse process of the last lumbar vertebra, and an elongated, dorsolaterally facing articular surface for the ilium on the posterior border.

The sacrum of AMNH FM 11662 preserves four anterior vertebrae (S1-S4), and S1 is completely fused with S2. S1 of AMNH FM
11662 further differs from S1 of AMNH FM 12664 in having deeply concave prezygapophyses that do not extend beyond the head. The sacrum is long and narrow with a slightly concave ventral surface. The spinous processes are inclined posteriorly.

COMPARISON OF THE VERTEBRAL COLUMN: Based on the brief description and figures of a few vertebrae of Heptodon posticus by Radinsky (1965a: fig. 5), the vertebrae of $H$. posticus are similar to those of Hyrachyus modestus in having an atlas with a deep, narrow alar notch and a posterior orifice of transverse foramen on the posterior edge of wing as in Triplopus cubitalis, but different from those of Hyrachyus modestus by the presence of a more laterally oriented cranial articular facets on the axis, anteroposteriorly longer ventral tubercles on C2-4, a longer spinous process on $\mathrm{C} 4$, and a nearly vertical spinous process of the last lumbar vertebra.

A few cervical and thoracic vertebrae of Triplopus cubitalis (AMNH FM 5065) have been described by Cope (1884). The vertebrae of $T$. cubitalis are different from those of Hyrachyus modestus in having a more posteriorly placed and larger foramen alare inferior of the atlas, and oval-shaped cranial articular facets of the axis divided into anterior and lateral parts.

The atlas of Juxia differs from that of Hyrachyus modestus by the presence of a shallow alar notch, $\mathrm{V}$-shaped anterior borders of the dorsal and ventral arches, a less bowed dorsal arch, a relatively wider wing with an expanded, rounded posterior end, and a more posteriorly placed foramen alare inferior. They are similar in having the posterior orifice of the transverse foramen on the posterior edge of the wing. The C3-6 of Juxia are characterized by the following features that differ from those of H.modestus: greatly elongated bodies; anteriorly inclined heads and fossae, with the former considerably higher than the latter; prominently large preand postzygapophyses, with the former higher than the latter; broad, platelike transverse processes without a bifurcation; and a complex transverse process of C6. 
Qiu and Wang (2007) mentioned two characters that distinguish the thoracic vertebrae of Hyrachyus eximius from those of Juxia: an anteriorly slanting proximal end of the spinous process and a well-developed mammillary process. The thoracic vertebrae of Juxia further differ from those of Hyrachyus modestus by the presence of median grooves on the posterior surface of the spinous process in the anterior thoracic vertebrae, and relatively more ventrally placed costal foveae. Based on more complete vertebrae of $H$. eximius (AMNH FM 5065), the thoracic vertebrae of Juxia are similar to those of Hyrachyus in having 18 thoracic vertebrae, the concave-convex embracing types of the preand postzygapophyses in posterior thoracic vertebrae, and a diaphragmatic vertebra.

Qiu and Wang (2007) determined that Juxia differs from Hyrachyus eximius in having 5 or 6 lumbar vertebrae; furthermore, the lumbar vertebrae of Juxia have transverse processes that are laterally extended except for the last, and that have relatively shorter and stouter bodies. They are similar in having concave-convex embracing facets on the pre- and postzygapophyses.

The vertebrae of Uintaceras were either heavily distorted or damaged (Holbrook and Lucas, 1997). It is worth mentioning that the thoracic vertebra labeled "first" was not correctly assigned, because it lacks the large prezygapophyses and the spinous process is more posteriorly slanted; thus, this "first" thoracic vertebra probably is a more posterior thoracic vertebra.

\section{Ribs}

Six complete right ribs (R1-R6) and five left ribs (R1-R5) were preserved, as well as a proximal end of another and a number of fragmentary shafts of more posterior ribs. It should be mentioned that the letters previously placed on the specimens to indicate right and left were erroneously reversed: the labeled right ribs should be left ones.

The first rib is short and somewhat curved (fig. 11). The head (= capitulum) bears two unequal facets: when the first rib is articulated with vertebrae in position, the anterior smaller facet (articulating with C7) is anteromedially oriented, whereas the larger posterior one (articulating with $\mathrm{T} 1$ ) is posteromedially and slightly dorsally oriented and is roughly rectangular in outline. Both facets are slightly convex, perpendicular to each other, and separated by a shallow groove on the medial side. The neck is long and narrow. The tubercle is higher than the head when the rib is in articulation. The tubercle bears an anteroposteriorly convex and elongated facet, extending from the dorsal part to the posteromedial part. The anterior and lateral sides of the tubercle are rugose and crossed by a groove. The rib shaft is transversely flat and gradually widens toward the distal end. The anterior and posterior borders are rounded. On the posterior side, below the tubercle is an indistinct transverse groove. The distal end bears a compressed oval rugose facet for the costal cartilage and is curved anteriorly.

The second rib is much longer than the first rib (fig. 11). Compared with the first rib, the head of R2 bears two subequal facets with the posterior one nearly dorsally oriented, and the tubercle bears a smaller and more medially extended facet. The anterolateral side of the tubercle is rugose without the groove present in the first rib. The shaft is transversely compressed, and becomes wider distally then narrow again at the distal end. The posterior border bears a shallow groove below the tubercle, and is more rounded than the anterior one. The distal end for the costal cartilage is oval in outline and less compressed compared with that of R1.

The third rib is similar to the second rib but has a short and wide neck, a wide, shallow groove below the tubercle on the posterior border, and a rudimentary costal groove on the medial side (fig. 11).

The fourth to sixth ribs are similar to each other (fig. 11). The head bears two facets with the posterior one larger than the anterior one. The neck is short, and the head and the tubercle are separated by a relatively shallow groove 


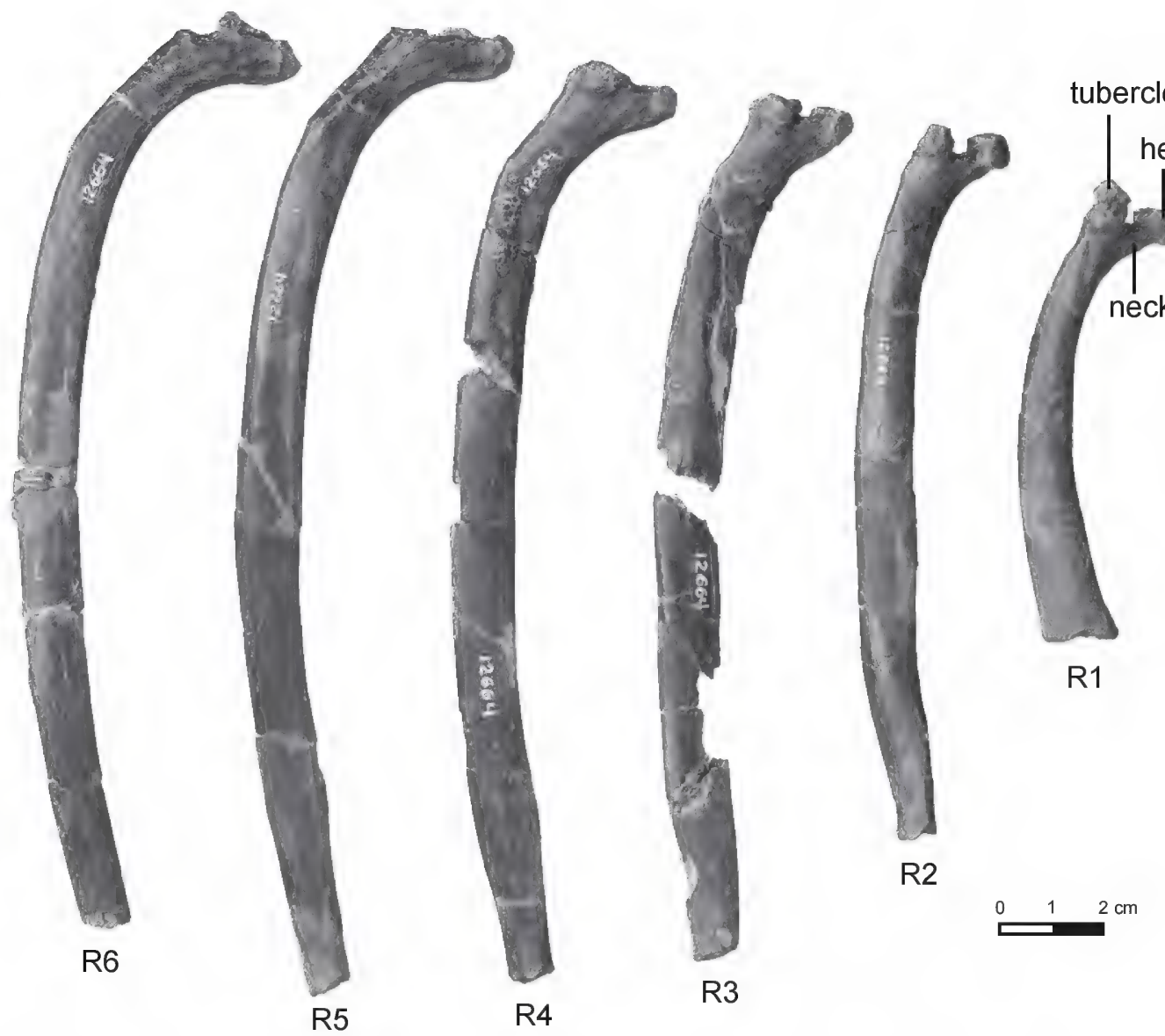

FIG. 11. Lateral view of the right first six ribs of Hyrachyus modestus (AMNH FM 12664).

proximally. The tubercle bears a transversely elongated oval facet, which is slightly convex anteroposteriorly and concave laterally, and faces dorsally (when in articulated position, it is dorsomedially oriented). The shaft is compressed laterally with a distinct costal groove on the medial surface near the proximal end. The distal end has a more or less rounded, rugose surface for articulation with a costal cartilage. Furthermore, on R4 and R5, below (or, when in position, lateral to) the tubercle on the posterior border there is a deep depression, bordered distally (or laterally in position) by another tubercle.

The proximal part of a more posterior rib is preserved. The head is reduced, bearing two small facets with a posterior one slightly larger. The tubercle bears a rectangular, proximally facing, and saddle-shaped facet. Below the tubercle is a relatively deep depression. The shaft is cylindrical with a cross section quadrilateral in outline in the proximal part.

\section{Sternum}

Three sternebrae are preserved in AMNH FM 12664. The manubrium is compressed laterally with thin and sharp anterior and ventral borders. The anterior end extends anterodorsally in front of the surfaces for the first costal cartilage. The surface for the first costal cartilage is concave, oval, and dorsally facing. Pos- 
A

B subscapular fossa

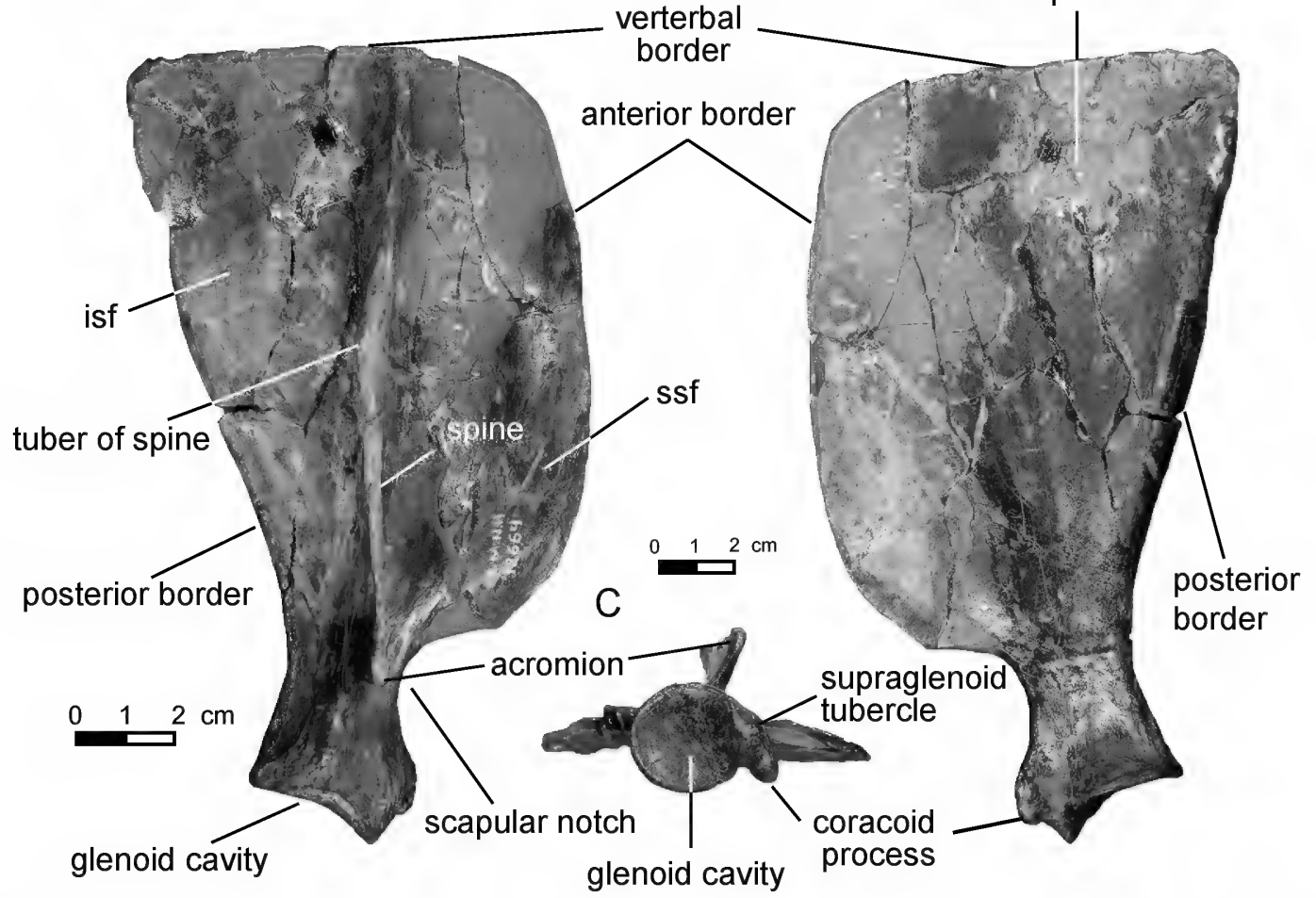

FIG. 12. Right scapula of Hyrachyus modestus (AMNH FM 12664). A, lateral; B, medial; and C, distal views. Abbreviations: isf, infraspinous fossa; ssf, supraspinous fossa.

terior to this surface, the dorsal border is a sharp ridge, and the lateral surface is convex above and slightly concave below. The posterior surface is rough and laterally compressed and oval in outline with a constriction in the middle on either side, probably for the attachment of the second costal cartilage.

Another sternebra is much shorter than the manubrium, but is also laterally compressed. The anterior surface is relatively higher and narrower than the posterior surface. The dorsal surface is a compressed rectangle in outline with a concave surface on either side, whereas the ventral border is a rounded ridge. The cross section in the middle is roughly triangular with an apex distally. Another more posterior sternebra is cubic with a quadrilateral cross section.

\section{Bones of the Thoracic Limb}

\section{Scapula}

The scapula has a slightly convex anterior border and straight vertebral and posterior borders (fig. 12A, B; table 5). The scapular notch is wide and relatively deep. The scapular spine arises abruptly from the neck; it is relatively tall here, with a moderately developed acromion, and maintains nearly the same height up to the tuber of spine, which is relatively small, situated in the midpoint of the spine, and slightly posteriorly curved (fig. 12A). From the tuber of spine to the vertebral border the spine gradually decreases in height. The supraspinous fossa is slightly larger than the infraspinous fossa. The glenoid cavity is circular in outline and concave (fig. 12C). The supraglenoid tubercle is moder- 
TABLE 5

Measurements of scapulae of Hyrachyus modestus and Hyrachyus eximius (mm)

\begin{tabular}{lrr}
\hline \hline & $\begin{array}{r}\text { Hyrachyus modestus } \\
\text { (AMNH FM 12664) }\end{array}$ & $\begin{array}{r}\text { Hyrachyus eximius } \\
\text { (Qiu and Wang, 2007) }\end{array}$ \\
\hline 1. Maximum length & 160.0 & 215 \\
2. Maximum width & 105.0 & 130 \\
3. Width at distal end & 35.1 & $?$ \\
4. Minimum width at neck & 23.0 & 36 \\
5. Glenoid cavity, length & 28.3 & 35 \\
Ratio (\%) & & 60.5 \\
2:1 & 65.6 & $?$ \\
4:3 & 65.4 & 97.2 \\
$5: 4$
\end{tabular}

ately developed with a short and distinct coracoid process curving medially (fig. 12C).

Comparison of THE SCAPUla: Compared with the scapula of Hyrachyus modestus, that of $H$. eximius is narrower and longer, with a spine rising gradually from the neck and a tuber of spine curving posteriorly in the middle, and it lacks an acromion (Cope, 1884).

Heptodon posticus preserves only the glenoid end of the scapula, and Radinsky (1965a) reconstructed it by extrapolation from known complete scapulae of "Hyracotherium" (Kitts, 1956) and Helaletes. The reconstructed scapula of $H$. posticus is similar to that of Hyrachyus modestus (AMNH FM 12664) in having straight vertebral and posterior borders, a distinct acromion, a coracoid process anteromedially directed (as in Triplopus cubitalis, which is missing the greater part of the blade in AMNH FM 5065), and a supraspinous fossa roughly equal to the infraspinous fossa in size. But the scapula of $H$. posticus differs from that of Hyrachyus modestus by the presence of a more convex anterior border, and a tuber of spine more proximally situated.

As determined by Qiu and Wang (2007), the scapula of Juxia is different from that of Hyrachyus in having a fan-shaped outline with a convex vertebral border, a relatively wider neck, and a higher spine with a large tuber of spine. The last two characters are also present in Uinta- ceras. The scapula of Juxia further differs from that of Hyrachyus modestus in having a larger supraglenoid tubercle without a distinct coracoid process as in Uintaceras, and an oval glenoid cavity. The scapulae of Hyrachyus modestus and Juxia have prominent acromion processes and spines arising abruptly from the necks, whereas that of Uintaceras lacks the acromion, and the spine arises gradually from the proximal end of the neck. Uintaceras has a rounded glenoid cavity of the scapula as in $H$. modestus.

\section{Humerus}

The humerus of Hyrachyus modestus was described based on the specimen of AMNH FM 12361 (fig. 13; table 6), which is associated with a maxilla and mandible. The greater tubercle and epicondyles are incomplete, and the proximal half of the shaft was compressed during fossilization in an anterolateral to posteromedial direction.

The head is hemispherical, slightly wider than long (a condition probably attributable to distortion), faces more posteriorly than proximally and overhangs the shaft posteriorly (fig. 13B). Although the greater tubercle is not complete, it appears that it was hardly higher than the level of the head and curved proximomedially at its anterior end (fig. 13A). The lesser tubercle is much smaller than the greater tubercle. The bicipital 
groove (= intertubercular groove) is undivided, and relatively wide and deep. The deltoid tuberosity, deltopectoral crest, teres tuberosity, and supinator ridge (= lateral supracondylar crest) were broken off, but were likely weak, as deduced from other specimens (Holbrook, 2001). The transverse, long axis of the humeral condyle is strongly oblique to the long axis of the shaft (fig. $13 \mathrm{~A}$ ). The trochlea (= medial condyle) is separated by a wide groove from the capitulum (= lateral condyle), and is wider than the medial part of the capitulum. The capitulum ridge is blunt, and the lateral articular shelf of the capitulum (= capitular tail) is relatively wide, tapers distally, and extends slightly proximally. The radial fossa is triangular and deep, perforated by an oval-shaped supracondylar foramen, which may be artificial due to postmortem damage. The medial epicondyle is more posteriorly extended than the lateral epicondyle.

Comparison of the humerus: The humerus of Heptodon posticus is different from that of Hyrachyus modestus in having a greater tubercle arising above the level of the head, a lesser tubercle relatively more prominent, and a more rounded head. Radinsky (1965a) attributed a supracondylar foramen of humerus in $H$. posticus to an artifact, but such a foramen has been also reported from $H$. eximus and Triplopus cubitalis by Cope (1884). The humerus of $H$. eximius is also characterized by a small proximal lappet on the capitulum.

The humerus of Triplopus cubitalis is different from that of Hyrachyus modestus in having a more rounded head, a greater tubercle higher above the level of the head as in Juxia and Uintaceras, and a prominent deltoid tuberosity, which is even stronger in Juxia and Uintaceras. Cope (1884) also determined that the humerus of T. cubitalis differs from that of Hyrachyus eximius in having a relatively larger and deeper olecranon fossa with equally elevated bounding ridges. The humerus of T. cubitalis is similar to that of Hyrachyus modestus in the possession of some plesiomorphic characters with a weak supinator ridge and a lateral articular shelf of

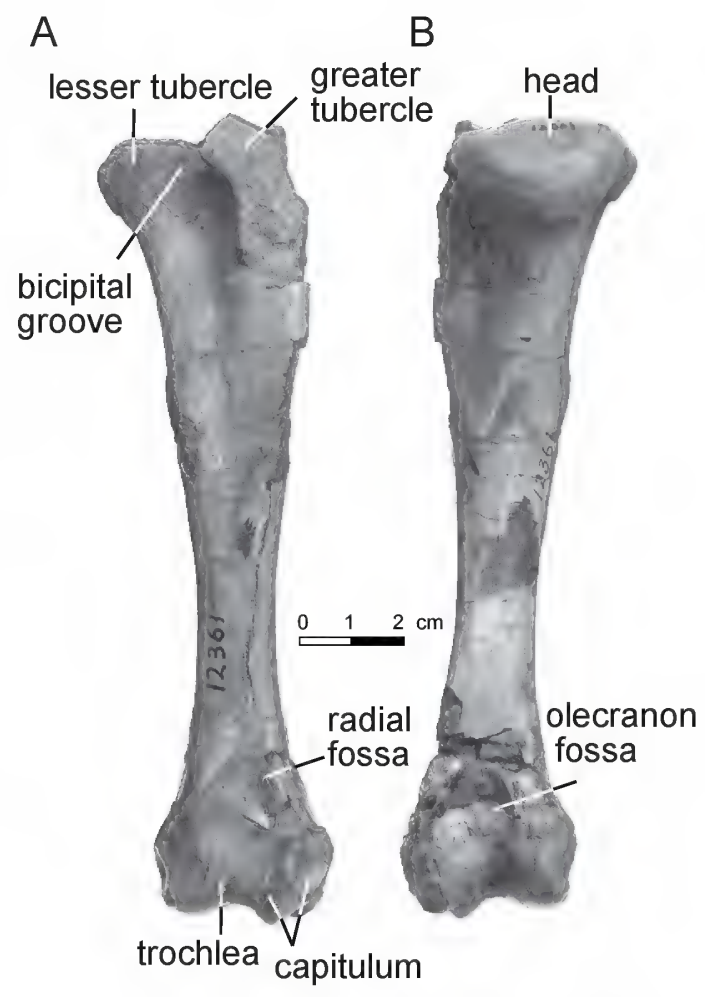

FIG. 13. Left humerus of Hyrachyus modestus (AMNH FM 12361). A, anterior; and B, posterior views.

the capitulum tapering distally, whereas those of Juxia and Uintaceras have more developed supinator ridges and lateral articular shelves of the capitulum not tapering distally. The proximal and distal ends of Juxia and Uintaceras are relatively wider than those of Hyrachyus modestus and Triplopus.

\section{Radius}

The radii of AMNH FM 12664 and 13089 are about as long as the humerus of AMNH FM 12361 (figs. 14, 15; table 7). The articular fovea of the proximal radius is divided by a sagittal, blunt ridge into two portions. The medial one is rectangular, concave anteroposteriorly, and inclined medially, whereas the lateral surface is more horizontal, slightly wider than (AMNH FM 12664) or as wide as (AMNH FM 13089) 


\section{TABLE 6}

Measurements of humeri of Hyrachyus modestus and Hyrachyus eximius (mm) $\mathrm{APD}=$ anteroposterior distance.

\begin{tabular}{|c|c|c|}
\hline & $\begin{array}{l}\text { Hyrachyus modestus } \\
\text { (AMNH FM 12361) }\end{array}$ & $\begin{array}{l}\text { Hyrachyus eximius } \\
\text { (AMNH FM 5065-A) }\end{array}$ \\
\hline 1. Total length & 150.0 & 210.0 \\
\hline 2. Head, width & 33.9 & 39.1 \\
\hline 3. Head, APD & 26.0 & 37.1 \\
\hline 4. Shaft, minimum width & 15.6 & 20.3 \\
\hline 5. APD at minimum width & 17.8 & 27.9 \\
\hline 6. Distal end, maximum width & 33.5 & 46.6 \\
\hline 7. Width at humeral condyle & 27.5 & 37.0 \\
\hline 8. Trochlea, APD & 22.9 & 33.4 \\
\hline 9. Capitulum, APD & 19.3 & 28.5 \\
\hline 10. Intercondylar Groove, APD & 15.5 & 21.3 \\
\hline 11. Trochlea, Width & 13.2 & 18.4 \\
\hline 12. Capitulum, Width & 13.3 & 18.1 \\
\hline \multicolumn{3}{|l|}{ Ratio (\%) } \\
\hline $4: 1$ & 10.4 & 9.7 \\
\hline $5: 4$ & 114.0 & 137.1 \\
\hline $6: 1$ & 22.3 & 22.2 \\
\hline $8: 7$ & 83.1 & 90.4 \\
\hline $9: 8$ & 84.6 & 85.2 \\
\hline $12: 11$ & 100.9 & 98.2 \\
\hline $10: 8$ & 67.8 & 63.7 \\
\hline $10: 9$ & 80.2 & 74.8 \\
\hline $3: 2$ & 76.7 & 94.9 \\
\hline
\end{tabular}

the medial one, tapers laterally and bears a broad, shallow (AMNH FM 12664), or relatively deep (AMNH FM 13089) sagittal groove (fig. 15A). The lateral process is nearly absent (AMNH FM 12664) or very weak (AMNH FM 13089). On the posterior side of the head there are two confluent facets for the ulna: the medial one is striplike and flat, whereas the lateral one is larger, boomerang shaped, and slightly concave (fig. 14B). Below the ulnar facet a roughened and slightly excavated area, extending distally for about $15 \mathrm{~mm}$, accommodates the interosseous ligaments. The lateral tuberosity is moderately developed (fig. 14A).
The radial shaft is arched anteriorly, anteroposteriorly compressed proximally, and relatively thickened distally. A rugosity extends proximodistally on the anteromedial side of the proximal shaft for the insertion of the brachialis muscle (fig. 14A, E). On the posterior side of the shaft, a prominent ridge extends distally and is truncated by smooth areas at both ends (fig. 14B). Along the lateral side of the ridge is a roughened area for the insertion of the interosseous ligaments, whereas the roughened area is separated by a narrow, smooth surface on the proximal half. On the medial side of the ridge there is a rugose area 
A

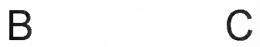

C

$\mathrm{D}$

$E$

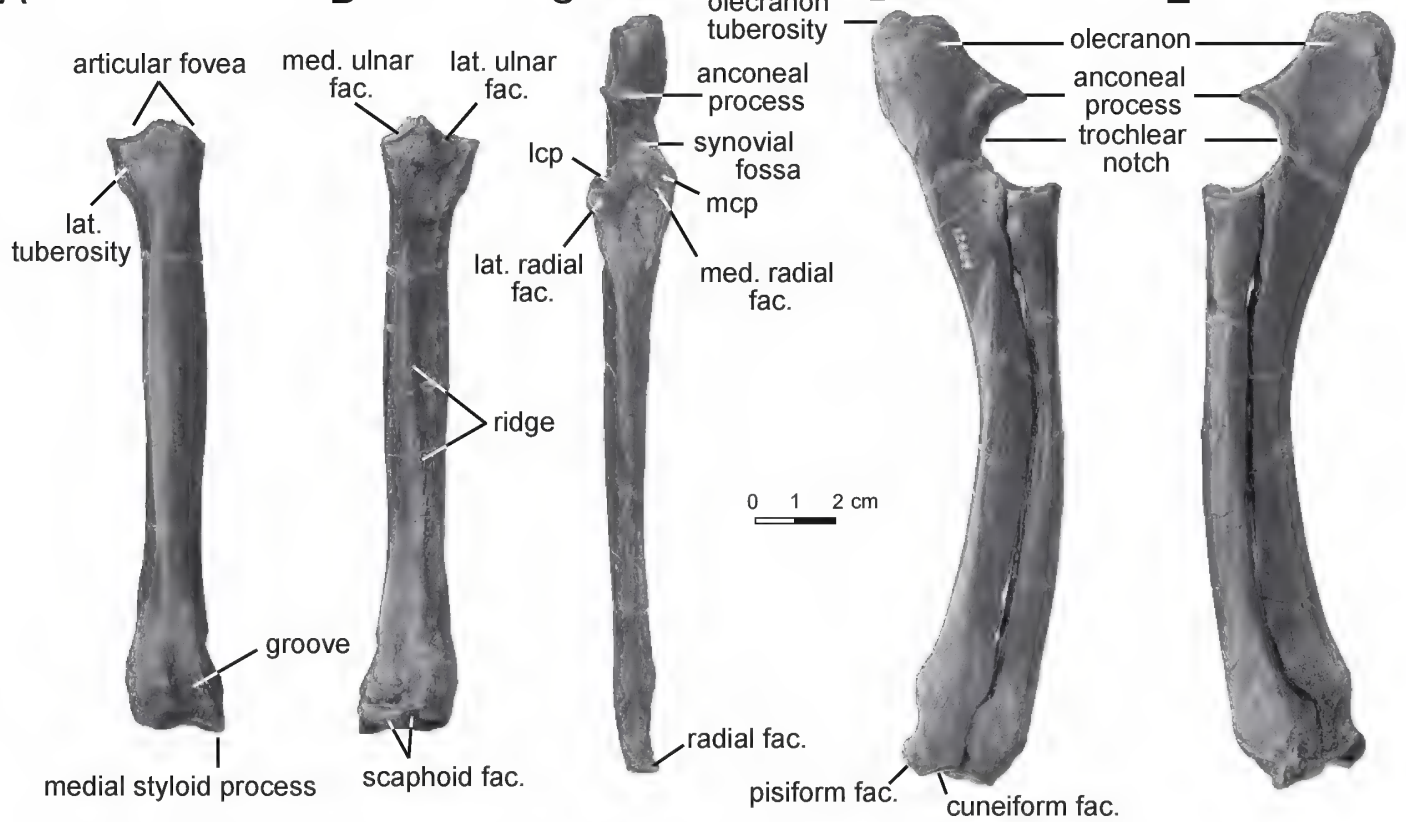

FIG. 14. Right forelimb of Hyrachyus modestus (AMNH FM 12664). A-B, radius. A, anterior; and B, posterior views. $\mathbf{C}$, ulna in anterior view. $\mathbf{D}-\mathbf{E}$, articulated radius and ulna. $\mathbf{D}$, lateral; and $\mathbf{E}$, medial views. Abbreviations: Icp, lateral coronoid process; mcp, medial coronoid process.

on the proximal half and a smooth, slightly concave area on the distal half.

On the distal end, the scaphoid facet is wider than the lunar facet, is concave anterolaterally and convex posteromedially, and extends onto the posterior side as a half cylinder with a lateral semiconical extension posterior to the lunar facet and separated from the latter by a narrow groove (figs. 14B, 15B). The medial styloid process is moderately developed. The lunar facet is concave anteroposteriorly. On the posterolateral side of the distal end is a small facet for the ulna. On the anterior surface of the distal end there is a wide and relatively deep groove extending obliquely toward the medial side (fig. 14A). The groove is bordered bilaterally by prominent ridges and is for the passage of the tendon of the extensor carpi radialis.

COMPARISON OF THE RADIUS: Three radii of Hyrachyus eximius (AMNH FM 5065-A, 93050, and 12225) are very similar to that of Hyrachyus modestus. However, the former has a deeper sagittal groove of the articular fovea, and sometimes an anterior inclined lateral process (AMNH FM 93050 and 12225). Cope (1884) mentioned the presence of a cuneiform facet on the distal end of the radius in Hyrachyus eximius, a character similar to that of Juxia but different from those of Hyrachyus modestus, Triplopus, and Uintaceras.

The radius of Heptodon differs from that of Hyrachyus modestus by the presence of a more concave lateral surface of the articular fovea, a lateral process of the articular fovea (in Heptodon calciculus), and a lunar facet slightly wider than a scaphoid facet (in H. calciculus). They are similar in having a shaft slightly bowed anteriorly and a medial styloid process moderately developed.

The radius of Triplopus cubitalis is characterized by a ridge dividing the subequal scaphoid and lunar facets on the distal end as in Juxia and Uintaceras, whereas in $H$. modestus such a 


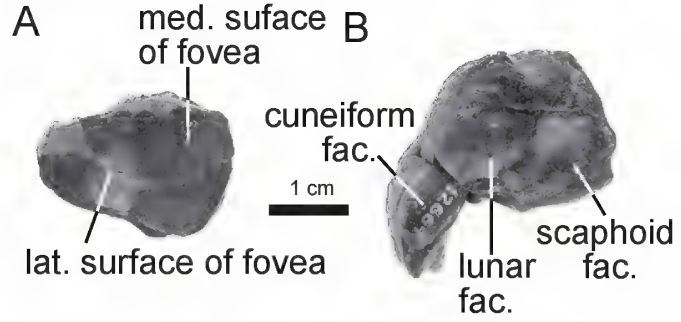

FIG. 15. Proximal and distal ends of right forelimbs of Hyrachyus modestus (AMNH FM 12664). A, proximal view of radius; $\mathbf{B}$, distal view of radius and ulna.

dividing ridge is absent, and the scaphoid facet is wider than the lunar facet. Furthermore, the articular fovea of T. cubitalis is rectangular in outline with rounded corners, whereas that of Hyrachyus modestus, Juxia, and Uintaceras is constricted laterally. All of them lack the lateral process of the articular fovea. The radii of Triplopus and Juxia are considerably longer than the humeri, whereas the radius is as long as the humerus in Hyrachyus modestus and even shorter than the humerus in Uintaceras.

\section{Ulna}

The shaft is arched anteriorly and compressed mediolaterally. The olecranon is relatively long and extends proximoposteriorly with a deeply concave medial surface and a convex lateral surface (fig. $14 \mathrm{D}$, E; table 8). Thus, the olecranon is slightly curved medially. The olecranon tuberosity is flat on the proximal end and rugose on the medial, lateral, and posterior surfaces. The posterior rugose surface extends distally to the level of the middle of the trochlear notch. The trochlear notch is concave proximodistally and convex mediolaterally with the lateral half wider and more proximally extended than the medial half (fig. 14D, E). The medial and lateral aspects of the coronoid process bear roughly equal-sized, oval facets for the humerus, with the lateral one more concave. A wide synovial fossa is present between the distal surface of the anconeal process and coronoid facets, as well as between the coronoid facets, except for the continuous medial border (fig. 14C). Just below the coronoid facets there are two facets for the radius: the medial one is flat and striplike, whereas the lateral one is much larger and slightly convex (fig. 14C). The rotation between the radius and ulna is very limited. Below the radial facets there is a roughened and excavated area for the insertion of the interosseous ligament.

The shaft is compressed mediolaterally. A prominent, roughened ridge extends from the lateral coronoid process and runs along the anterior border of the shaft (fig. 14C, D). The anterior edge of the medial side of the shaft is a relatively sharp ridge, extending from the medial coronoid process to the distal epiphysis. These two ridges border the narrow anterior surface of the shaft. On the lateral side, a scar for the lateral digital extensor muscle is present below the lateral coronoid process, and then diverges into two ridges distally (fig. 14D). The posterior one forms the posterior border of the lateral side, whereas the anterior ridge becomes indistinct distally. Distally, the shaft is excavated to fit the swollen distal end of the radius. A small radial facet is present at the anteromedial side of the distal end (fig. 14C).

The distal end bears a roughly triangular cuneiform facet (fig. 15B), which is concave anteroposteriorly and convex laterally. Posteromedial to the cuneiform facet, there is a roughly oval, convex pisiform facet, which is subequal in size with the cuneiform facet (fig. 14D).

COMPARISON OF THE ULNA: The ulna of Hyrachyus eximius is nearly identical to that of $H$. modestus, however, the former has a less laterally compressed and medially twisted shaft.

The ulna of Heptodon is very similar to that of Hyrachyus modestus, except that the former has a more proximally projected olecranon with a less concave medial side, and a shaft slightly less laterally compressed and less bowed anteriorly. They are similar in having a pisiform facet nearly subequal in size with the cuneiform facet.

The ulna of Triplopus cubitalis is mainly different from that of Hyrachyus modestus in having an olecranon more proximally extended, a shaft 
TABLE 7

Measurements of radii of Hyrachyus modestus and Hyrachyus eximius ( $\mathrm{mm}$ ) $\mathrm{APD}=$ anteroposterior distance; $\mathrm{PAF}=$ proximal articular facet.

\begin{tabular}{lrr}
\hline \hline & $\begin{array}{r}\text { Hyrachyus modestus } \\
\text { (AMNH FM 12664) }\end{array}$ & $\begin{array}{r}\text { Hyrachyus eximius } \\
\text { (AMNH FM 93050) }\end{array}$ \\
\hline 1. Total length & 158.0 & 210.0 \\
2. Proximal end, width & 25.0 & 39.9 \\
3. Proximal end, APD & 17.0 & 24.9 \\
4. Distal end, width & 25.1 & 40.5 \\
5. Distal end, APD & 19.1 & $25.7^{\mathrm{a}}$ \\
6. Distal articular facet, width & 24.0 & 32.7 \\
7. Width at middle of shaft & 17.0 & 24.0 \\
8. APD at middle of shaft & 11.0 & 15.6 \\
9. Medial PAF, width $\times$ APD & $12.3 \times 16.3$ & $19.9 \times 23.2$ \\
10. Lateral PAF, width $\times$ APD & $14.1 \times 15.2$ & $23.1 \times 22.0$ \\
11. Lunar facet, APD & 10.6 & 16.3 \\
12. Scaphoid facet, APD & 13.3 & 18.6 \\
Ratio (\%) & & 113.8 \\
2:1 & 15.8 & 19.0 \\
4:1 & 15.9 & 19.3 \\
7:2 & 67.8 & 60.1 \\
12:11 & 125.2 & \\
\hline
\end{tabular}

a Approximate measurements.

much slender on its distal two-thirds and less bowed anteriorly, but they are similar in having narrow coronoid processes. The ulnae of Juxia and Uintaceras have wide coronoid processes; however, the former possesses a wide and nearly posteriorly extended olecranon and a relatively slender shaft, whereas the latter has a posteroproximally extended olecranon and a stout shaft. The ulnae of Triplopus and Juxia are considerably longer than the humeri, whereas the ulna is slightly longer than the humerus in Hyrachyus modestus and as long as that in Uintaceras.

\section{Carpals}

Scaphoid (fig. 16A-D; table 9): On the proximal side, the outline of the radial facet is roughly rhomboid with a rounded anteromedial border (fig. 16A). The surface is slightly convex at the anterolateral part, and concave or nearly planar at the posteromedial portion. The posterior process is inclined medially with a relatively wide and truncated posterior end. On the lateral side, there are two lunar facets (fig. 16B). The proximal facet is relatively wide and convex anteroposteriorly, and is thus embraced by the lunar in proximal view; the distal lunar facet is much narrower, and confluent with the posterior magnum facet on the posterior end. Distally, there are three facets for the magnum, trapezoid, and trapezium, respectively (fig. 16C). The magnum facet is concave anteroposteriorly and is roughly triangular in outline with a convex anterior border and an elevated, pointed posterior end, where it curves slightly onto the lateral side. The trapezoid facet is larger than the magnum facet, roughly square in outline, slightly concave, and separated from the magnum facet by a weak ridge. On the pos- 


\section{TABLE 8}

Measurements of ulnae of Hyrachyus modestus and Hyrachyus eximius (mm) $\mathrm{APD}=$ anteroposterior distance; $\mathrm{W}=$ width; $\mathrm{L}=$ length; post-super. = posterosuperior.

\begin{tabular}{lrr}
\hline \hline & $\begin{array}{r}\text { Hyrachyus modestus } \\
\text { (AMNH FM }\end{array}$ & $\begin{array}{r}\text { Hyrachyus eximius } \\
\text { (AMNH FM 93050) }\end{array}$ \\
\hline 1. Total L & 194.0 & $?$ \\
2. Trochlear notch, height & 23.5 & 30.5 \\
3. W at upper 1/3 of trochlear notch & 11.6 & 16.4 \\
4. Trochlear notch, maximum W & 21.9 & 32.0 \\
5. Olecranon, height & 38.5 & 46.4 \\
6. Olecranon, W & 15.1 & 18.8 \\
7. L of post-super. border of olecranon & 26.8 & 34.0 \\
8. W at middle of shaft & 8.3 & 16.1 \\
9. APD at middle of shaft & 14.4 & 16.6 \\
10. Cuneiform articular facet, W & 12.8 & $?$ \\
11. Cuneiform articular facet, APD & 9.4 & $?$ \\
Ratio (\%) & & 51.1 \\
3:4 & & 65.7 \\
2:5 & 53.0 & 55.3 \\
6:7 & 61.0 & 96.9 \\
8:9 & 56.5 & $?$ \\
\hline
\end{tabular}

teromedial side of the trapezoid facet, there is a small trapezium facet, directed more distally than posteriorly. An anteroposteriorly convex, half-cylindric surface occupies the distal part of the posterior process, separated from the trapezoid facet by a deep groove. In anterior and medial views, the distal process formed by the anterior magnum facet is rather weak, and the trapezoid facet is only slightly more proximal than the magnum facet (fig. 16D).

LUNAR (fig. 16E-I; table 9): In proximal view, the anterior part of the radial facet is a transversely elongate half cylinder, convex anteroposteriorly and slightly inclined toward the medial side. The radial facet extends posteriorly in the middle as a flat, striplike surface (fig. 16E). On the medial side, there are two facets for the scaphoid (fig. 16F). The proximal one is wider and longer than the distal one, and the former is concave anteroposteriorly, embracing the scaph- oid. The distal scaphoid facet is rather narrow and confined to the anterior half. Laterally, there are two flat facets for the cuneiform (fig. 16G). The proximal one is oval in outline and short, whereas the distal one is lunate and nearly twice the length of the proximal one. The distal side bears two facets. The unciform facet occupies the anterolateral portion and is trapezoidal in outline with a posterior apex, is concave anteroposteriorly, and is flat transversely (fig. $16 \mathrm{H}, \mathrm{I}$ ). The magnum facet is composed of two parts: the anterior one is nearly vertical, quadrilateral in outline, flat, and confluent with the distal scaphoid facet; the posterior one occupies the posteromedial portion, is spherically concave, and faces mediodistally (fig. 16F, H, I).

Cuneiform (fig. 16J-M; table 9): In anterolateral view, the cuneiform is trapezoidal in outline and wider than high (fig. 16M). On the proximal surface, the ulnar facet is roughly 
A

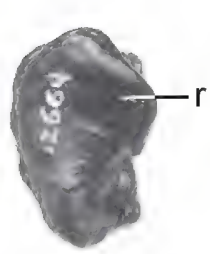

$E$

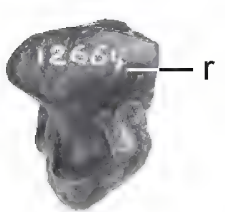

$J$
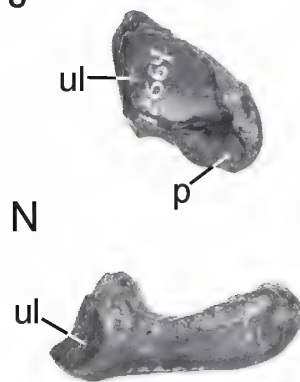

B

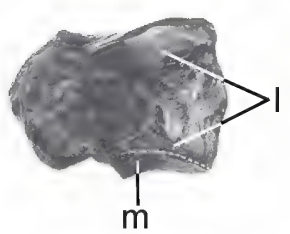

$\mathrm{F}$

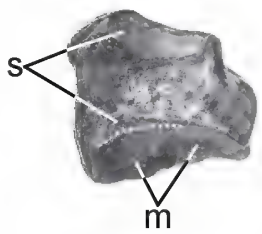

$\mathrm{K}$

$\mathrm{O}$

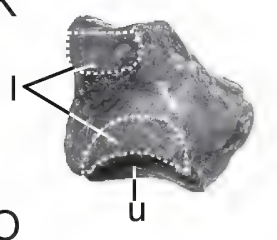

C

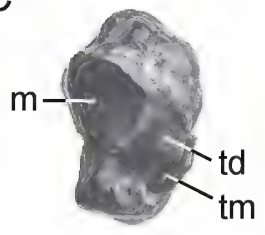

G

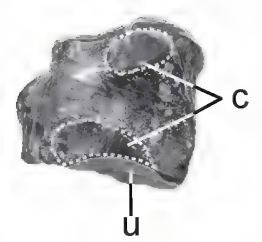

L

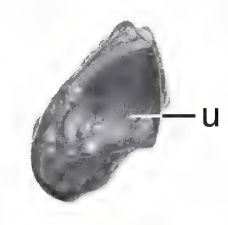

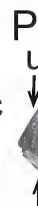

D
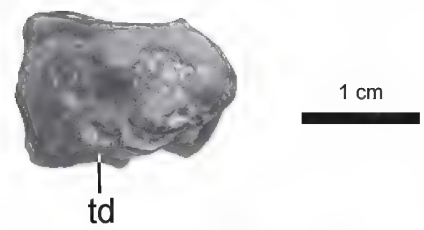

$\mathrm{H}$

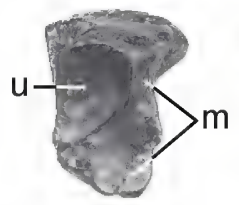

M

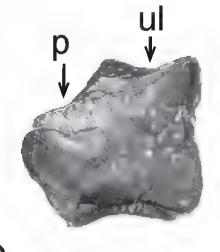

I

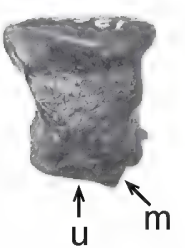

Q

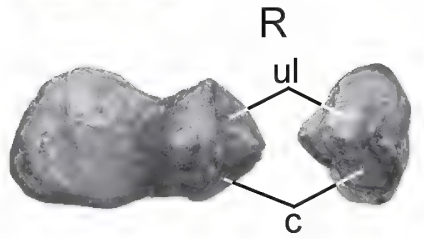

FIG. 16. Right proximal carpals of Hyrachyus modestus (AMNH FM 12664). A-D, scaphoid. A, proximal; B, lateral; C, distal; and D, medial views. E-I, lunar. E, proximal; F, medial; G, lateral; H, distal; and I, anterior views. J-M, cuneiform. J, proximal; $\mathbf{K}$, medial; $\mathbf{L}$, distal; and $\mathbf{M}$, lateral views. $\mathbf{N}-\mathbf{R}$, pisiform. $\mathbf{N}$, proximal; $\mathbf{O}$, distal; $\mathbf{P}$, lateral; $\mathbf{Q}$, medial; and $\mathbf{R}$, anterior views. Abbreviations: c, cuneiform; $\mathbf{l}$ lunar; $\mathbf{m}$, magnum; $\mathbf{p}$, pisiform; $\mathbf{r}$, radius; $\mathbf{s}$, scaphoid; $\mathbf{t d}$, trapezoid; tm, trapezium; $\mathbf{u}$, unciform; $\mathbf{u l}$, ulna.

quadrilateral in outline, wider than long, anteroposteriorly concave, and transversely flat (fig. 16J, M). The pisiform facet is striplike and concave anteroposteriorly, extending toward the posterolateral side (fig. 16J, M). The medial side is relatively high and narrow, bearing two facets for the lunar: one flat, rectangular, and proximal, and the other slightly convex, lunate, and distal (fig. 16K). The distal surface forms a right triangle in outline and is concave anteroposteriorly and flat transversely (fig. 16L).

Pisiform (fig. 16N-R; table 9): The anterior end of the pisiform bears two equal-sized facets for the ulna and cuneiform. The ulnar facet is slightly concave and faces anteroproximally, whereas the cuneiform facet is flat and faces anterodistally (fig. 16N, O, R). In lateral view, the angle between the two facets is slightly less than $90^{\circ}$ (fig. 16P). On the medial side of the anterior end there is a tubercle (fig. 16Q, R). The posterior process is slightly proximodistally expanded and curved medially.

Trapezium: The trapezium is not preserved in AMNH FM 12664, though its presence is indicated by facets on the scaphoid, trapezoid, and second metacarpal. One articulated manus with the trapezium of $H$. modestus (AMNH FM 13089) has three facets, and the trapezoid and Mc II facets are about equal in size in lateral view. 
TABLE 9

Measurements of carpals of Hyrachyus modestus (AMNH FM 12664) (mm) Measurements correspond to those of Qiu and Wang (2007: table 14-17, 41-42, 46).

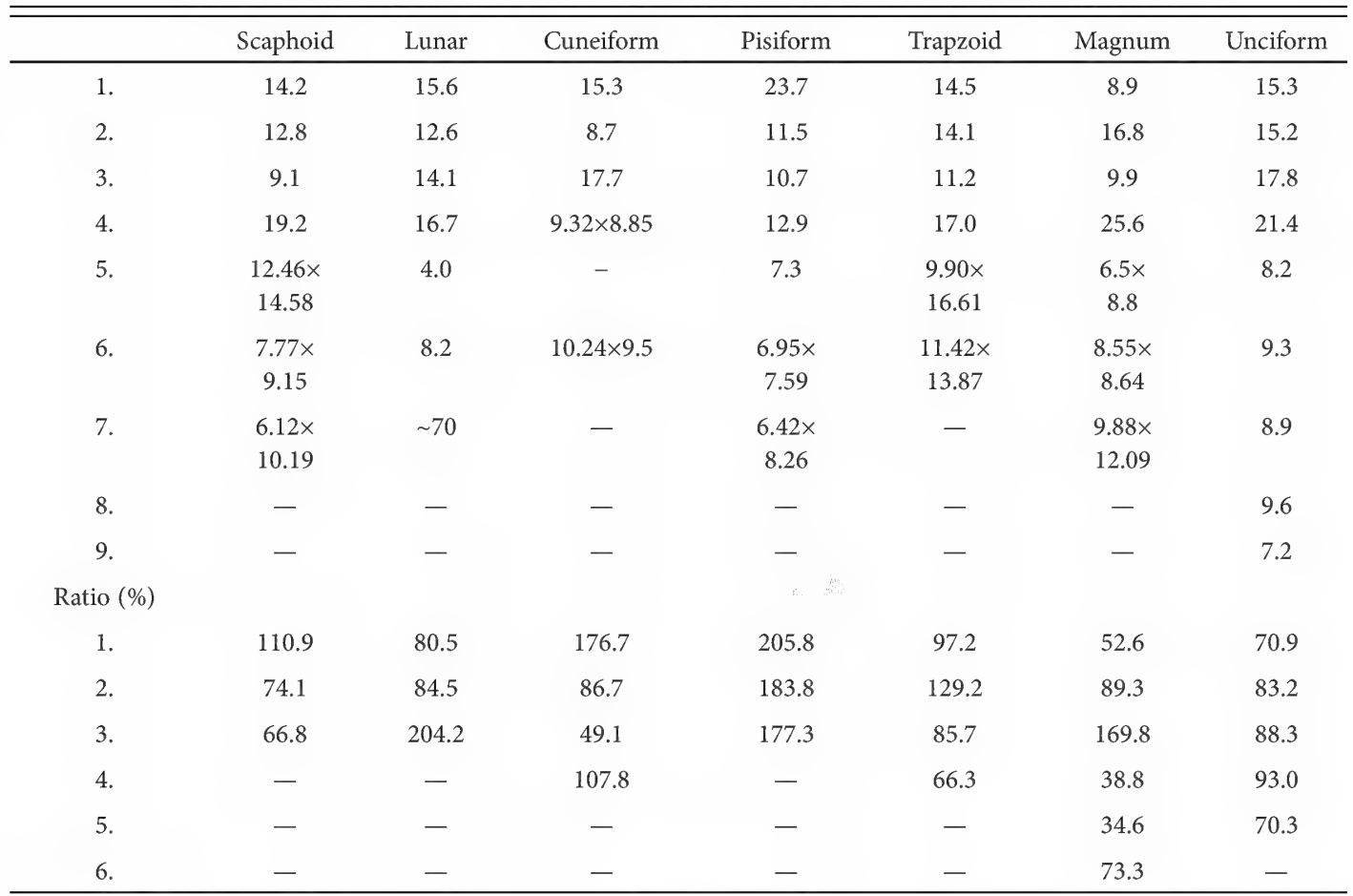

Trapezoid (fig. 17A-D; table 9): A left trapezoid is preserved in AMNH FM 12664. The bone is elongated anteroposteriorly. The anterior surface is rugose and roughly rectangular in outline with a convex distal border. Proximally, the scaphoid facet is an irregular quadrilateral and generally flat (fig. 17A). On the medial side there is a trapezoidal, slightly concave facet for the trapezium, which is smoothly continuous with the proximal surface but separated from the distal surface by a distinct ridge (fig. 17B). On the lateral side there is a rectangular and concave facet for the magnum, which is separated from the proximal surface by a distinct ridge but smoothly continuous with the distal surface (fig. 17C). Distally, the Mc II facet is an anteroposteriorly elongate oval, and saddle shaped with an anteroposteriorly concave and laterally convex surface (fig. 17D). The posterior process is absent.
Magnum (fig. 17E-I; table 9): The magnum has a rectangular anterior surface, a relatively low hump, and a large, medially curved posterior process. The scaphoid facet is composed of two parts: the anterior part is nearly horizontal, slightly convex anteroposteriorly and concave laterally, whereas the posterior part is on the medial side of the hump and is narrow and vertical (fig. 17E, F, I). The lunar facet has roughly equal-sized anterior and posterior portions: the anterior one is flat and vertical, whereas the posterior one covers the top of the hump and is convex anteroposteriorly (fig. 17E, G). On the medial side there is a slightly anteroposteriorly convex trapezoid facet (fig. 17F), which becomes narrower toward the anterior side. Distal to the trapezoid facet there is a large, flat, and vertical Mc II facet (fig. 17F). On the lateral side there is a flat unciform facet, which is confluent with the anterior lunar facet and nearly as large as 


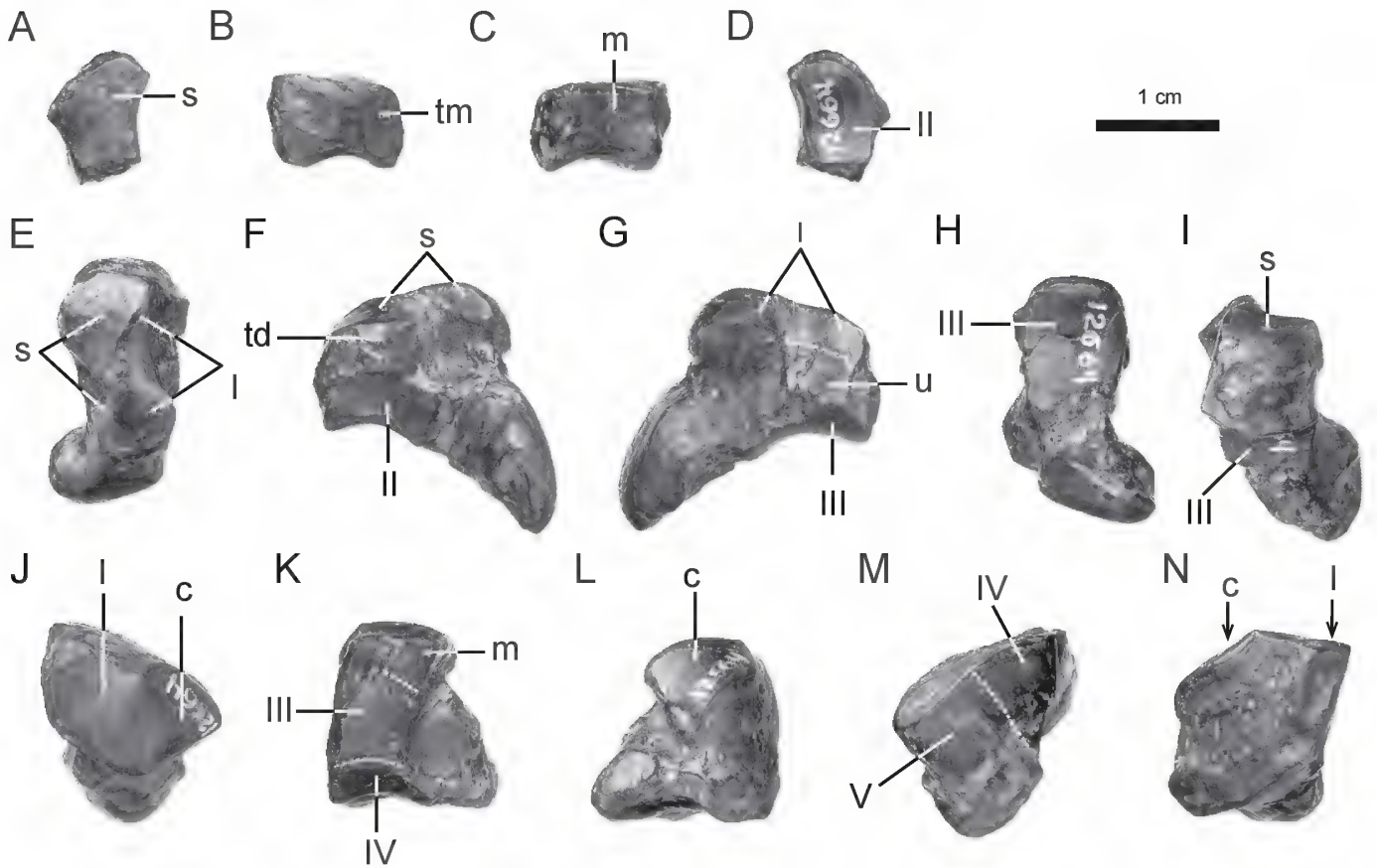

FIG. 17. Right distal carpals of Hyrachyus modestus (AMNH FM 12664). A-D, trapezoid. A, proximal; B, medial; C, lateral; and D, distal views. E-I, magnum. E, proximal; F, medial; G, lateral; H, distal; and I, anterior views. J-N, unciform. J, proximal; K, medial; L, lateral; $\mathbf{M}$, distal; and $\mathbf{N}$, anterior views. Abbreviations: c, cuneiform; l, lunar; m, magnum; s, scaphoid; $\mathbf{t d}$, trapezoid; tm, trapezium; $\mathbf{u}$, unciform; II, III, IV, and V, second, third, fourth, and fifth metacarpals.

the latter (fig. 17G). On the distal side, the Mc III facet is concave anteroposteriorly and slightly convex mediolaterally, occupying the anterior half of the distal surface (fig. 17H, I).

UNCIFORM (fig. 17J-N; table 9): The unciform is wider than high and has a relatively short posterior process (fig. 17J, N). The proximal surface is divided by a blunt ridge into approximately equal-sized lunar and cuneiform facets (fig. 17J, N). The lunar facet is roughly rhomboidal in outline, flat at the anteromedial corner, and convex at the posterolateral part. The cuneiform facet is triangular in outline, convex anteroposteriorly, and slightly concave laterally (fig. 17J). This facet descends on the posterior side (fig. 17L). On the medial side there are two confluent and striplike facets (of approximately equal size) for the magnum and the third metacarpal (fig. 17K). The medial articular surface curves gently to join the distal surface, which bears approximately equal-sized, anteroposteriorly concave facets for the fourth and fifth metacarpals (fig. 17M).

\section{Metacarpals}

The right Mc II-IV of AMNH FM 12664 are articulated in situ with the trapezoid and magnum, whereas the left Mc II-V are isolated and the proximal ends of Mc III-IV are broken. The description of the metacarpals is based on AMNH FM 12664 (Mc II-V) (table 10) and 91775 (Mc III).

Mc II (fig. 18A-D): Mc II is shorter than Mc III and nearly as long as Mc IV. In proximal view, the trapezoid facet is oval in outline, saddle shaped, and concave anteriorly and convex posteriorly (fig. 18C). On the posteromedial side of the trapezoid facet there is a small, convex facet 
TABLE 10

Measurements of metacarpals (Mc) of Hyrachyus modestus (AMNH FM 12664) (mm)

$\mathrm{APD}=$ anteroposterior distance; $\mathrm{DAF}=$ distal articular facet.

\begin{tabular}{lcccc}
\hline \hline & Mc II & Mc III & Mc IV & Mc V \\
\hline 1. Total length & 71.0 & 78.5 & 66.3 & 49.7 \\
2. Proximal end, width & 8.5 & 14.3 & $?$ & 8.3 \\
3. Proximal end, APD & 15.7 & $?$ & $?$ & 9.9 \\
4. Distal end, width & 12.4 & 17.2 & 12.5 & 10.6 \\
5. DAF, width & 11.2 & 13.9 & 10.5 & 7.9 \\
6. Distal end, APD & 11.3 & 11.1 & 12.1 & 8.8 \\
7. Width at midshaft & 9.7 & 11.7 & 9.3 & 7.7 \\
8. APD at midshaft & 6.8 & 7.6 & 6.5 & 5.1 \\
Ratio (\%) & & & & \\
2:1 & 12.0 & 18.2 & $?$ & 16.7 \\
4:1 & 17.5 & 21.9 & 18.8 & 21.2 \\
2:3 & 54.4 & $?$ & $?$ & 84.0 \\
5:6 & 99.6 & 125.0 & 86.2 & 90.2 \\
\hline
\end{tabular}

for the trapezium. On the lateral side of the proximal end there is a striplike and nearly vertical facet for the magnum. A small process extends anterolaterally from the proximal end of the dorsal surface, with a small, flat, posterodistally facing facet for the Mc III on the posterior side (fig. $18 \mathrm{~A}, \mathrm{~B})$. The shaft is somewhat laterally compressed and slightly bowed medially. The distal end is asymmetrical, and the medial groove on the medial side of the sagittal ridge is deeper and wider than the lateral one (fig. 18D).

MC III (fig. 18E-I): Mc III is the largest of the metacarpals (AMNH FM 91775). In proximal view, the magnum facet is roughly triangular in outline, strongly convex anteroposteriorly, and slightly concave laterally (fig. 18H). The magnum facet extends more distally on the posterior side than on the anterior side (fig. 18E, $\mathrm{G})$. On the anteromedial side of the magnum facet there is a small, anterodistally inclined facet for the Mc II (fig. 18E, F). On the lateral side of the magnum facet there is a triangular, laterally inclined, and slightly convex facet for the unciform, which is separated from the magnum facet by a sharp ridge and bordered posteriorly by a wide notch (fig. $18 \mathrm{~F}-\mathrm{H}$ ). The Mc IV facet consists of two facets (fig. 18G): the anterior one is overhung by the unciform facet with a slightly concave, laterodistally facing surface; the posterior Mc IV facet is nearly vertical and planar, separated from the anterior facet by a rugose area. The shaft is straight and anteroposteriorly compressed. The distal end is symmetrical with the blunt sagittal ridge extending to the midline of the distal surface (fig. 18I).

Mc IV: Mc IV is shorter than Mc II, but the only preserved Mc IV on the manus of AMNH FM 12664 is covered by sediment matrix on its medial side. Proximally, the unciform facet is triangular in outline, convex anteroposteriorly, and slightly concave laterally. The anterior Mc III facet is small, flat, and mediodistally inclined, forming an obtuse angle with the unciform facet from the anterior view. The posterior Mc III facet is not visible but is probably oval shaped based on the corresponding facet of $\mathrm{Mc}$ III. On the lateral side of the proximal end, there is a narrow, striplike, and laterally concave facet for the Mc V, beneath which a shallow fossa is present. The shaft is slightly laterally curved and the distal end is asymmetric and mirrors that of Mc II. 

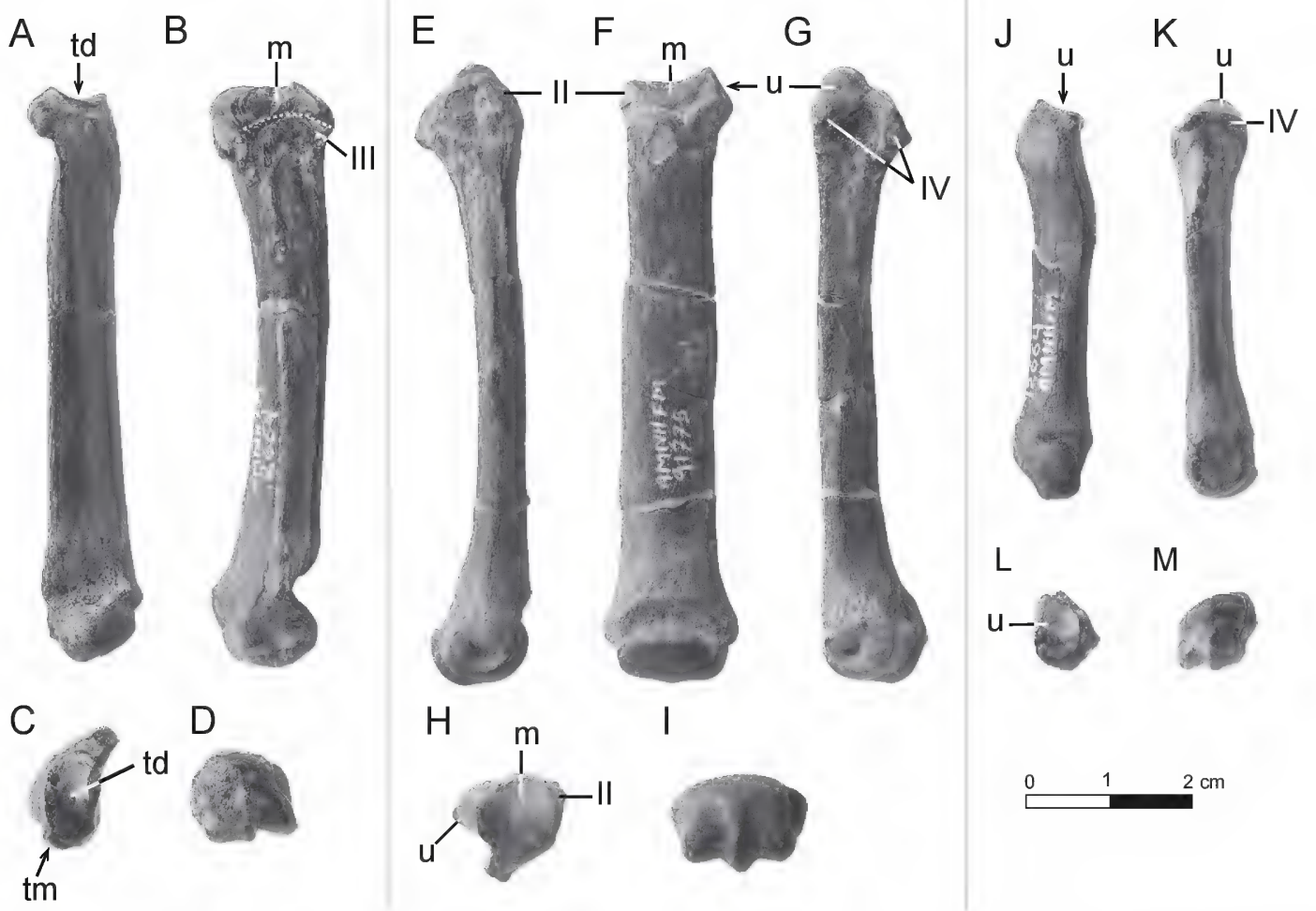

FIG. 18. Partial metacarpals of Hyrachyus modestus. A-D, right second metacarpal (AMNH FM 12664). A, anterior; B, lateral; C, proximal; and D, distal views. E-I, left third metacarpal (AMNH FM 91775). E, medial; F, anterior; G, lateral; $\mathbf{H}$, proximal; and I, distal views. J-M, right fifth metacarpal (AMNH FM 12664). J, anterior; K, medial; L, proximal; and M, distal views. Abbreviations: m, magnum; td, trapezoid; tm, trapezium; u, unciform; II, III, and IV, second, third, and fourth metacarpals.

Mc V (fig. 18J-M): Mc V is functional with three phalanges as induced from that of $H$. eximius. The length of $\mathrm{Mc} \mathrm{V}$ is about three-fifths that of Mc III. On the proximal end, the unciform facet is roughly trapezoidal in outline, slightly convex anteroposteriorly with an extension onto the posterior surface, and slightly concave laterally with a raised lateral border (fig. 18J-L). On the medial side of the unciform facet there is a narrow, striplike, and vertically placed Mc IV facet (fig. 18K). On the lateral surface of the proximal end there are two rugose depressions with the anterior one considerably larger than the posterior one. The shaft is more laterally curved than that of Mc IV, and the medial border is somewhat convex in anterior view. The distal end is more asymmetrical than that of Mc IV in having a more distally extended medial portion (fig. 18M).

A reconstruction of the manus is shown in figure 19.

COMPARISONS OF THE MANUS: The most conspicuous feature of manus in Hyrachyus eximius, according to the figure by Cope (1884: pl. 55, fig. 3), lies in the distal surface of lunar bearing symmetrical, equally divided magnum and unciform facet in the anterior view; however, after checking the specimen AMNH FM 5065, the lunar of $H$. eximius is similar to that of $H$. modestus in having a large, horizontal unciform facet and a narrow, nearly vertical magnum facet in the anterior view. The manus of $H$. eximius (AMNH FM 1602) differs from that of $H$. modestus by the possession of a more promi- 


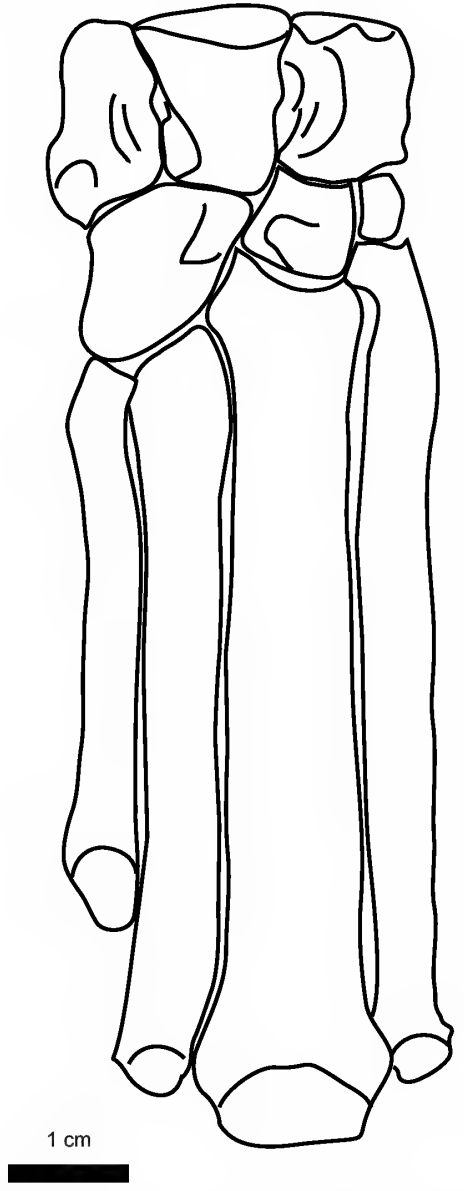

FIG. 19. Reconstruction of right manus of Hyrachyus modestus based on AMNH FM 12664 and 91775.

nent distal process of the scaphoid with a relatively larger, laterodistally directed posterior magnum facet, a L-shaped outline of the cuneiform in the lateral view, an elongated cuneiform facet of the pisiform, a magnum with a rhombic anterior surface, a higher hump, and a nearly flat anterior scaphoid facet, and the anterolateral process of Mc II all but entirely absent.

The manus of Heptodon posticus is different from that of Hyrachyus modestus in having a scaphoid with a tear-shaped facet for the radius and without the trapezium facet, a posterior magnum facet of the lunar probably facing more laterally but less distally, and a higher hump of the magnum. They are similar in having a lunar with a nearly horizontal unciform facet and a small, nearly vertical anterior magnum facet, a pisiform with equal facets for the ulna and cuneiform, and a functionally tetradactyl manus.

The manus of Triplopus differs from that of Hyrachyus modestus in being relatively higher and narrower, and in having a more oblique and concave trapezoid facet of the scaphoid, continuous proximal facets for the ulna and pisiform of the cuneiform (the two facets are bordered by a distinct ridge in Juxia and Uintaceras), a larger trapezoid, an anteroposteriorly convex anterior scaphoid facet, a much more concave Mc III facet of the magnum, a remarkably long posterior process of the unciform, and a functional tridactyl manus with a highly reduced Mc V. They are similar in having a scaphoid embraced by the lunar with a long contact in the proximal view as in Uintaceras, whereas in Juxia the scaphoid-lunar contact is more anteroposteriorly extended in the proximal view.

The manus of Juxia and Uintaceras are tetradactyl as in Hyrachyus modestus, but the manus of Juxia is relatively higher and narrower, with a more reduced Mc V. The manus of Uintaceras is very similar to that of Hyrachyus modestus in having a wide facet for the radius in the lunar, and a moderately concave Mc III facet of the magnum, whereas the manus of Juxia has a lunar with a narrow facet for the radius, and probably a more concave Mc III facet of the magnum. The manus of Juxia is also characterized by the presence on the cuneiform of a small facet for the radius. On the other hand, the manus of Uintaceras is different from that of Hyrachyus modestus in having a more oblique trapezoid facet of the scaphoid, and a pentagonal outline of the anterior surface of the magnum.

\section{Phalanges}

Several isolated phalanges of AMNH FM 12664 were assigned to the manus, since the pes was not preserved in AMNH FM 12664. However, it is hard to distinguish the phalanges in 
different lateral digits, and from manus to pes as noted by Qiu and Wang (2007).

Proximal phalanges (fig. 20A, B): The proximal phalanx of the middle digit (III) is higher (proximodistally, $19.3 \mathrm{~mm}$ ) than wide (15.6 mm) (fig. 20A). The proximal surface is concave and oval in outline with an indentation on the posterior border. A shallow median groove is present on the posterior half of the proximal surface. On the posterior side of the proximal end there are two relatively small tubercles. The distal end mainly faces distally and is anteroposteriorly convex with a wide, shallow groove in the middle and a small "pseudo-articular facet" on the anterior surface.

The proximal phalanx of the lateral digits is more laterally compressed but less anteroposteriorly compressed than that of the middle digit (fig. 20B). The phalanx is about $18.0 \mathrm{~mm}$ long and $12.2 \mathrm{~mm}$ wide across its proximal end. The proximal surface is roughly round with a shallow indentation on the posterior border, and moderately concave. The lateral side of the proximal end is more posteriorly extended and thicker than the medial side. The distal end is generally flat, slightly concave transversely, and asymmetrical with the medial side slightly thicker, more distally facing, and less proximally extended on the posterior side than the lateral side.

Middle PHAlanges (fig. 20C, D): The middle phalanx of the middle digit is slightly wider $(13.5 \mathrm{~mm})$ than high (proximodistally, 13.0 $\mathrm{mm}$ ) (fig. 20C). The proximal surface is oval in outline without an indentation on the posterior border, and anteroposteriorly concave. The distal end is symmetrical and anteroposteriorly convex with a moderately deep median groove.

The middle phalanx of the lateral digit is more laterally compressed but less anteroposteriorly compressed than that of the middle digit (fig. 20D). The phalanx is about $12.2 \mathrm{~mm}$ long and $10.1 \mathrm{~mm}$ wide across its proximal end. The proximal surface is irregularly oval in outline with the lateral part thicker and more proximally extended than the medial one. The distal end is similar to that of proximal phalanx of the
A
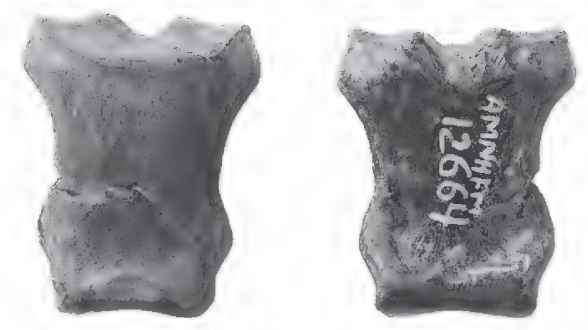

B

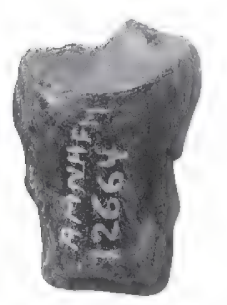

C
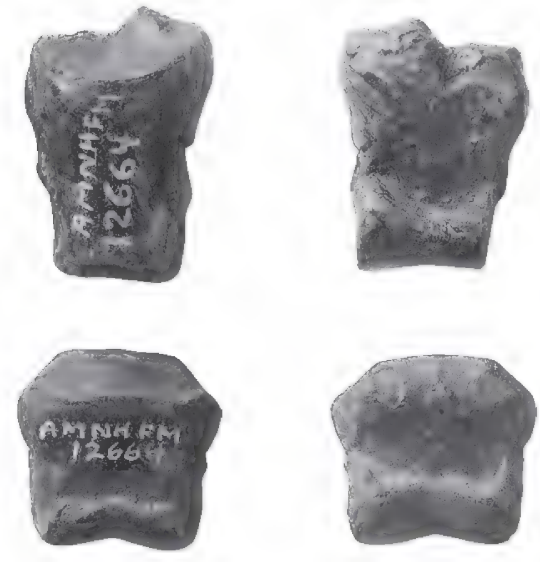

D

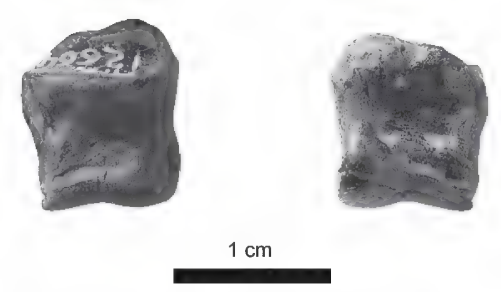

FIG. 20. Partial phalanges of Hyrachyus modestus (AMNH FM 12664). A, anterior and posterior views of proximal phalanx of middle digit; $\mathbf{B}$, anterior and posterior views of proximal phalanx of lateral digit; C, anterior and posterior views of middle phalanx of middle digit; $\mathrm{D}$, anterior and posterior views of middle phalanx of lateral digit.

lateral digit, but is more convex anteroposteriorly with a deeper longitudinal groove.

Distal PHALANGes: Three fragmentary distal phalanges are preserved in AMNH FM 12664. The distal phalanx is generally hooflike and flat with a relatively deep fissure on the distal end. The middle distal phalanx is symmetric, whereas the lateral distal phalanx is asymmetric. 
TABLE 11

\begin{tabular}{|c|c|c|}
\hline & $\begin{array}{l}\text { Hyrachyus modestus } \\
\text { (AMNH FM 11662) }\end{array}$ & $\begin{array}{r}\text { Hyrachyus eximius } \\
\text { (Qiu and Wang, 2007) }\end{array}$ \\
\hline 1. Total length & 243.0 & $280^{\mathrm{b}}$ \\
\hline 2. Ilium, length & 146.0 & $145^{\mathrm{b}}$ \\
\hline 3. Iliac wing, width & 150.0 & $148^{b}$ \\
\hline 4. Iliac body, width & 24.6 & 30 \\
\hline 5. Ischium, length & 90.0 & 110 \\
\hline 6. Ischium, width & 57.8 & ? \\
\hline 7. Acetabulum, length $\times$ width & $31.98 \times 29.89$ & ? \\
\hline 8. Obturator, length $\times$ width & $47.29 \times 19.72$ & $41 \times 34$ \\
\hline 9. Pelvic symphysis, length & $80.9^{\mathrm{a}}$ & $\sim 73^{\mathrm{b}}$ \\
\hline \multicolumn{3}{|l|}{ Ratio (\%) } \\
\hline $1: 2$ & 166.4 & 9.7 \\
\hline $1: 3$ & 162.0 & 137.1 \\
\hline 1:5 & 270.0 & 22.2 \\
\hline $3: 4$ & 608.8 & 90.4 \\
\hline
\end{tabular}

${ }^{a}$ Approximate measurements; ${ }^{\mathrm{b}}$ measured from the plates.

Comparisons of the phalanx: The proximal phalanx of the middle digit of Heptodon posticus is relatively higher and narrower (the ratio of the length to the width is about 131\%) than that of Hyrachyus modestus (the ratio is 123\%) (Radinsky, 1965a). Further, the distal phalanx of $H$. posticus has a rather shallow fissure on the distal end, whereas that of $H$. modestus is deep. The proximal phalanx of the middle digit of Triplopus cubitalis has a similar ratio of the length to the width (125\%) as that of Hyrachyus modestus (Qiu and Wang, 2007: table 20), but the former has a deeper fissure of the distal phalanx reaching the middle of the length. The proximal phalanx of the middle digit of Uintaceras is relatively shorter and wider, and has a shallower indentation and median groove of the proximal surface than that of Hyrachyus modestus. The proximal phalanx of the middle digit of Juxia is characterized by a deep median groove on the proximal surface reaching almost to the anterior margin, and the ratio of the length to the width is about $118.9 \%$ (Qiu and Wang, 2007: table 20).

\section{Bones of the Pelvic Limb}

Innominate Bones

Of the innominate bones, AMNH FM 12664 preserves only a broken right ilium. The specimen of AMNH FM 11662, however, has more complete left and right innominate bones (table 11).

The wing of the ilium is hammer shaped and the body is more or less laterally compressed (figs. 21-22). Its gluteal surface (= lateral surface) is flattened ventrally and concave dorsally (fig. 22A, B). The gluteal line is indistinct. The medial surface (= sacropelvic surface) is convex with a rough medial part for articulation with the sacrum and a generally smooth lateral part; the latter bears a ridge extending toward the coxal tuberosity, which is more prominent on AMNH FM 12664. The ilio-pectineal line is weak and bears a prominent psoas tubercle near the acetabulum. A possible arcuate line is distinct on the specimen of AMNH FM 11662. The iliac crest is concave (fig. 22A, B). The greater ischiatic notch is deeply concave with a 


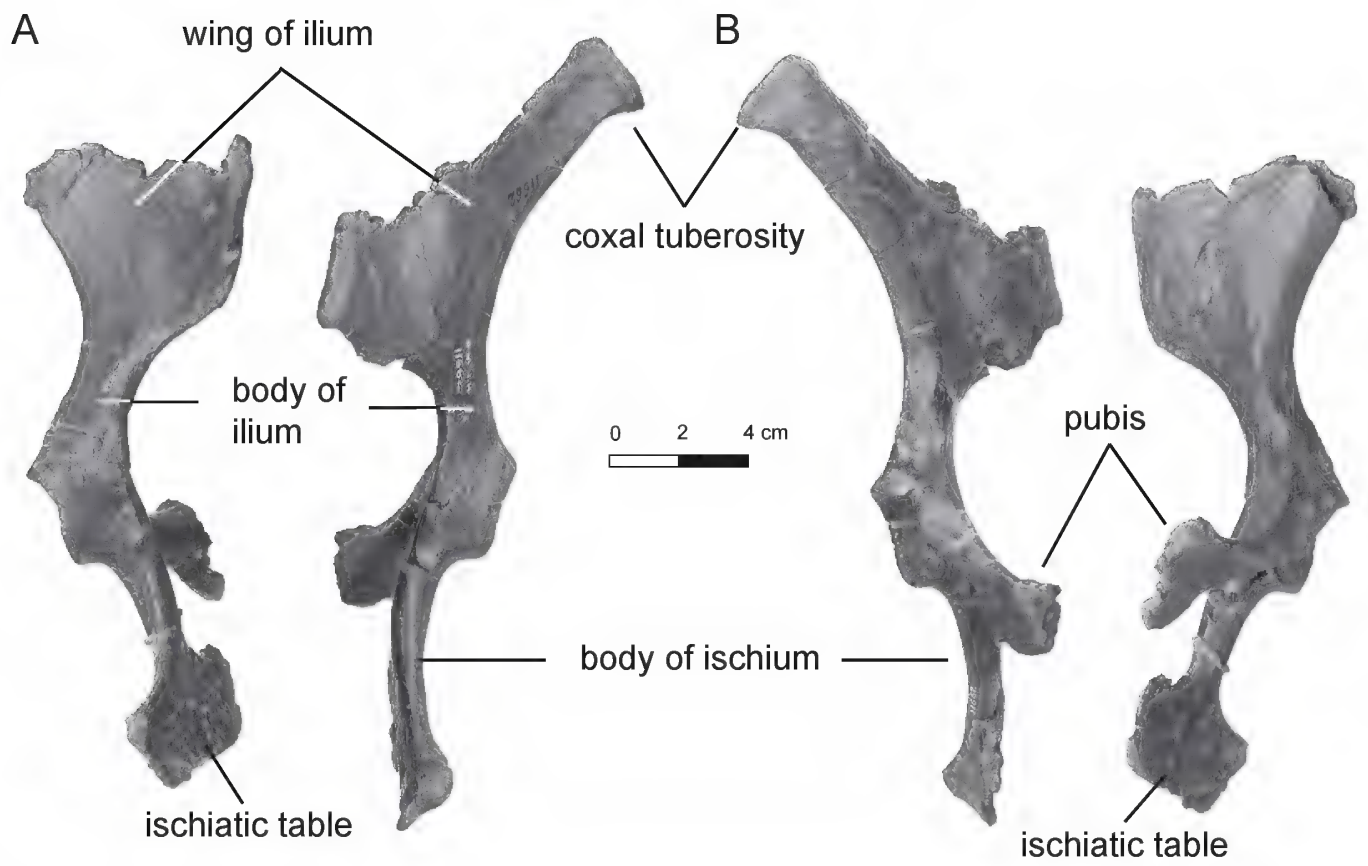

FIG. 21. Innominate of Hyrachyus modestus (AMNH FM 11662). A, dorsal; and B, ventral views.

slight convexity in the middle and is continuous with the long, narrow, rough ischiatic spine, which is bordered posteriorly by a shallow notch (fig. 22A, B). The lateral border is also very concave. The sacral tuberosity extends dorsally and is widely quadrangular in outline (fig. $22 \mathrm{~A}$ ). The coxal tuberosity is long and narrowly quadrangular in outline, extending anterolaterally (fig. 22A). The body is relatively long, narrow, and transversely compressed with a narrowly triangular cross section. Two depressions for the rectus femoris muscle are present anterodorsal to the acetabulum. On AMNH FM 12664, the more medial depression is much larger and deeper than the lateral one, whereas the lateral depression is larger than the medial one on the specimen of AMNH FM 11662.

The ischium is incomplete with a broken symphyseal branch. The ischiatic table is irregularly quadrangular in outline, and wider than long. The dorsal surface is slightly convex, whereas the ventral surface is generally concave (fig. 21A, B). The anterior border of the ischiatic table forms the posterior border of the obturator foramen. The cross section of the body is roughly semicircular in outline with a slightly concave lateral border and rounded medial border. The posterior border of the ischium is rough, forming the ischiatic arch with its counterpart. The lesser ischiatic notch is widely concave (fig. 22A, B).

The dorsal surface of the pubis is concave transversely and slightly convex anteroposteriorly. The ventral surface is concave (fig. 21B). The anterior border is rough, wide laterally, becoming narrower medially, then swollen again at the symphyseal border. The iliopectineal eminence is indistinguishable. The posterior border is thin and forms the anterior border of the obturator foramen.

The acetabulum forms a hemispherical cavity that is anteriorly placed such that the anterior rim of the pubis is located behind its anterior border (figs. 21B, 22A, B). The articular surface is crescentic, and the acetabular notch is wide and $\mathrm{U}$-shaped. The obturator 
A

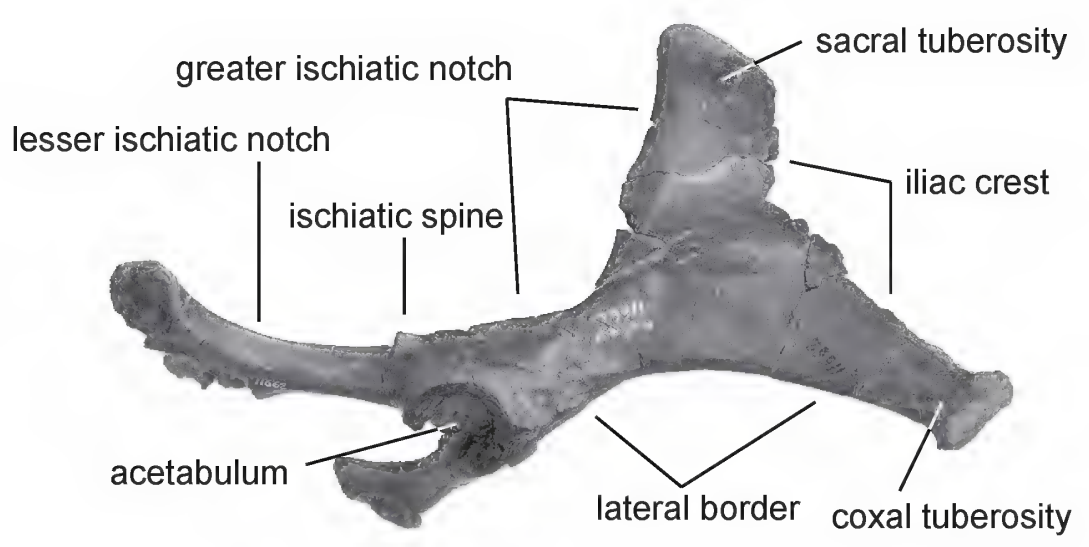

B

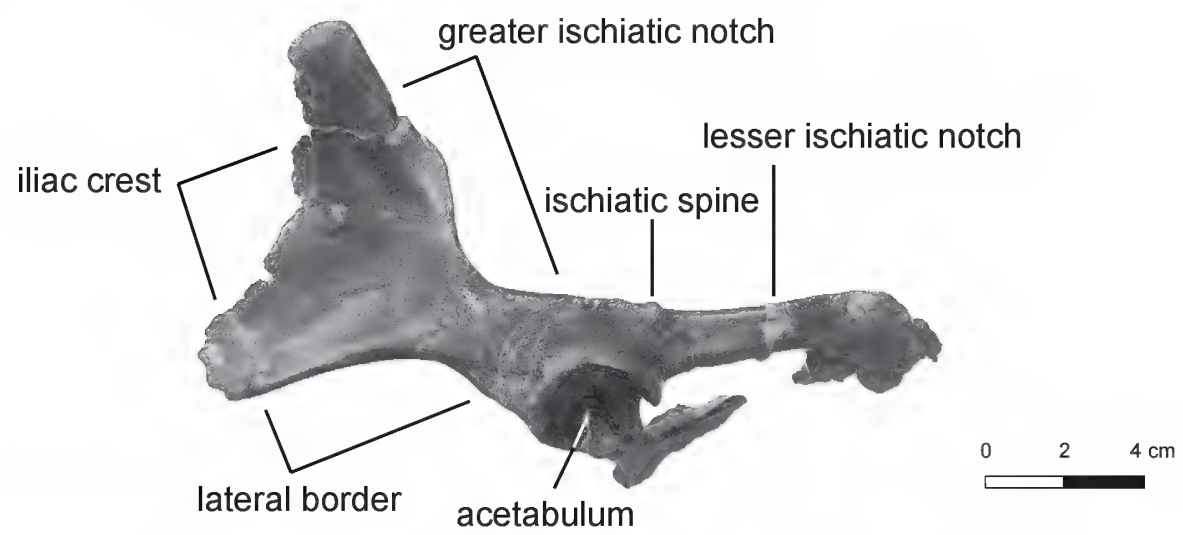

FIG. 22. Innominate of Hyrachyus modestus (AMNH FM 11662). A, right lateral; and B, left lateral views.

foramen is oval in outline, and longer than wide with the long axis extending anteriorly and slightly laterally.

COMPARISONS OF THE INNOMINATE BONE: Cope (1884) described the innominate bone of Hyrachyus eximius (AMNH FM 5065). It is nearly identical to that of $H$. modestus (AMNH FM 11662) except it is slightly larger. Further, it is clear that the ischia of $H$. eximius do not fuse with each other and are separated by a long fissure except at their anterior and posterior ends.

The innominate bone of Heptodon posticus is different from that of Hyrachyus modestus (AMNH FM 11662) in having a less concave iliac crest, an ischiatic spine located a short distance posterior to the acetabulum, and in lacking a convexity in the middle of the greater ischiatic notch. They are similar in having a long, narrow coxal tuberosity, a concave lateral border of the ilium, and a concave greater ischiatic notch.

The innominate bones of Triplopus and Uintaceras are not preserved. Qiu and Wang (2007) determined the similarities between the innominate bones of Juxia and Hyrachyus eximius, the latter nearly identical to that of $H$. modestus, in having a concave lateral border of the ilium, a concave greater ischiatic notch with a convexity in the middle, and a deep ischiatic arch. However, the innominate bone of Juxia has a nearly straight iliac crest, a relatively wider coxal tuberosity, and an acetabulum placed in the middle of the innominate bone. 
TABLE 12

Measurements of femora of Hyrachyus modestus (mm)

$\mathrm{APD}=$ anteroposterior distance.

\begin{tabular}{lrr}
\hline \hline & AMNH FM 12664 & AMNH FM 11662 \\
\hline 1. Total length & 227.0 & 241.8 \\
2. Head, maximum APD & 26.9 & 34.2 \\
3. Proximal end, maximum width & 60.8 & 60.9 \\
4. Distal end, width & 45.5 & 53.9 \\
5. Distal end, APD & 53.2 & 57.0 \\
6. Greater trochanter, maximum APD & 42.7 & 39.7 \\
7. Trochlea, medial length & 38.7 & 60.5 \\
8. Trochlea, lateral length & 41.5 & 54.5 \\
9. Trochlea, length of middle groove & 32.4 & 38.5 \\
10. Medial condyle, length $\times$ width & $27.9 \times 16.26$ & $28.3 \times 17.3$ \\
11. Lateral condyle, length $\times$ width & $29.57 \times 19$ & $34.1 \times 21.8$ \\
Ratio (\%) & & 25.2 \\
3:1 & 26.8 & 22.3 \\
4:1 & 20.0 & \\
\hline
\end{tabular}

Femur

The femur of AMNH 12664 is relatively long and slender (table 12). The head is hemispherical and extends anteromedially, with a short neck. The fovea is large and deep and located near the margin of the head (fig. 23A, C). The greater trochanter is elevated proximally considerably above the level of the head and is undivided (figs. 23A, B, 24A); however, a lateral ridge on the proximal surface of the greater trochanter possesses a little break in the middle, indicating the boundary of the anterior and posterior parts.

The shaft is relatively wide and flat on the proximal part and becomes cylindrical on the middle and distal parts. The cross section of the shaft is an anteroposteriorly elongated oval in the middle and more circular distally (fig. 23A, C). On the posterior side, the trochanteric fossa is rather deep and the intertrochanteric crest is vertical (fig. 23B, C). On the distal part of the posterior side, the supracondyloid fossa is distinct and moderately deep, and the medial supracondylar ridge is short and sharp (fig. 23B). The medial side of the shaft bears a proximodistally elongated, flangelike lesser trochanter (whose proximal end is broken off), occupying the proximal third of the shaft (fig. 23A, C). On the lateral side the third trochanter is slightly more distal than the level of the lesser trochanter, and relatively large, flared, and recurved anteriorly with a rugose surface on the lateral side (fig. 23A, $\mathrm{B}, \mathrm{D})$. The distal boundary of the third trochanter is a relatively sharp ridge, extending distally along the posterior border of the lateral side to the supracondyloid fossa.

The trochlea is long, narrow, nearly symmetrical, and slightly narrowing distally (figs. $23 \mathrm{~A}, 24 \mathrm{~B})$. The long axis of the trochlea is parallel to that of the shaft. The supratrochlear fossa is proximodistally elongated, rectangular, and moderately deep (fig. 23A). The medial condyle is slightly smaller, more distally placed, and less convex mediolaterally than the lateral condyle (figs. 23B, 24B). The medial condyle is continuous with the trochlea with a broad contact anteriorly and is separated from the shaft by a relatively wide and shallow groove on the posterior side. The lateral condyle has a narrow 
A

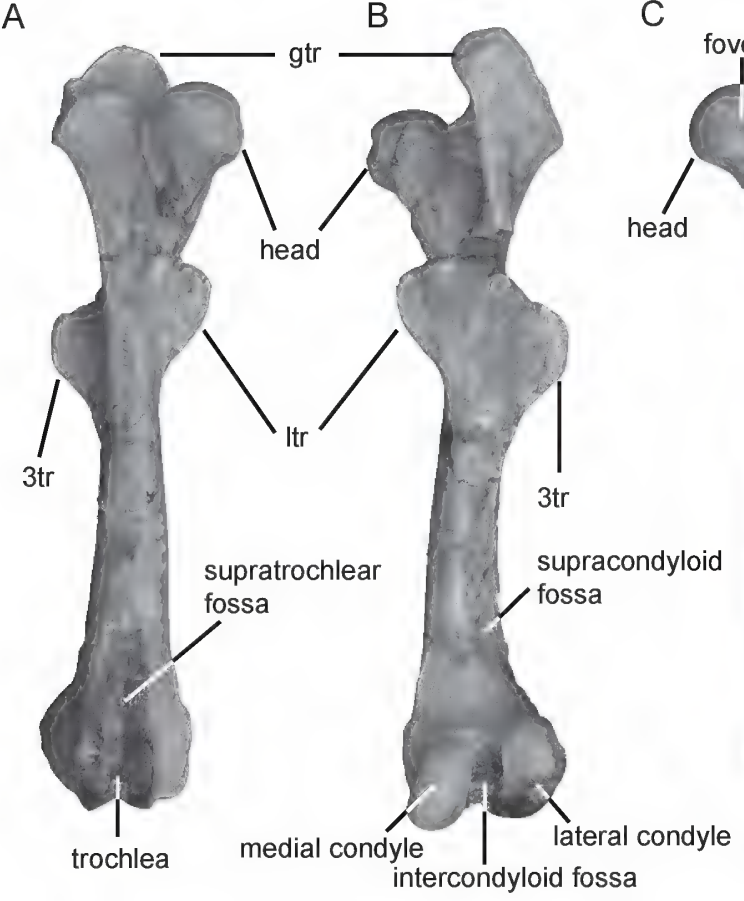

C

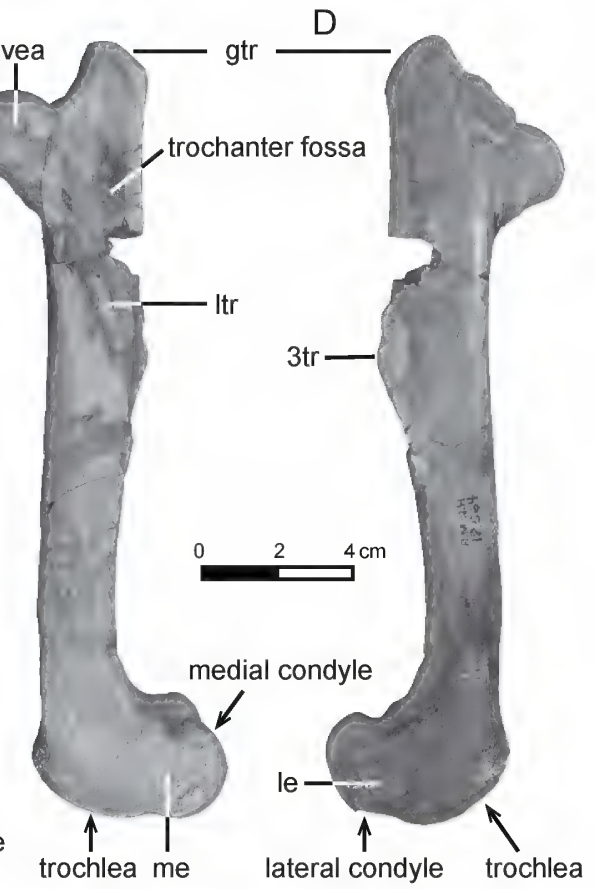

FIG. 23. Right femur of Hyrachyus modestus (AMNH FM 12664). A, anterior; B, posterior; C, medial; and D, lateral views. Abbreviations: gtr, greater trochanter; le, lateral epicondyle; ltr, lesser trochanter; me, medial epicondyle; 3 tr, third trochanter.

contact with the trochlea due to interruption by a large extensor fossa anteriorly and is continuous with the shaft posteriorly (figs. 23C, D, 24B). The intercondyloid fossa is narrow and deep (fig. 23B). The medial epicondyle is less prominent than the lateral one and is situated anterior to the posterior border of the medial condyle with a shallow fossa (fig. 23C). The lateral epicondyle is slightly proximal to the level of the medial one and has a deeper fossa in the middle. Posterodistal to the fossa is another larger and deeper fossa for the insertion of the popliteus muscle (figs. 23D, 24B).

COMPARISON OF THE FEMUR: The femur of Hyrachyus eximius (AMNH FM 5065) is nearly identical to that of $H$. modestus, except for a relatively less flared third trochanter, and a shallower trochlea.

The femur of Heptodon posticus is similar to that of Hyrachyus modestus in having a greater trochanter elevated proximally above the level of the head, a rugose portion of the greater trochanter extending distally as far down as the distal margin of the head, a vertical intertrochanteric crest, a distinct supracondyloid fossa, and a narrow, nearly symmetric trochlea. However, the femur of $H$. posticus has smaller and more proximally placed lesser and third trochanters than that of $H$. modestus.

The femur of Triplopus was not preserved. Qiu and Wang (2007) determined that the femur of Juxia is different from that of Hyrachyus eximius in having a greater trochanter nearly as high as the level of the head, a relatively weaker lesser trochanter, and a more distally placed third trochanter; those characters are also present in Uintaceras. Furthermore, the femur of Juxia is different from that of Hyrachyus modestus by the presence of a relatively weaker third trochanter and a distal mar- 


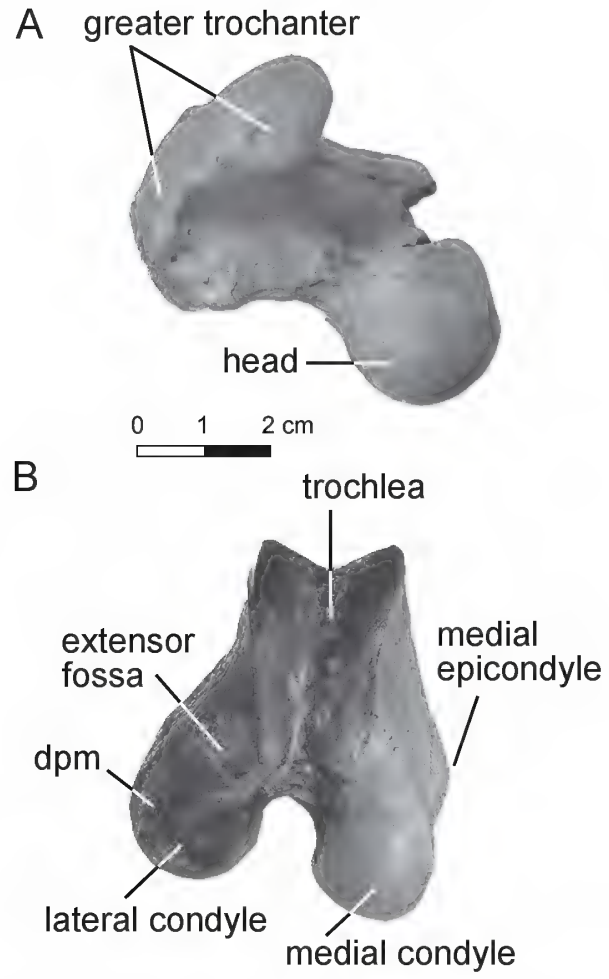

FIG. 24. Right femur of Hyrachyus modestus (AMNH FM 12664). A, proximal; and B, distal views. Abbreviation: dpm, depression for popliteus muscle.

gin of the rugose portion of the greater trochanter lying below that of the head as in Uintaceras, and an asymmetric trochlea with a medial ridge more longitudinally convex than the lateral one. The trochlea of the femur in Uintaceras is partially broken, but it is probably symmetric and relatively long and narrow. They are similar in having a vertical intertrochanteric crest, and a distinct supracondyloid fossa.

\section{Patella}

A left patella is preserved in AMNH FM 12664 , but the proximolateral part and the distal extremity have been broken off. It is oval in outline, longer than wide, and moderately deep anteroposteriorly (fig. 25A; table 13). The articular surface occupies the whole posterior side, and is divided by a vertical, rounded ridge into two parts, the lateral one narrower than the medial one and both of them concave transversely (fig. 25B). The angle between the two surfaces is obtuse (about $125^{\circ}$ ). The anterior surface is convex and rugose with a large, vertically depressed area on the medial side for the attachment of the middle patellar ligament (fig. 25C). On the lateral side of the anterior surface there is a relatively small depressed area for the lateral patellar ligament (fig. 25D). The base is rugose, facing proximally and slightly posteriorly. The apex is pointed distally and compressed anteroposteriorly.

COMPARISON OF THE PATELla: The patella of Hyrachyus eximinus (AMNH FM 5065) was mounted. It is very similar to that of $H$. modestus as far as can been observed.

The patella of Triplopus obliquidens (YPM VPPU 10397) is different from that of Hyrachyus modestus primarily in being flatter anteroposteriorly, and in having a more transversely concave medial articular surface than the lateral one. They are similar in having the medial articular surface wider than the lateral one.

The patella of Juxia is similar to that of Hyrachyus modestus in having a medial articular surface wider than the lateral one, whereas that of Uintaceras has subequal medial and lateral articular surfaces with the lateral one more distally extended. The patella of Uintaceras is similar to that of Hyrachyus modestus in having a base much thicker than the apex, and in lacking a distinct medial angle, whereas the patella of Juxia has an apex nearly as thick as the base, and a distinct medial angle.

Tibia

The description of the tibia is based on AMNH FM 11662, which also includes a right femur. The tibia of Hyrachyus modestus is relatively long (slightly shorter than the femur) and slender (fig. 26; table 14). The proximal end is wider than its anteroposterior depth (fig. 27A). The medial condyle is flat and roughly triangular in outline, whereas the lateral condyle is slightly convex anteroposteriorly and wider (fig. 
TABLE 13

Measurements of patella of Hyrachyus modestus $(\mathrm{mm})$

$\mathrm{APD}=$ anteroposterior distance; $\mathrm{PE}=$ proximal end.

\begin{tabular}{lr}
\hline \hline & $\begin{array}{r}\text { AMNH } \\
\text { FM } 12664\end{array}$ \\
\hline 1. Height & 33.9 \\
2. Width & 21.1 \\
3. Articular facet, width of lateral half & 8.9 \\
4. Articular facet, width of medial half & 12.3 \\
5. Maximum APD of PE & 13.1 \\
6. Max APD of patella & 17.7 \\
Ratio (\%) & \\
2:1 & 62.3 \\
3:4 & 72.4 \\
6:1 & 52.3 \\
\hline
\end{tabular}

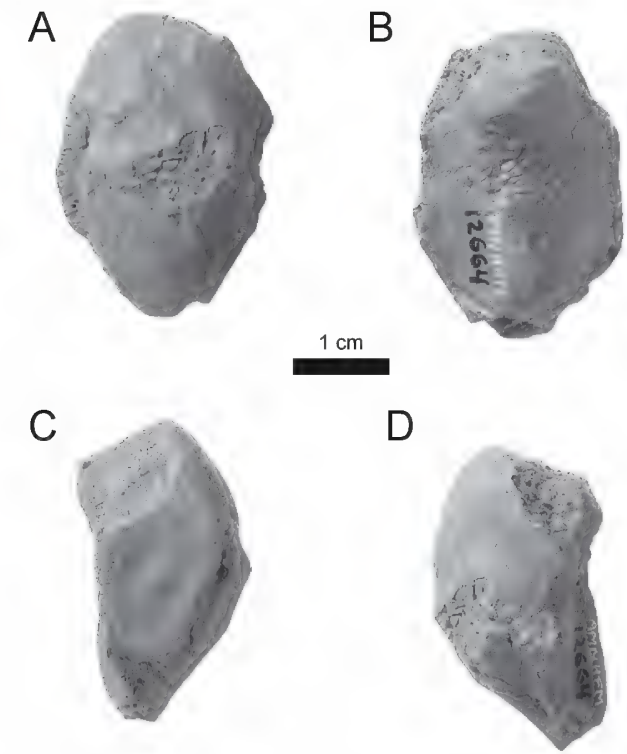

FIG. 25. Left patella of Hyrachyus modestus (AMNH FM 12664). A, anterior; B, posterior; C, medial; and $\mathbf{D}$, lateral views.
27A). The intercondyloid eminences are about equal in height with a wide and shallow central intercondyloid area between them for the cranial cruciate ligament (fig. 26B). The tibial tuberosity is large and projects anteriorly, and it is excavated by a wide and deep groove (sulcus tuberosititas tibiae) (figs. 26A, 27A). On the lateral side of the tibial tuberosity there is a prominent extensor sulcus (figs. 26D, 27A). The tibial crest (= cranial border) occupies the proximal third of the anterior surface of the shaft (fig. 26A).

The shaft is slightly S-shaped in anterior view. The proximal end of the shaft is deeply concave on the lateral and posterior sides, having a triangular cross section. The lateral side curves anteriorly from the middle of the shaft (fig. 26A, D). On the posteroproximal corner of the lateral surface there is a rough, concave, distally facing facet for articulation with the fibula (fig. 26D). The posterior side of the shaft bears a distinct, oblique, and rough popliteal line below the proximal concavity (fig. 26B). The posterior side gradually curves medially distal to the midshaft and is separated from the medial side by a prominent ridge on the proximal three-fourths of the shaft (fig. 26B, C). Because the lateral surface curves anteriorly and the posterior surface curves medially at the distal end, a surface between the posterior and lateral surfaces expands from the proximal third to the posterior and lateral sides on the distal end (fig. 26B, D).

On the distal end, the ridge and grooves that designate the two trochlear facets are directed obliquely anterolaterally (fig. 27B). The ridge is blunt and anteroposteriorly concave, and the medial groove is slightly narrower than the lateral one. The posteromedial process is more distally extended than the medial malleolus (figs. 26C, 27B). The medial malleolus is prominent with an indistinct malleolus sulcus posteriorly for the long digital flexor.

COMPARISON OF THE TIBIA: According to the description by Cope (1884) with reference to AMNH FM 12364, the tibia of Hyrachyus exi- 


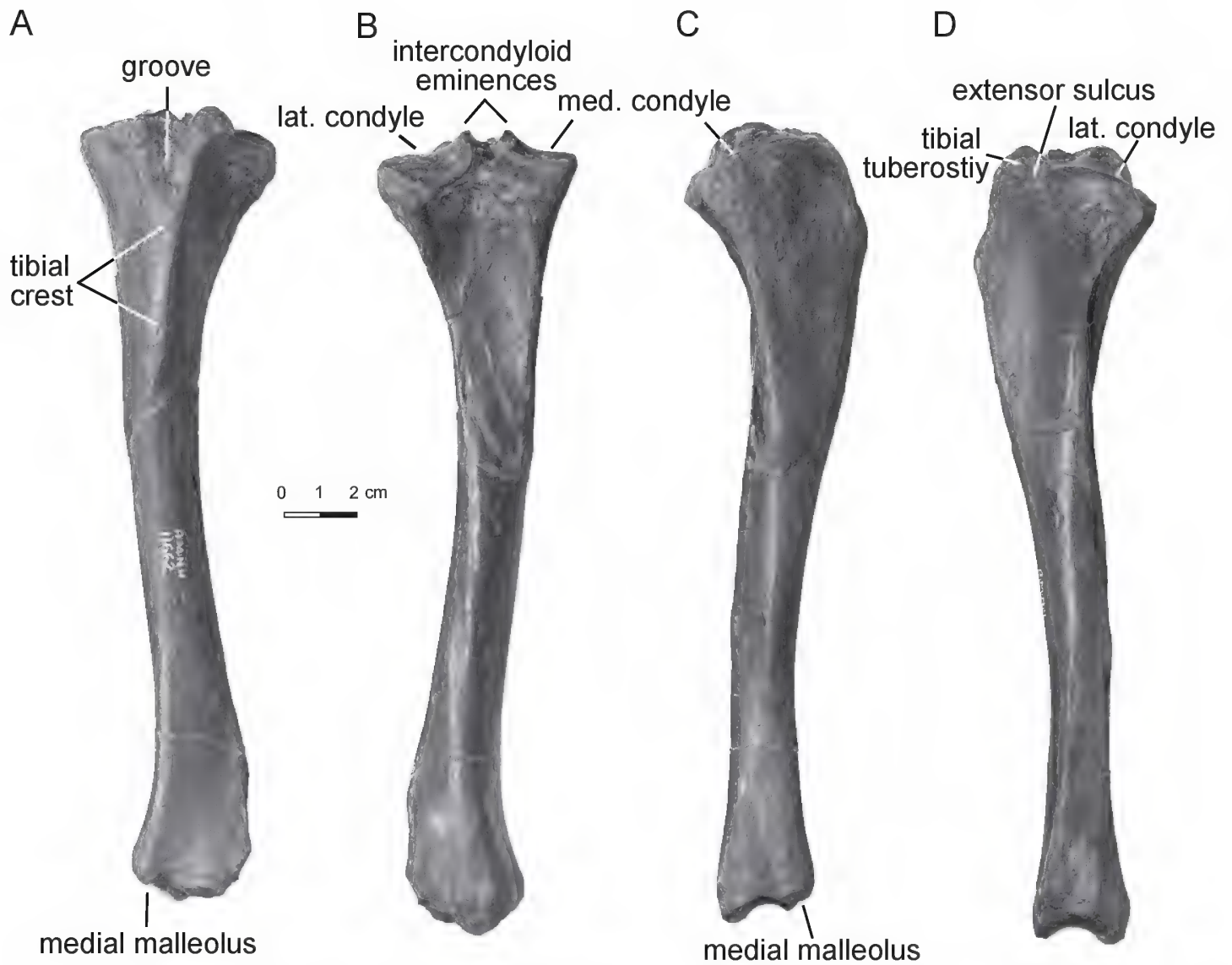

FIG. 26. Left tibia of Hyrachyus modestus (AMNH FM 11662). A, anterior; B, posterior; C, medial; and D, lateral views.

mius is different from that of $H$. modestus in having a narrower and deeper central intercondyloid area, a more swollen tibial tuberosity excavated by a narrow groove, a posterior side curving medially on the distal fourths part, a distal end more square and a deeper malleolus sulcus. It should be noted that the mounted skeleton of $H$. eximius (AMNH FM 5065) has mistakenly switched the left and right distal ends of the tibia as figured by Cope (1884: pl. 55, fig. 6).

The tibia of Heptodon differs mainly from that of Hyrachyus modestus by the presence of a narrower and deeper central intercondyloid area, and a much less developed tibial tuberosity with a shallower and shorter groove. They are similar in having intercondyloid eminences equal in height, a deep extensor sulcus, ridge and grooves on the distal end directed toward the anterolateral side, and a medial groove narrower than the lateral one on the distal end; all these characters are also present in the tibia of Uintaceras. The tibia of Uintaceras is further similar to that of Hyrachyus modestus in having a relatively large tibial tuberosity, but different from the latter in being much stouter and in possession of a shaft bowed laterally and a larger medial malleolus.

The tibia of Juxia mainly differs from that of Hyrachyus modestus in having a proximal end longer than wide, a lateral condyle narrower and more posteriorly extended than the medial 
TABLE 14

Measurements of tibiae of Hyrachyus modestus (mm) $\mathrm{APD}=$ anteroposterior distance.

\begin{tabular}{lrr}
\hline \hline & AMNH FM 12664 & AMNH FM 11662 \\
\hline 1. Total length & 192.0 & 219.8 \\
2. Proximal end, width & 52.2 & 54.31 \\
3. Proximal end, APD & 48.5 & 48.54 \\
4. Distal end, width & 29.0 & 31.96 \\
5. Distal end, APD & 26.3 & 26.44 \\
6. Width at middle of shaft & 20.4 & 18.72 \\
7. Medial condyle, width $\times$ APD & $12.06 \times 23.29$ & $12.51 \times 22.39$ \\
8. Lateral condyle, width $\times$ APD & $14.31 \times 20.14$ & $15.52 \times 18.28$ \\
9. Trochlea, width & 25.4 & 25.22 \\
10. Trochlea, APD & 20.3 & 22.85 \\
Ratio (\%) & & \\
2:1 & 27.2 & 24.7 \\
4:1 & 15.1 & 14.5 \\
10:9 & 80.0 & 90.6 \\
\hline
\end{tabular}

one, a lateral intercondyloid eminence higher than the medial one, a narrower central intercondyloid area, a relatively narrower and deeper groove excavated the tibial tuberosity, and ridge and grooves on the distal end less obliquely directed. They are similar in having a large tibial tuberosity and a S-shaped shaft in anterior view.

Fibula

There is no complete fibula of Hyrachyus modestus available for study. AMNH FM 11662 (fig. 28) and 11664 preserve only proximal and distal ends. The proximal end is expanded, transversely compressed, and platelike with a process on the posterior side (fig. 28A). The lateral side of the proximal end is a low trapezoid in outline and rough, bearing a shallow longitudinal groove posteriorly. The medial side of the proximal end is uneven and rugose, bearing a striplike and mediodistally inclined facet for the tibia along the proximal border. The distal end is transversely expanded and bears a large lateral malleolus on the lateral side with a narrow, deep groove posteriorly (fig. 28B). On the medial side of the distal end there is a slightly concave and distomedially facing surface for the astragalus with a rectangular (AMNH FM 11662 ) or semilunate (AMNH FM 11664) outline (fig. 28C). Along its anteroproximal border is a striplike facet for the tibia. On the posterior extremity of the distal end is a small and indistinct facet for the calcaneus.

COMPARISON OF THE FIBUla: The fibula of Hyrachyus eximius (AMNH FM 12364, 12675) is nearly identical to that of $H$. modestus. However, the tibia of AMNH FM 12364 lacks a posterior process of the proximal end, and has a more prominent, tongue-shaped tibia facet on the distal end. On the other hand, AMNH FM 5065 has a prominent posterior process on the proximal end.

The fibula of Heptodon posticus is different from that of Hyrachyus modestus in having a proximal tibial facet horizontally oriented, the epiphyses less expanded, and a proximal end partially exposed lateral to the tibia.

The fibulae of Juxia and Uintaceras are similar to that of Hyrachyus modestus in having an expanded proximal end entirely covered by the lateral condyle of the tibia, but the fibula of 
Juxia has a laterally compressed distal end as pointed out by Qiu and Wang (2007).

\section{Tarsals}

The pes of AMNH FM 12664 is not preserved, except for a right navicular and an astragalus. The following description was based on AMNH FM 1643c (astragalus, calcaneus, mesocuneiform), AMNH FM 12664 (navicular), AMNH FM 11662 (cuboid, ectocuneiform), and AMNH FM 1612 (entocuneiform).

Astragalus (fig. 29A-E; table 15): The height of the trochlea is greater than its width (fig. 29A). A relatively wide, deep groove divides the trochlea into two asymmetrical parts: a narrow, steep medial portion and a wide, gradual lateral portion. The lateral surface of the trochlea for the fibula is vertical with a weak, laterally projected process on the distal end (fig. 29A, C). The distal edge of the medial ridge of the trochlea almost contacts the navicular facet, whereas that of AMNH FM 12664 appears to be separate from the navicular facet. The neck is moderately long and as wide as the trochlea. The angle of obliquity of the trochlea is about $125^{\circ}$, and the torsion angle of the astragalus is about $26^{\circ}$.

On the posterior side, the ectal facet is wider than long and deeply concave with a convex lappet on the laterodistal corner (fig. 29B). The sustentacular facet is a proximodistally elongate oval in outline with a slightly convex surface and a long axis roughly parallel to that of neck (fig. 29B). The sustentacular facet is separated from the ectal facet by a narrow, deep astragalar sulcus, but does contact the distal calcaneal facet (fig. 29B, C). The distal calcaneal facet is generally striplike and composed of two anteroposterior facets bordered by a faint ridge. On the proximomedial corner of the posterior surface there is a prominent tubercle (fig. 29D).

On the distal end, the navicular facet is quadrilateral in outline, as long as wide, and saddle shaped with a small convexity near the posterior end (fig. 29E). Posterolateral to the navicular facet there is a cuboid facet, which is bordered laterally by the distal calcaneal facet
A

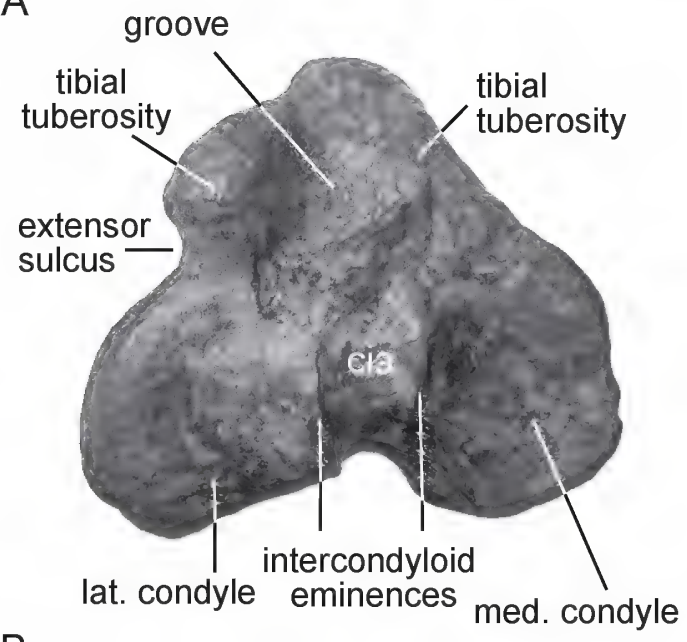

B

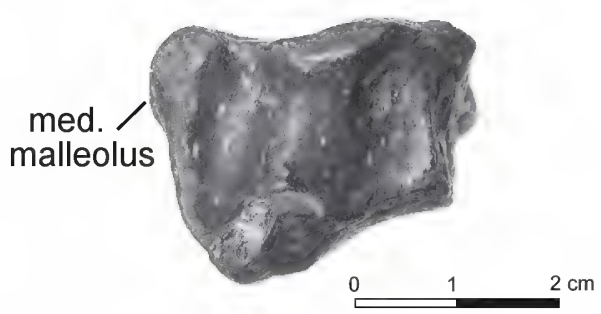

FIG. 27. Left tibia of Hyrachyus modestus (AMNH FM 11662). A, proximal; and B, distal views. Abbreviation: cia, central intercondyloid area.
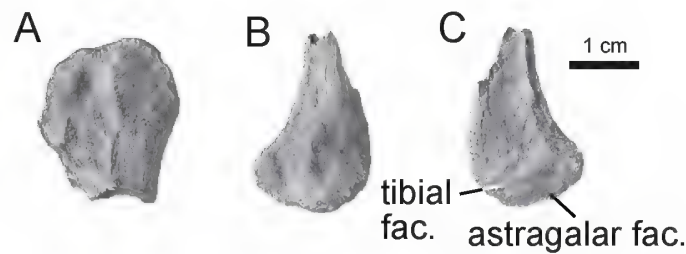

FIG. 28. Right fibula of Hyrachyus modestus (AMNH FM 11662). A, lateral view of proximal end; $B$, lateral view of distal end; $\mathbf{C}$, medial view of distal end. 
A

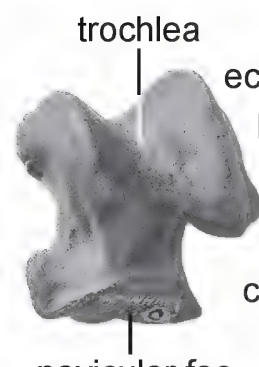

navicular fac.

$E$

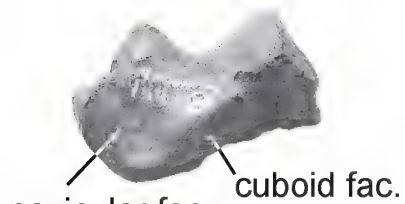

navicular fac.
B

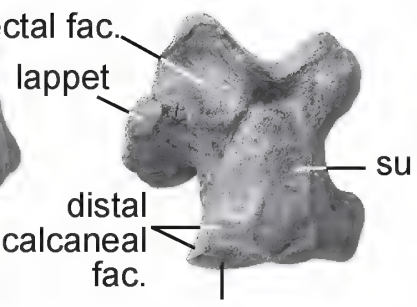

cuboid fac.

C

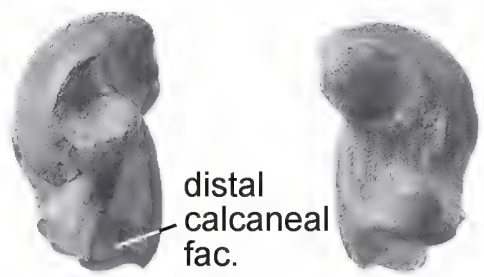

F ectal fac.

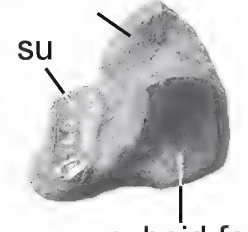

cuboid fac.

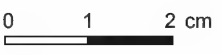

fac.
D

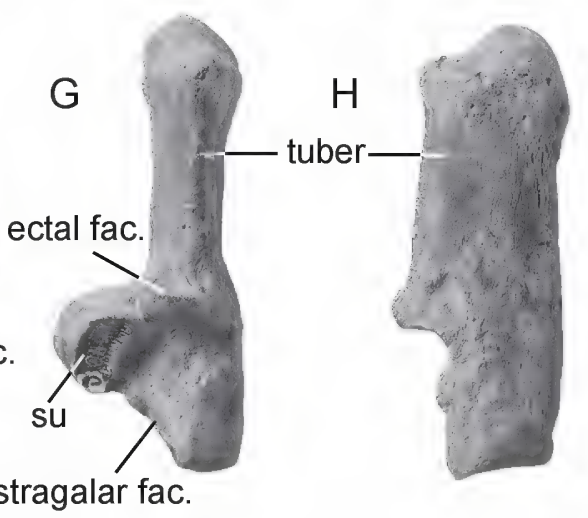

distal astragalar fac.

FIG. 29. Left astragalus and calcaneus of Hyrachyus modestus (AMNH FM 1643c). A-E, astragalus. A, anterior; B, posterior; C, lateral; D, medial; and E, distal views. F-H, calcaneus. F, distal; G, anterior; and H, lateral views. Abbreviation: su, sustentaculum.

and is narrowly fusiform and concave near the posterior end (as shown on the specimen of AMNH FM 12664) (fig. 29B, E).

On the medial side of the astragalus, a prominent tubercle is present medial to the navicular facet, and a shallow cavity is present between the tubercle and the trochlea (fig. 29A, D). A smaller tubercle is present at the posteroproximal corner as mentioned above. On the lateral side, a deep fossa is bordered anteriorly by the lateral surface of the trochlea (fig. 29C).

Calcaneus (fig. 29F-H; table 16): The calcaneus is relatively long and thin. The calcaneal tuber is laterally compressed with an oval, rugose free end (fig. 29G, H). The ectal facet is placed at a point $42 \%$ distal of the length of the calcaneus. It consists of two portions: the distal part is concave and distally facing with a narrow distal extension on the lateral side for the articulation with the lappet of the astragalus; the proximal part is convex, faces anteromedi- ally, and extends slightly onto the tuber (fig. 29F, G). A pit for the fibula at the proximolateral part of the ectal facet is barely discernable. On the lateral side of the ectal facet there is also a rather shallow depression (fig. 29H). The sustentaculum bears a concave, elongate facet for the astragalus with its long axis slightly medially oblique (fig. 29F, G). In medial view, the sustentaculum is thick proximally and narrows distally. The distal astragalar facet is striplike and composed of two portions, a flat anterior one and a slightly convex posterior one. On the distal end, the cuboid facet is roughly quadrilateral in outline, concave transversely, and slightly convex anteroposteriorly with a deep pit at the posteromedial end, although the latter is exaggerated by breakage (fig. 29F).

Navicular (fig. 30A-D; table 17): The navicular is wider than long. The proximal astragalar facet is roughly quadrilateral in outline with a triangular apex at the antero- 
TABLE 15

Measurements of astragali of Hyrachyus modestus and Hyrachyus eximius (mm)

\begin{tabular}{|c|c|c|}
\hline & $\begin{array}{l}\text { Hyrachyus modestus } \\
\text { (AMNH FM 1643C) }\end{array}$ & $\begin{array}{l}\text { Hyrachyus eximius } \\
\text { (AMNH FM 12674) }\end{array}$ \\
\hline 1. Maxium height & 31.3 & 44.5 \\
\hline 2. Maxium width & 28.3 & $39.4^{\mathrm{a}}$ \\
\hline 3. Trochlea, medial length & 24.6 & 32.7 \\
\hline 4. Trochlea, lateral length & 23.2 & 31.7 \\
\hline 5. Trochlea, maximum width & 15.9 & 23.5 \\
\hline 6. Distal end, width & 21.4 & 26.2 \\
\hline 7. Navicular facet, width $\times$ length & $18.5 \times 14.9$ & $22.5 \times 22.5$ \\
\hline 8. Cuboid facet, width $\times$ length & $5.4 \times 13.2$ & $4.1 \times 17.4$ \\
\hline 9. Ectal facet, height $\times$ width & $11.5 \times 12.4$ & $15.9 \times 15.0$ \\
\hline 10. Sustentacular facet, height $\times$ width & $17.0 \times 8.00$ & $24.5 \times 10.3$ \\
\hline 11. Inclination angle, $a$ & $120^{\circ}$ & ? \\
\hline 12. Torsion angle, $\beta$ & $24^{\circ}$ & ? \\
\hline \multicolumn{3}{|l|}{ Ratio (\%) } \\
\hline $2: 1$ & 90.6 & 88.5 \\
\hline $6: 2$ & 75.6 & 66.5 \\
\hline $3: 4$ & 106.0 & 103.0 \\
\hline
\end{tabular}

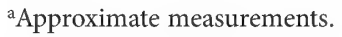

lateral side, strongly concave anteroposteriorly with a posteromedial corner arising upward, and nearly flat transversely (fig. 30A, D). On the anterolateral corner of AMNH FM 1612 there is a small, distally inclined facet that appears to be for the calcaneus, but similar facets on other taxa and other specimens of Hyrachyus turn out to be for the cuboid or they articulate with nothing (Holbrook, 2001). On the lateral side, the cuboid facet is composed of two flat portions: the posterior one is large and slightly medially inclined, whereas the proximal one is striplike and extends along the proximal border (fig. 30B). Distally, three facets are present, from lateral to medial, for the articulation with the ecto-, meso-, and entocuneiform (fig. 30C). The ectocuneiform facet is triangular in outline, generally flat, and tapering posteriorly. The mesocuneiform facet is approximately oval, whereas the entocunei- form facet is the smallest one, facing posterodistally. The anterior and medial surfaces of the navicular are rugose (fig. 30D).

Cuboid (fig. 30E-H; table 17): In anterior view, the cuboid is higher than wide (fig. $30 \mathrm{H}$ ). On the proximal surface, the calcaneus and astragalus facets are confluent as a rounded facet without a clear boundary (fig. 30E). The proximal surface is saddle shaped, concave anteroposteriorly, and convex mediolaterally with a prominent swelling on the posterior part. On the proximal half of the medial surface of the cuboid there are two facets for the navicular (fig. 30F): the posterior one is roughly bandlike and slightly concave, whereas the proximal one is striplike and extends along the proximal edge. On the distal half of the medial surface there are two small facets for the ectocuneiform: the posteroproximal one is in contact with the posterior navicular facet and is distomedially inclined, whereas the anterodistal one is nearly 
A

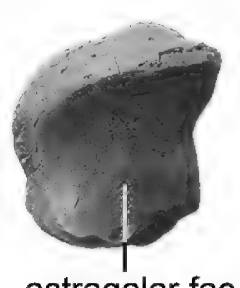

astragalar fac.

E

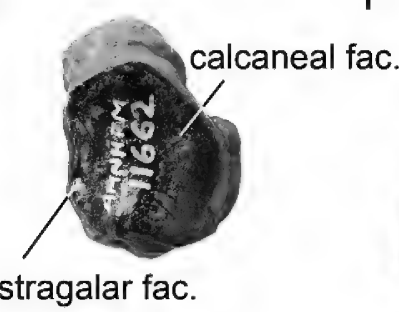

B

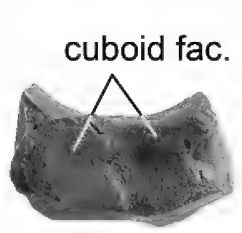

C
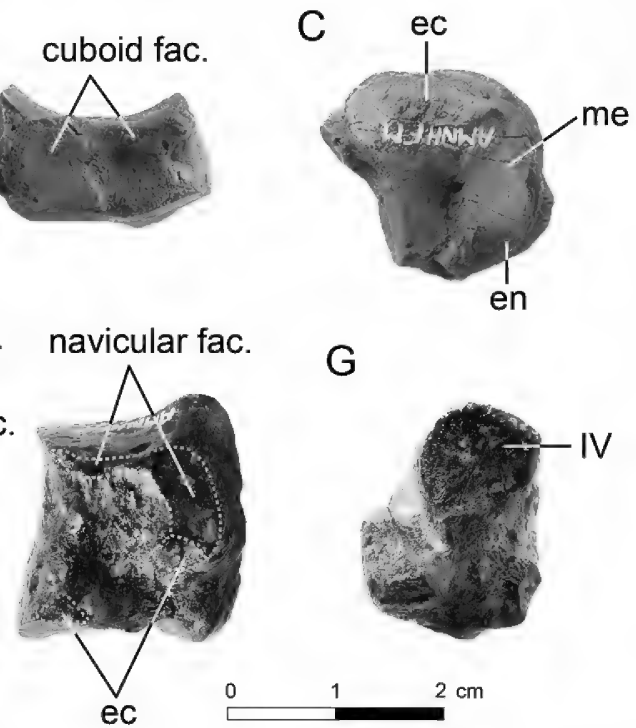

G

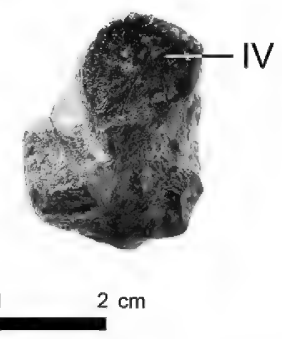

D astragalar fac.

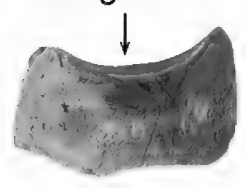

$\mathrm{H}$

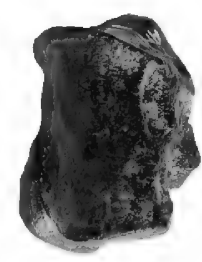

$\mathrm{N}$

$\mathrm{O}$

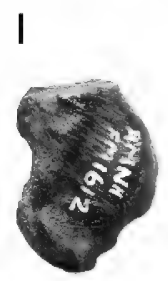

$J$

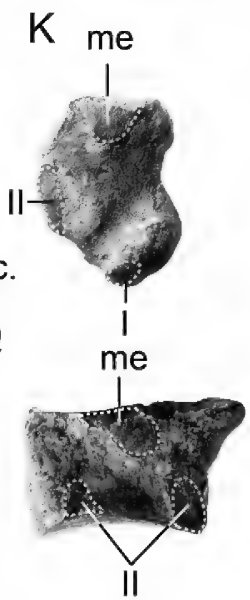

$\mathrm{L}$

navicular fac.
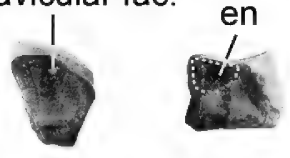

$\mathrm{R}$

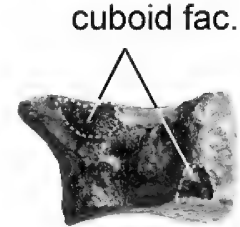

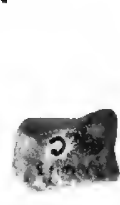

S

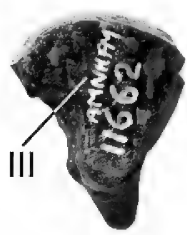

FIG. 30. Partial tarsals of Hyrachyus modestus. A-D, right navicular (AMNH FM 12664); A, proximal; B, lateral; C, distal; and D, medial views. E-H, right cuboid (AMNH FM 11662); E, proximal; F, medial; G, distal; and $\mathbf{H}$, anterior views. I-K, left entocuneiform (AMNH FM 1612). I, posterior; J, proximal; and $\mathbf{K}$, anterior views. L-O, left mesocuneiform (AMNH FM 1643c). L, proximal; M, medial; N, lateral; and $\mathbf{O}$, distal views. P-S, right ectocuneiform (AMNH FM 11662). P, proximal; Q, medial; R, lateral; and S, distal views. Abbreviations: ec, ectocuneiform; en, entocuneiform; me, mesocuneiform; I, II, III, and IV, first, second, third, and fourth metatarsals.

vertical and in contact with the distal Mt IV facet. The distal Mt IV facet is roughly rounded and flat (fig. 30G). A posterior process is situated on the posterolateral side.

Entocuneiform (fig. 30I-K; table 18): The entocuneiform is irregularly quadrilateral in outline in posterior view and anteroposteriorly compressed, having a convex medial border and a concave lateral border (fig. 30I). The proximal end bears an oval, slightly concave facet for the navicular (fig. 30J). On the anterior side of the navicular facet and perpendicular to it there is a flat, semilunate facet for the mesocuneiform (fig. 30K). An oval, slightly 
TABLE 16

Measurements of calcanei of Hyrachyus modestus and Hyrachyus eximius (mm) $\mathrm{DE}=$ distal end; $\mathrm{PE}=$ proximal end $\mathrm{APD}=$ anteroposterior distance.

\begin{tabular}{lrr}
\hline \hline & $\begin{array}{r}\text { Hyrachyus modestus } \\
\text { (AMNH FM 1643C) }\end{array}$ & $\begin{array}{r}\text { Hyrachyus eximius } \\
\text { (AMNH FM 12674) }\end{array}$ \\
\hline 1. Total length & 60.9 & 87.0 \\
2. PE-middle of ectal facet & 39.3 & 59.0 \\
3. DE-middle of ectal facet & 23.2 & 30.3 \\
4. Maximum, width & 24.4 & 33.3 \\
5. Width, tuber & 13.7 & 20.1 \\
6. APD, tuber & 20.1 & 26.0 \\
Ratio (\%) & & \\
4:1 & 40.1 & 38.3 \\
3:2 & 59.0 & 51.4 \\
5:6 & 67.9 & 77.4 \\
\hline
\end{tabular}

convex facet for Mt II occurs along the middle one-third of the medial border of the anterior surface. The distal end is expanded and thickened, bearing a small, oval facet for Mt I at the anteromedial corner (fig. 30K).

Mesocuneiform (fig. 30L-O; table 19): The mesocuneiform is slightly wider than high in anterior view. The proximal facet for the navicular is triangular, anteroposteriorly concave, and mediolaterally flat (fig. 30L). On the proximal half of the medial side there is a semilunate entocuneiform facet (fig. 30M). On the lateral side the ectocuneiform facet is not clear due to weathering; however, the facet appears flat and not in contact with the distal Mt II facet (fig. $30 \mathrm{~N}$ ). The distal surface for the Mt II is triangular in outline, anteroposteriorly flat, and slightly convex laterally (fig. 30O).

ECTOCUNEIForm (fig. 30P-S; table 19): The ectocuneiform is wider than high in anterior view and proximodistally compressed. The proximal surface for the navicular is roughly triangular in outline with a convex anterior border (fig. 30P). The lateral border is notched in the middle, and the surface is uneven with a depression around the lateral notch. A small process extends posteriorly from the posterior end of the proximal surface. On the medial side
TABLE 17

Measurements of navicular and cuboid of Hyrachyus modestus ( $\mathrm{mm}$ )

Measurements correspond to those of Qiu and Wang (2007: table 30, 43).

\begin{tabular}{crr}
\hline \hline & $\begin{array}{r}\text { Navicular } \\
\text { (AMNH } \\
\text { FM 12664) }\end{array}$ & $\begin{array}{r}\text { Cuboid } \\
\text { (AMNH } \\
\text { FM 11662) }\end{array}$ \\
\hline 1. & 9.76 & 20.8 \\
2. & 20.23 & 12.9 \\
3. & 20.12 & 21.7 \\
4. & $14.15 \times 17.37$ & $13.6^{\mathrm{a}}$ \\
5. & $7.14 \times 12.11$ & 17.6 \\
6. & $4.45 \times 6.72$ & $3.3^{\mathrm{a}}$ \\
7. & - & 10.8 \\
8. & - & 12.0 \\
Ratio (\%) & & \\
1. & 48.25 & 161.9 \\
2. & 100.55 & 96.1 \\
3. & 9.76 & 59.3 \\
4. & - & 90.0 \\
5. & - & 24.2 \\
\hline
\end{tabular}

${ }^{\mathrm{a} A p p r o x i m a t e ~ m e a s u r e m e n t s . ~}$ 
TABLE 18

Measurements of entocuneiform of Hyrachyus modestus ( $\mathrm{mm})$

\begin{tabular}{lr}
\hline \hline & $\begin{array}{r}\text { Entocuneiform } \\
\text { (AMNH FM 1612) }\end{array}$ \\
\hline 1. Length & 17.9 \\
2. Width & 13.2 \\
3. Anteroposterior distance & 6.0 \\
Ratio (\%) & \\
2:1 & 73.8 \\
$3: 2$ & 45.3 \\
\hline
\end{tabular}

there is a flat, oval mesocuneiform facet running along the anterior half of the proximal border (fig. 30Q). Two Mt II facets are anteriorly and posteriorly placed on the distal half of the medial side with the posterior of the two larger than the anterior one. On the lateral side there are two small facets for the cuboid: the posteroproximal one is flat, slightly proximally oriented, and in contact with the navicular facet; the anterodistal one is flat and nearly vertical, adjoining the distal Mt III facet (fig. 30R). The distal surface for Mt III is roughly triangular in outline with a convex anterior border and a notched lateral border. The surface is anteroposteriorly concave and laterally flat (fig. 30S).

\section{Metatarsals}

The following description of metatarsals of Hyrachyus modestus was based on AMNH FM 1612 (table 20). H. modestus has four metatarsals (Mt I-IV) with functional Mt II-IV and a nodulelike Mt I.

Mт I (fig. 31): The Mt I is highly reduced and nodulelike. In posterior view, the outline of $\mathrm{Mt}$ I is irregularly quadrilateral with a wide, shallow longitudinal groove in the middle (fig. 31A). A projection is present on its anterior side, bearing two concave facets, for the entocuneiform and posterior process of the Mt III on the medial and lateral sides, respectively (fig. 31B). The entocuneiform facet faces anteromedially without a clear boundary. The Mt III facet
TABLE 19

Measurements of meso- and ectocuneiform of Hyrachyus modestus ( $\mathrm{mm}$ )

\begin{tabular}{lrr}
\hline \hline & $\begin{array}{r}\text { Mesocuneiform } \\
\text { (AMNH } \\
\text { FM 1643C) }\end{array}$ & $\begin{array}{r}\text { Ectocuneiform } \\
\text { (AMNH } \\
\text { FM 11662) }\end{array}$ \\
\hline 1. Length & 10.2 & 20.6 \\
2. Width & 7.2 & 16.0 \\
3. Height & 7.5 & 11.5 \\
Ratio (\%) & & \\
2:1 & 70.0 & 77.7 \\
$3: 2$ & 104.3 & 71.9 \\
\hline
\end{tabular}

is oval and somewhat proximally oriented with a distinct discrimination.

Mт II (figs. 32A, B, 33): The Mt II is slightly shorter than the Mt III, and the shaft diverges somewhat medially. Proximally, the mesocuneiform facet is roughly triangular in outline with a concave lateral border, and is concave transversely and flat anteroposteriorly (fig. $33 \mathrm{~A})$. On the medial side of the proximal end, just below the mesocuneiform facet, there is an elongate, oval, and slightly concave facet for the entocuneiform (fig. $32 \mathrm{~A}$ ). On the lateral side of the proximal end, there are two composite facets: the upper pair for the ectocuneiform is large and vertical, whereas the lower pair for the Mt III is smaller and nearly confluent with the upper one, with the anterior Mt III facet more distinct and larger than the posterior Mt III facet (fig. 32B). The shaft becomes slightly more robust toward its distal end, and the rough area for the interosseous ligaments extends along the proximal thirds of the lateral side. The distal end is asymmetrical and similar to that of Mc II (fig. 33B).

MT III (figs. 32C, D, 33): The Mt III is the longest and the most robust of the metatarsals. The proximal articular surface for the ectocuneiform is roughly triangular with a concave lateral border and is slightly concave transversely, rising toward the lateral side (fig. 33A). The medial side of the proximal end of Mt III in AMNH FM 1612 is partially broken off, but AMNH FM 
TABLE 20

\begin{tabular}{lccc} 
Measurements of metatarsals (Mt) of Hyrachys modestus & (AMNH FM 1612) (mm) \\
\hline \hline & Mt II & Mt III & Mt IV \\
\hline 1. Total length & 105.7 & 112.2 & 104.9 \\
2. Proximal end, maximum width & 14.0 & 20.6 & 17.3 \\
3. Proximal end, anteroposterior distance & 18.9 & $20.0^{\mathrm{a}}$ & 17.3 \\
4. Distal end, width & 19.3 & 26.1 & 16.0 \\
5. Distal articular facet, width & 16.4 & 20.7 & 15.4 \\
6. Distal end, anteroposterior distance & 18.5 & 16.6 & 18.7 \\
7. Width at midshaft & 11.5 & 17.5 & 9.6 \\
8. Anteroposterior distance at midshaft & 14.2 & 9.2 & 13.6 \\
Ratio (\%) & & & \\
2:1 & 13.2 & 18.3 & 16.5 \\
4:1 & 18.3 & 23.3 & 15.2 \\
2:3 & 74.1 & 102.9 & 100.1 \\
5:6 & 88.6 & 124.6 & 82.5 \\
\hline
\end{tabular}

${ }^{a}$ Approximate measurements.

11662 exhibits two small facets for Mt II with the anterior one larger and more distinct than the posterior one (fig. 32C). On the lateral side of the proximal end there are two oval facets for the Mt IV (fig. 32D): the anterior one is slightly concave and posterolaterally facing; the posterior one is flat and laterally facing. On the medial side of the posterior Mt IV facet there is a distinct, flat, and oval facet for the Mt I on the posterior process of the proximal end (figs. $32 \mathrm{C}$, $33 \mathrm{~A})$. The cross section of the shaft is roughly trapezoidal in outline proximally, and becomes anteroposteriorly compressed toward the distal end. The shaft gradually becomes wider in anterior view toward the distal end. The distal end is symmetrical as in the Mc III (fig. 33B).

Mт IV (figs. 32E, F, 33): The Mt IV is slightly shorter and more slender than the Mt II. The proximal end bears a flat, roughly rounded cuboid facet, which is inclined slightly anteriorly and laterally (figs. 32F, 33A). The posterior portion of the proximal surface is occupied by a rough area. On the medial side of the proximal end there are two facets for Mt III (fig. $32 \mathrm{E}$ ). The anterior Mt III facet is rectangular in outline, is slightly concave, and faces anterome-

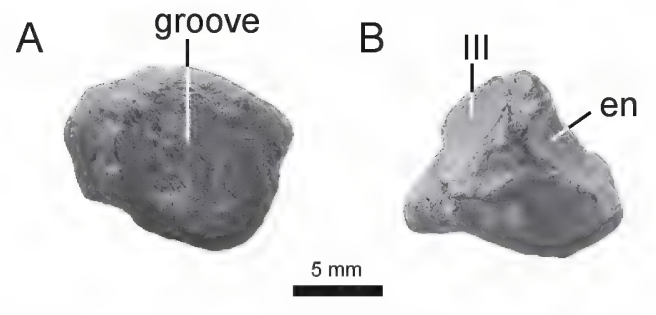

FIG. 31. Left first metatarsal (AMNH FM 1612). A, posterior; and B, proximal views. Abbreviations: en, entocuneiform; III, third metatarsal.

dially, separated from the cuboid facet by a sharp ridge. The posterior Mt III facet is slightly concave, roughly rounded, and faces nearly medially, separated from the cuboid facet by a rough area. The cross section of the shaft is somewhat compressed proximally and becomes rounded distally. The distal end is asymmetric and mirrors that of Mt II (fig. 33B).

A reconstruction of the pes is shown in figure 34.

Comparison of the pes: Cope (1884) described the morphology of the pes of Hyrachyus eximius on the basis of AMNH FM 5065, and we also examined AMNH FM 12665 

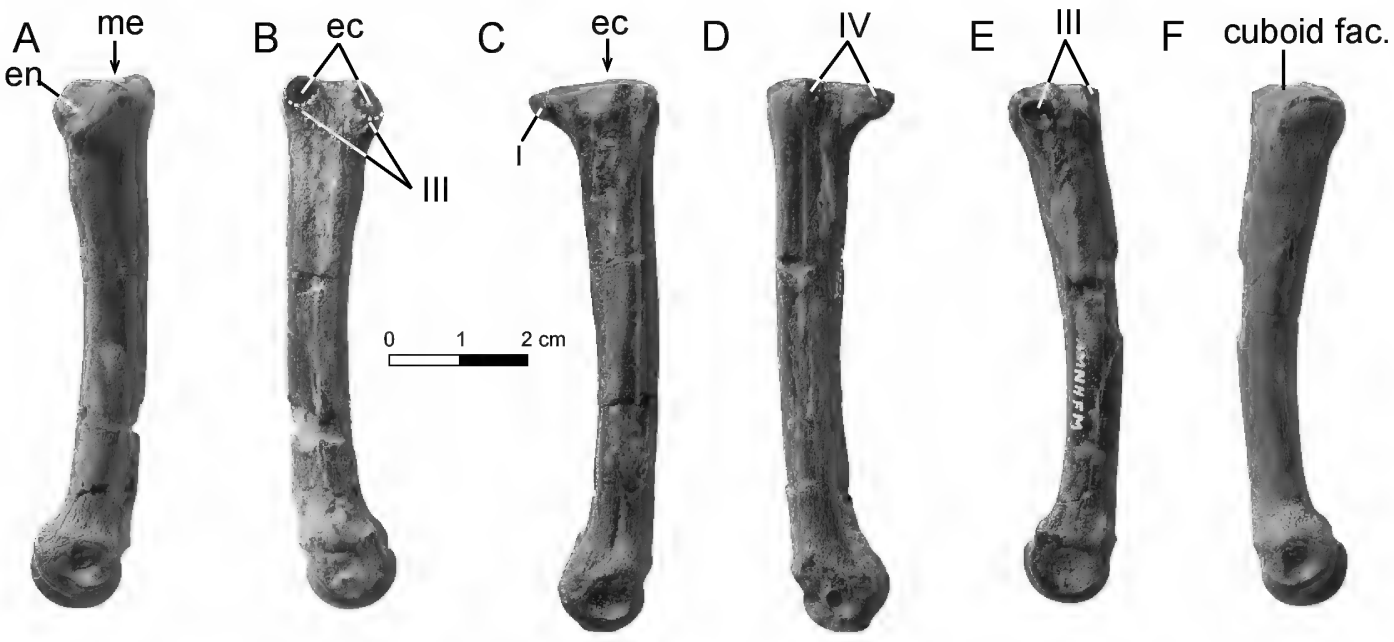

FIG. 32. Left metatarsals of Hyrachyus modestus (AMNH FM 1612). A-B, second metatarsal. A, medial; and B, lateral views. C-D, third metatarsal; C, medial; and D, lateral views. E-F, fourth metatarsal. E, medial; and F, lateral views. Abbreviations: ec, ectocuneiform; en, entocuneiform; me, mesocuneiform; I, III, and IV, first, third, and fourth metatarsals.

and 12674 . The pes of $H$. eximius is very similar to that of $H$. modestus except for a proximal surface of the navicular with a small facet on the anterolateral corner not in contact with the calcaneus (Holbrook, 2001), and an ectocuneiform with a mesocuneiform facet not in contact with a proximal surface and with a flat Mt III facet. The entocuneiform of Hyrachyus eximius varies in that its mesocuneiform facet is striplike and anterior to the navicular facet in AMNH FM 12675, as in H. modestus, whereas the mesocuneiform facet of AMNH FM 12665 is larger than the navicular facet and more anteromedially placed than that of AMNH FM 12675, as in Heptodon posticus.

The pes of Heptodon posticus is different from that of Hyrachyus modestus in having an astragalus with a medial ridge of the trochlea not contacting the navicular facet as in $H$. eximius and a sustentacular facet separated from the distal calcaneal facet (but contacting in $H$. calciculus), a calcaneus contacting the navicular, an ectocuneiform contacting the Mt IV on the lateral side, an entocuneiform circular in posterior view with a mesocuneiform facet anteromedially placed to the navicular facet.
The pes of Triplopus obliquidens (YPM VPPU 10397) differs from that of Hyrachyus modestus by the presence of sharper trochlear ridges, a lateral surface of the trochlea without a laterally projecting process on the distal end, a medial ridge of the trochlea not contacting the navicular facet, more laterally compressed Mt II and IV (as well as the distal ends of the cuboid and presumably the mesocuneiform), and in lacking a pit for the fibula proximal to the ectal facet of the calcaneus. They are similar in lacking calcaneo-navicular and Mt IV-ectocuneiform contacts, and a sustentacular facet confluent with the distal calcaneal facet of the astragalus as in Uintaceras. But in Triplopus the border between a sustentacular facet and a distal calcaneal facet of the astragalus was marked by a ridge. Osborn (1889: pl. 11, fig. 9) suggested the ectocuneiform of T. obliquidens articulates with Mt III only, but two separate Mt II facets are present on the distal part of the medial surface of the ectocuneiform.

The pes of Juxia is different from that of Hyrachyus modestus primarily in having a less oblique trochlea of the astragalus with blunter ridges, a medial ridge of the trochlea not con- 
tacting the navicular facet, a lateral surface of the trochlea without a laterally projected process on the distal end, a sustentacular facet separated from the distal calcaneal facet, Mt III contacting the cuboid by a small triangular facet, and Mt II and IV much more slender compared to Mt III and diverging laterally. Qiu and Wang (2007), based on the brief description and plates of Hyrachyus eximius by Cope (1884), suggested the entocuneiform and Mt I of $H$. eximius is rounded in posterior view and contacting the Mt III; however, the "entocuneiform+Mt I" of $H$. eximius as interpreted by Qiu and Wang (2007) was more likely a vestigial Mt I based on the materials of $H$. modestus. In fact, the entocuneiform of Juxia is very similar to that of $H$. modestus in being roughly quadrilateral in posterior view, and in having the mesocuneiform facet anterior to the navicular facet, and in having a distal process bearing a Mt I facet. They are further similar in having a pit for the fibula proximal to the ectal facet of the calcaneus.

The pes of Uintaceras differs from that of $H$. modestus in being relatively wider and lower, and in having a relatively wider, blunter trochlear with a lateral part much wider than the medial one, a medial ridge of the trochlear not contacting the navicular facet, a larger cuboid facet of the astragalus with a wide anterior end, a more prominent pit for the fibula proximal to the ectal facet of the calcaneus, a distinct peroneal tubercle, an oval-shaped entocuneiform in posterior view, and relatively stouter metatarsals.

\section{DISCUSSION}

\section{ORIGIN OF HYRACHYUS}

Hyrachyus has a long time range from late Wasatchian to Uintan in North America (Wood, 1934), and a wide distribution across North America, Asia, and Europe (Radinsky, 1967b; Huang and Wang, 2002). Historically, Hyrachyus was considered very close to the ceratomorph
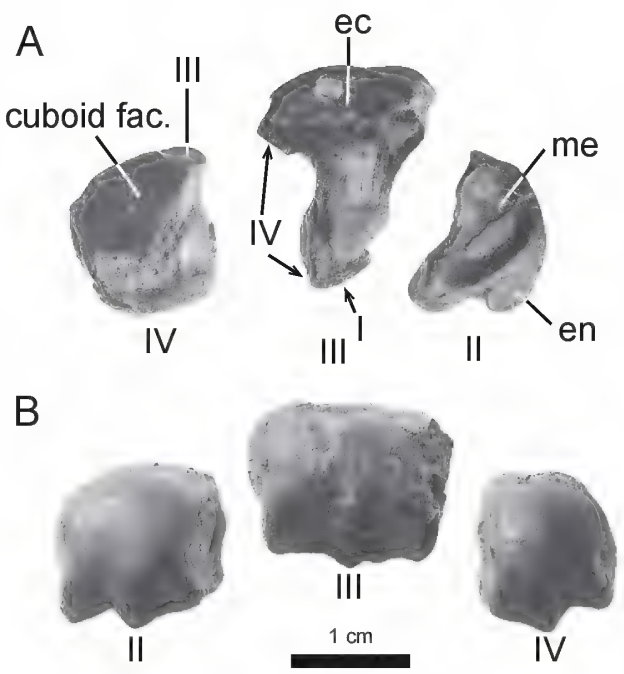

FIG. 33. Left second, third, and fourth metatarsals of Hyrachyus modestus (AMNH FM 1612). A, proximal; and B, distal views. Abbreviations: ec, ectocuneiform; en, entocuneiform; me, mesocuneiform; I, II, III, and IV, first, second, third, and fourth metatarsals.

helaletid Heptodon mainly on the basis of its large parastyles, unmodified molar metacones, and low paralophids and cristids obliquae (Radinsky, 1967b). Radinsky (1967b) assigned the subfamily Hyrachyinae in Helaletidae, which also includes Helaletinae and Chasmotheriinae, although he still maintained that Hyrachyus was the ancestor of Rhinocerotoidea (Radinsky, 1967b: 18-19). However, based on the skeletal comparisons between Hyrachyus modestus and Heptodon, with a reference to the skeleton of basal perissodactyl Hyracotherium grangeri (Wood et al., 2011), the skeleton of Hyrachyus modestus shows some characters even more primitive than that of Heptodon posticus, such as a shallow narial notch, naso-lacrimal contact, a relatively posteriorly placed sphenorbital fissure, a greater tubercle of the humerus just slightly higher than the level of the head, a scaphoid with a trapezium facet, a proximodistally elongated entocuneiform with a mesocuneiform facet placed anterior to the navicular facet, absence of contact between the calcaneus and navicular, and absence of contact 


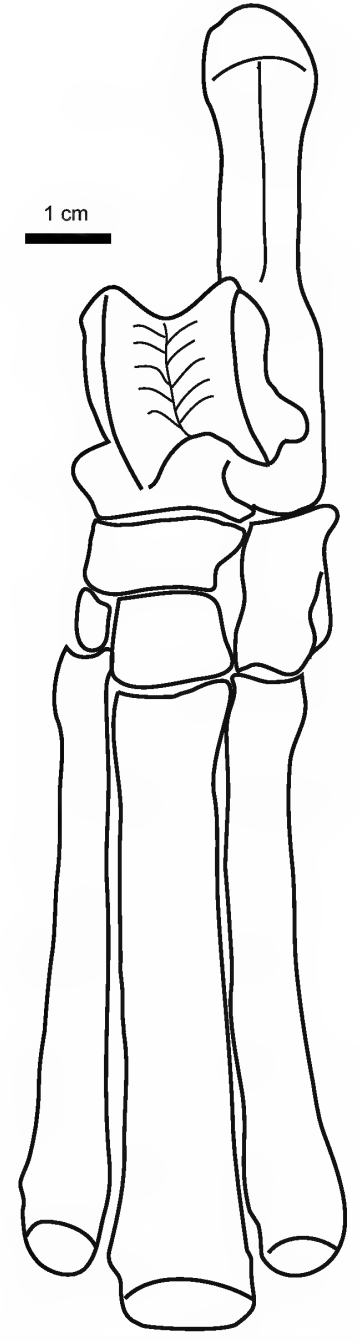

FIG. 34. Reconstruction of left pes of Hyrachyus modestus based on the specimens of AMNH FM $12664,1643 c, 1612$, and 11662 . The entocuneiform and $\mathrm{Mt} \mathrm{I}$ are not visible in this view. between the ectocuneiform and Mt IV. On the other hand, Heptodon does possess some more primitive characters than Hyrachyus modestus, such as a more proximally extended olecranon of the ulna, a shallow groove excavated the tibial tuberosity, a proximally oriented tibial facet of the proximal end of the fibula, and a sustentacular facet separated from the distal calcaneal facet of the astragalus. Furthermore, the dentitions of Hyrachyus differ from those of Heptodon in having more elongated M1-2 metacones, more distinct paralophids and cristids obliquae, and retention of $\mathrm{p} 1$, whereas Heptodon exhibits reduced M1-2 metacones, weak paralophids and cristids obliquae, and absence of $\mathrm{p} 1$. Thus, we propose that Hyrachyus was probably divergent from a more basal group of early ceratomorphs than Heptodon. This is consistent with the results of Holbrook (1999, 2001).

Emry (1989) suggested that the smallestknown ceratomorph Fouchia from the early Bridgerian of Nevada is closely related to Hyrachyus based on their similar degree of molarization of the premolars, presence of $\mathrm{p} 1$, unreduced paralophids and cristids obliquae, and $\mathrm{m} 3$ lacking a hypoconulid. He further suggested that Dilophodon is also similar to Fouchia and Hyrachyus, except for the lack of the p1. Fouchia could represent a group that is closer to the origin of Hyrachyus than is Heptodon, but Emry noted that many of the similarities among Hyrachyus, Fouchia, and Dilophodon are features that have evolved more than once in perissodactyls (if not ceratomorphs). The cladistic analysis of the ceratomorphs without Fouchia by Colbert (2005) placed Dilophodon within Tapiroidea and assigned Hyrachyus to Rhinocerotoidea, and also indicated that Hyrachyus diverged from a more basal ceratomorph group than Heptodon, consistent with this study.

\section{From HyRACHyUs to Other RHINOCEROTOIDEA}

The Hyrachyus complex, as Savage et al. (1966) referred to the many species of Hyrachyus recognized at that time, was long considered to 
be ancestral to all later rhinocerotoids, conventionally composed of Amynodontidae, Hyracodontidae, and Rhinocerotidae (Radinsky, 1966). Rhinocerotoidea has historically been united by elongation of the ectoloph, the absence of the m3 hypoconulid, and relatively large size (Wood, 1934; Radinsky, 1966; Savage et al., 1966; Qiu and Wang, 2007). Prothero et al. (1986) followed Radinsky's taxonomy but raised Hyrachyidae to familial rank and included it in Rhincerotoidea. Prothero et al. (1986) also ostensibly followed Radinsky (1967a) in including the giant rhinoceroses (paraceratheres or indricotheres) in Hyracodontidae, although Radinsky (1967a) clearly defined this family as a "wastebasket." Holbrook (1999) also included Hyrachyidae in Rhinocerotoidea and proposed Indricotheriidae as a family including paraceratheres that is distinct from Hyracodontidae. Qiu and Wang (2007) thoroughly reviewed the paraceratheres from China, and proposed that Rhinocerotoidea was composed of four families: Hyrachyidae, Eggysodontidae, Paraceratheriidae, and Rhinocerotidae. The family Hyrachyidae, comprising Hyrachyinae, Amynodontinae, and Hyracodontinae, was defined by a trapezoid M3 with a crestlike metacone. But Qiu and Wang (2007) still regarded Hyrachyus as a stem member of all the rhinocerotoids, making the Hyrachyinae a paraphyletic group according to their definition. Wang et al. (2016), by contrast, proposed Amynodontidae and Eggysodontidae as sister groups to Paraceratheriidae and Rhinocerotidae, respectively; Hyracodontidae was the basal clade of Rhinocerotoidea. Hyrachyus forms the sister group to other rhinocerotoids.

The statement that the Hyrachyus complex is ancestral to all later rhinocerotoids was also exemplified by transferring some species of Hyrachyus to variable groups of rhinocerotoids. Ephyrachyus implicatus, named by Wood (1934), was reassigned to hyracodont Triplopus implicatus by Radinsky (1967a); Hyrachyus grandis, named by Peterson (1919), was transferred to paraceratheriid Forstercooperia? by Radinsky (1967a), and later to rhi- nocerotid Uintaceras radinskyi by Holbrook and Lucas (1997).

Based on the skeletal comparison between Hyrachyus and earliest known hyracodontid Triplopus, we think Triplopus (and Hyracodontidae) could not derive from Hyrachyus but could from other, unknown forms. The skeleton of Triplopus shows the following particular features distinguishable from those of Hyrachyus: a large tympanic bulla, a posttympanic process separated from the paracondylar process by an open shallow groove, a prominent deltoid tuberosity, a ridge between scaphoid and lunar facets of the radius with a rectangular articular fovea on the proximal end, a relatively longer forearm, a shaft of the ulna much reduced distally, a magnum with a more convex anterior scaphoid facet and a more concave Mc III facet, an unciform with a long posterior process, a relatively flat patella, more laterally compressed Mt II and Mt IV, and in lacking a pit proximal to the ectal facet of the calcaneus. Triplopus is especially characterized by possessing a tridactyl manus with a nodulelike Mc V, whereas all other known early rhinocerotoids and Hyrachyus retain a tetradactyl manus. Radinsky (1967a: 10) also illustrated certain dental characters that distinguish Triplopus from Hyrachyus, and so it is not necessary to repeat here.

It is interesting to note that Colbert (2005, 2006) suggested a close relationship between Triplopus and the Asian lophialetids Schlosseria, Lophialetes, and Eoletes, which were historically included in Tapiroidea. In fact, Wood (1927: 16) noted some resemblances between Lophialetes and Triplopus cubitalis, but he attributed the similarities to parallelism. Resolution of the origin of Triplopus and Hyracodontidae requires further discoveries.

The skeleton of Hyrachyus is very similar to that of Uintaceras but less similar to that of Pappaceras and Juxia, as discussed above. The skeleton of Hyrachyus is similar to that of Juxia and Uintaceras, but different from that of Triplopus, in having a posttympanic process fused with the paracondylar process, an articular fovea of the radius constricted laterally with- 
out the lateral process, a tetradactyl manus, a distinct supracondyloid fossa of the femur, a relatively large tibial tuberosity with a deep groove, and a quadrilateral entocuneiform with the mesocuneiform facet anterior to the navicular facet.

The skeleton of Juxia shows some characters that reveal differences from that of Hyrachyus: elongated cervical vertebrae, large pre- and postzygapophyses, median grooves on the posterior surface of the spinous processes of the thoracic vertebrae, a relatively longer forearm compared with the humerus, a cuneiform contacting the radius by a small facet, and Mt III in contact with the cuboid. It should be noted that the skeleton of Pappaceras, possibly ancestral to Juxia and later paraceratheres, is known only from skulls and currently lacks postcrania (Wang et al., 2016), which would provide more important information on its phylogenetic relationship when compared with Hyrachyus and other rhinocerotoids. Amynodontidae, an early rhinocerotoid family with a square M3, probably also derived from a Hyrachyus-like ancestor. Based on known evidence, all non-hyracodontid rhinocerotoids probably derive from an ancestor similar to Hyrachyus, whereas hyracondontids represent a separate lineage and derive from a currently unknown group.

\section{FUNCTIONAL ANALYSIS}

\section{NECK}

The neck is approximately as long as the skull. From C3 to C7, the head and vertebral fossa are somewhat anteriorly inclined with the former slightly higher than the latter, which means the neck arises anteriorly as reconstructed by Cope (1884). Since the linea divisa condyli forms an angle of about $60^{\circ}$ with the long axis of the skull, it can be inferred that the angle between the long axis of the neck and skull was about $60^{\circ}$ in life (Qiu and Wang, 2007). The slightly convex head and concave vertebral fossa suggests limited motion between cervical vertebrae. The sharp ventral crests with prominent tubercles on the axis and C3-5 would have provided large attachment surfaces for the ventral flexor muscles, as in Hyracotherium grangeri (Wood et al., 2011).

\section{Dorsal Vertebrae}

The high spinous processes with expanded and rugose tips on T1-3 suggest well-developed supraspinous and nuchal ligaments for lifting the head and neck. The thin, narrow spinous processes and relatively weak mammillary processes on T1-3 suggest a weak thoracic spinalis and semispinalis muscles and relatively good flexibility in the anterior region of the thorax. Since the spinous processes of the posterior thoracic vertebrae are not preserved, it is unclear whether an anticlinal vertebra was present in Hyrachyus modestus. Considering that the lumbar vertebrae have concave-convex embracing pre- and postzygapophyses, it is reasonable to deduce that the posterior thoracic vertebrae of $H$. modestus have similar structures to those in H. eximius (AMNH FM 5065). These characters suggest that the posterior part of the thoracolumbar vertebral column in $H$. modestus was relatively rigid (Wood et al., 2011).

\section{SCAPUlar ANd Forelimb Function}

The rounded glenoid cavity of the scapula and the head of humerus suggest a wide range of motion of the shoulder joint. The scapula of $H$. modestus shows the following cursorial characters: truncate vertebral border, reduced tuber of spine, and elongated and constricted neck (Osborn, 1929). The moderately developed acromion process is a primitive character in perissodactyls and indicates the presence of an acromial part of the deltoid muscle. The humerus of $H$. modestus also shows the following cursorial adaptations: greater tubercle not elevated, medial and lateral epicondyles reduced, and presence of a blunt sagittal ridge on the capitulum. The olecranon of the ulna is more proximally than posteriorly extended, 
TABLE 21

Measurements (in $\mathrm{mm}$ ) and ratios of forelimbs among compared ungulates

\begin{tabular}{|c|c|c|c|c|c|c|}
\hline Locomotion Type & Species & $\begin{array}{l}\text { Humerus } \\
\text { Length }\end{array}$ & $\begin{array}{l}\text { Radius } \\
\text { Length }\end{array}$ & $\begin{array}{l}\text { Mc III } \\
\text { Length }\end{array}$ & $\begin{array}{c}\text { Radio- } \\
\text { Humerus (\%) }\end{array}$ & $\begin{array}{c}\text { Mc- } \\
\text { Humerus (\%) }\end{array}$ \\
\hline Ambulatory & $\begin{array}{c}\text { Pantolambda } \\
\text { bathmodon }^{\mathrm{a}}\end{array}$ & 124 & 82 & 31 & 66 & 25 \\
\hline Subcursorial & $\begin{array}{l}\text { Phenacodus } \\
\text { primaevus }^{\text {a }}\end{array}$ & 173 & 145 & 72 & 84 & 42 \\
\hline Cursorial & $\begin{array}{l}\text { Hyracotherium } \\
\text { grangeri }^{\mathrm{b}}\end{array}$ & 99 & 86.6 & $47^{\mathrm{e}}$ & 87 & 47 \\
\hline Cursorial & Eohippus ${ }^{\mathrm{a}}$ & 121 & 110 & 64 & 91 & 53 \\
\hline Cursorial & Heptodon posticus ${ }^{\mathcal{C}}$ & 150 & 139 & 83 & 93 & 55 \\
\hline Cursorial & Heptodon calciculus ${ }^{\mathrm{a}}$ & 115 & 114 & 67 & 99 & 58 \\
\hline Cursorial & Hyrachyus modestus & 150 & 158 & 79 & 105 & 52 \\
\hline Cursorial & Hyrachyus eximius ${ }^{\mathrm{d}}$ & 270 & 200 & - & 74 & - \\
\hline Medioportal & Tapirus terrestris ${ }^{\mathrm{a}}$ & 205 & 177 & 106 & 86 & 52 \\
\hline Medioportal & Tapirus indicus ${ }^{\mathrm{a}}$ & 250 & 228 & 120 & 91 & 48 \\
\hline
\end{tabular}

a Osborn, 1929; ${ }^{\mathrm{b}}$ Wood et al., 2011; ${ }^{\mathrm{c}}$ Radinsky, 1965a; ${ }^{\mathrm{d}}$ Cope, $1884 ;{ }^{\mathrm{e}}$ measured from the plate.

also suggestive of cursorial adaptation (Osborn, 1929).

The ratio of the length of the radius to that of the humerus is about $105 \%$ in $H$. modestus (based on AMNH FM 12361 for the humerus and AMNH FM 12664 for the radius, making the ratio open to question), whereas the same ratio in Hyrachyus eximius is about 92\% (Holbrook, 2001). The ratio of the length of Mc III to that of humerus is about $52 \%$ in $H$. modestus (AMNH FM 12361 for the humerus and AMNH FM 12664 for the Mc III). Compared with the ratios among ambulatory (Pantol$a m b d a$ ), subcursorial (Phenacodus), cursorial ("Hyracotherium," Heptodon), and mediportal (Tapirus), the ratios of $H$. modestus clearly indicate its cursorial adaptation (table 21).

\section{InNominate AND Hind-Limb FunCtion}

The ilium of $H$. modestus shows the following cursorial characters: a narrow, thin, concave iliac crest, and relatively long, narrow wing and body. The femur of $H$. modestus has an elevated greater trochanter, and relatively high lesser and third trochanters, also suggesting cursorial adaptation (Osborn, 1929; Zhang and Yang, 2016). The tibiofemoral ratio of Hyrachyus modestus (AMNH FM 11662 ) is about 90.9 , and metatarso-femoral ratio from the different individual (based on AMNH FM 1612 for the Mt III and AMNH FM 11662 for the femur) is about 46.4, which is questionable (table 22). The tibio-femoral ratio and the metatarso-femoral ratio of $H$. agrarius, which was considered to be a junior synonym of Hyrachyus modestus (Radinsky, 1967), are about 96 and 43, respectively (Osborn, 1929). Compared with the ratios among ambulatory (Pantolambda), subcursorial (Phenacodus), cursorial ("Hyracotherium," Heptodon), and medioportal (Tapirus), the ratios of $H$. modestus clearly indicates its cursorial adaptation (table 22).

In general, the skeleton of $H$. modestus has a relatively low mass and cursorial adaptation. Recently, Stilson et al. (2016) indicated that relatively low body mass in Hyrachyus probably account for its low frequency of osteopathology compared with later large rhinocerotids. 
TABLE 22

Measurements (in $\mathrm{mm}$ ) and ratios of hindlimbs among compared ungulates

\begin{tabular}{|c|c|c|c|c|c|c|}
\hline Locomotion Type & Species & $\begin{array}{l}\text { Femur } \\
\text { Length }\end{array}$ & $\begin{array}{c}\text { Tibia } \\
\text { Length }\end{array}$ & $\begin{array}{l}\text { Mt III } \\
\text { Length }\end{array}$ & $\begin{array}{c}\text { Tibio- } \\
\text { femur (\%) }\end{array}$ & $\begin{array}{c}\text { MtIII- } \\
\text { femur }(\%)\end{array}$ \\
\hline Ambulatory & Pantolambda bathmodon ${ }^{\mathrm{a}}$ & 149 & 114 & 36 & 77 & 24 \\
\hline Subcursorial & Phenacodus primaevus ${ }^{\mathrm{a}}$ & 234 & 198 & 74 & 85 & 32 \\
\hline Cursorial & Hyracotherium grangeri ${ }^{b}$ & 138.3 & 123 & $56^{\mathrm{c}}$ & 89 & 40 \\
\hline Cursorial & Eohippus $^{\mathrm{a}}$ & 167 & 162 & $82^{\mathrm{d}}$ & 97 & 49 \\
\hline Cursorial & Heptodon calciculus ${ }^{\mathrm{a}}$ & 175 & 175 & 75 & 100 & 43 \\
\hline Cursorial & Hyrachyus modestus & 241.8 & 219.8 & 112.2 & 90.9 & 46.4 \\
\hline Cursorial & Hyrachyus modestus ${ }^{\mathrm{a}}$ & 254 & 243 & 110 & 96 & 43 \\
\hline Medioportal & Tapirus terrestris ${ }^{\mathrm{a}}$ & 262 & 208 & 108 & 79 & 41 \\
\hline Medioportal & Tapirus indicus ${ }^{\mathrm{a}}$ & 320 & 258 & 120 & 81 & 38 \\
\hline
\end{tabular}

a Osborn, 1929; ${ }^{\mathrm{b}}$ Wood et al., 2011; ${ }^{\mathrm{c}}$ measured from the plate; ${ }^{\mathrm{d}}$ approximate.

\section{PERSPECTIVES}

Our analyses on the skeleton of Hyrachyus modestus indicate Hyrachyus diverged from a more basal group of ceratomorphs rather than from Heptodon. Since Hyrachyus shares a close ancestry with at least non-hyracodontid rhinocerotoids and should be reasonably included in Rhinocerotoidea, this suggests a divergence time between Rhinocerotoidea and Tapiroidea in the early Eocene instead of middle Eocene as previous thought (Tougard et al., 2001; Hooker, 2005; Steiner and Ryder, 2011). Wang et al. (2011) reported the occurrence of rhinocerotoid-like Pataecops from an early Eocene Bumbanian deposit in Asia, and suggested the earliest record of the Rhinocerotoidea as the earliest Eocene, although the phylogenetic relationship of the enigmatic Pataecops remains controversial. Further, although Steiner and Ryder (2011) estimated the divergence of rhinoceroses and tapirs around 51 $\mathrm{Ma}$, the $95 \%$ confidence interval of the divergence period shows the possibility of an early Eocene divergence (Steiner and Ryder, 2011). The transition from Hyrachyus to Rhinocerotoidea requires additional study of early rhinocerotoids, especially Triplopus, the earliest representative of Hyracodontidae, whose affinities are less clear. Resolution of the specific transition from the basal ceratomorphs to rhinocerotoids and the rise of different groups of Rhinocerotoidea will require a through revision of Hyrachyus and a phylogenetic analysis of perissodactyls with a large, comprehensive data set. Further, new discoveries of pivotal fossils from early and middle Eocene will improve or change our traditional views on the evolutionary history of the Rhinocerotoidea.

\section{ACKNOWLEDGMENTS}

We thank Zhan-Xiang Qiu, Chuan-Kui Li, Yong-Sheng Tong, Zhao-Qun Zhang, Tao Deng, Xi-Jun Ni, Qian Li, Xun Jin, and Fang-Yuan Mao (all IVPP) for discussion; R. O'Leary, J. Galkin, A. Gishlick, C. Mehling, L. Jurgielewicz (all AMNH), A. Henrici and A. Tabrum (both Carnegie Museum of Natural History), P. Gingerich and A. Rountrey (both Museum of Paleontology, University of Michigan), C. Norris and D. Brinkman (both Yale Peabody Museum of Natural History), and W. Simpson (Field Museum of Natural History) for access to the specimens in their care; A. Balcarcel, R. Evander, V. Lee, A. Davidson (all AMNH), and M. Fox (Yale Peabody Museum of Natural History) for providing the comparative casts; S. Bell, T. Baione, M. Reitmeyer, A. Springer (all $\mathrm{AMNH}$ ) for providing literature access and assistance at the AMNH. We are grateful to N. Wong (AMNH) and W. Gao (IVPP) for the photographs. The first author is indebted to J.J. Flynn, C. Grohé (both AMNH), and Z.J. Tseng (University at Buffalo, State University of New York) for 
their invitation and collaboration in the 2015 expedition in the Bridger Basin and Washakie Basin, Wyoming. The review comments of $\mathrm{M}$. Coombs, P. O. Antoine, R. S. Voss, and an anonymous reviewer greatly improved the manuscript. We thank M. Knight (AMNH) for instructive editorial comments. Funding was provided by grants from China Scholarship Council, Frick Funds from the Division of Paleontology, American Museum of Natural History, the National Natural Science Foundation of China (41672014, 41572021, 41002009), the U.S. National Science Foundation (DEB 1456826), the Special Fund for Fossil Excavation and Preparation, CAS, State Key Laboratory of Palaeobiology and Stratigraphy (Nanjing Institute of Geology and Palaeontology, CAS) (no.163103), and Youth Innovation Promotion Association, CAS.

\section{REFERENCES}

Antoine, P. 2002. Phylogénie et évolution des Elasmotheriina (Mammalia, Rhinocerotidae). Mémoires du Muséum National d'Histoire Naturelle 188: 1-359.

Cerdeño, E. 1995. Cladistic analysis of the family Rhinocerotidae (Perissodactyla). American Museum Novitates 3143: 1-25.

Chow, M.C., and T. Qi. 1982. Mammals from the Middle Eocene Kuanchuang Formation of Sintai, Shandong. Vertebrata PalAsiatica 20 (4): 302-314.

Colbert, M.W. 2005. The facial skeleton of the early Oligocene Colodon (Perissodactyla, Tapiroidea). Palaeontologia Electronica 8 (1): 1-27.

Colbert, M.W. 2006. Hesperaletes (Mammalia: Perissodactyla), a new tapiroid from the middle Eocene of southern California. Journal of Vertebrate Paleontology 26 (3): 697-711.

Constantinescu, G., and O. Schaller. 2007. Illustrated veterinary anatomical nomenclature. Stuttgart: Enke Verlag.

Cope, E.D. 1884. The vertebrata of the Tertiary formations of the West. Book 1. Report of the United States Geological Survey of the Territories 3: 1-1009.

Deng, T., and Y. Chen. 2016. Chinese Neogene Rhinoceroses. Shanghai: Shanghai Scientific and Technical Publishers.

Emry, R.J. 1989. A tiny new Eocene ceratomorph and comments on tapiroid systematics. Journal of Mammalogy 70 (4): 794-804.
Emry, R.J.. 1990. Mammals of the Bridgerian (Middle Eocene) Elderberry Canyon local fauna of eastern Nevada. In T. M. Brown and K. R. Rose (editors), Dawn of the age of mammals in the northern Rocky Mountain Region. Geological Society of America Special Paper 243: 187-210.

Evans, H.E., and A. de Lahunta. 2013. Miller's Anatomy of the dog, 4th ed. St. Louis, Missouri: Elsevier Saunders.

Flower, W.H. 1885. An introduction to the osteology of the Mammalia. London: Macmillan and Co.

Franzen, J.L. 1981. Hyrachyus minimus (Mammalia, Perissodactyla, Helaletidae) aus den mitteleozänen Ölschiefern der 'Grube Messel' bei Darmstadt (Deutschland, S-Hessen). Senckenbergiana Lethaea 61 (3/6): 371-376.

Gromova, V. 1959. Giant rhinoceroses. Trudy Paleontology Institut Akademii Nauk SSSR 71: 1-164.

Hellmund, M. 2016. Tooth emergence and replacement in the European Hyrachyus minimus (Fischer, 1829) (Mammalia, Perissodactyla) from the Geiseltal Fossillagerstätte - a further example for 'Schultz's rule' in ungulates. Neues Jahrbuch für Geologie und Paläontologie, Abhandlungen 282 (2): 157-180.

Holbrook, L.T. 1999. Phylogeny and classification of tapiromorph perissodactyls (Mammalia). Cladistics 15: 331-350.

Holbrook, L.T. 2001. Comparative osteology of tapiromorph perissodactyls (Mammalia). Zoological Journal of the Linnean Society 132: 1-54.

Holbrook, L.T., and J. Lapergola. 2011. A new genus of perissodactyl (Mammalia) from the Bridgerian of Wyoming, with comments on basal perissodactyl phylogeny. Journal of Vertebrate Paleontology 31(4): 895-901.

Holbrook, L.T., and S.G. Lucas. 1997. A new genus of rhinocerotoid from the Eocene of Utah and the status of North American "Forstercooperia." Journal of Vertebrate Paleontology 17 (2): 384-396.

Hooker, J.J. 2005. Perissodactyla. In K.D. Rose and J.D. Archibald (editors), The rise of placental mammals: origins and relationships of the major extant clades: 199-214. Baltimore: Johns Hopkins University Press.

Huang, X., and J. Wang. 2002. Notes on Hyrachyus (Mammalia, Perissodactyla, Tapiroidea) from the Middle Eocene of Yunqu basin, Shanxi Province. Vertebrata PalAsiatica 40 (3): 211-218.

Huang, X.S., and T. Qi. 1982. Notes on late Eocene tapiroids from the Lunan Basin eastern Yunnan. Vertebrata PalAsiatica 20 (4): 315-326.

Kitts, D.B. 1956. American Hyracotherium (Perissodactyla, Equidae). Bulletin of the American Museum of Natural History 110 (1): 1-60. 
Osborn, H.F. 1890. The Perissodactyla. In W.B. Scott and H. F. Osborn, The Mammalia of the Uinta Formation. Transactions of the American Philosophical Society 16 (3): 461-572.

Osborn, H.F. 1898. The extinct rhinoceroses. Memoirs of the American Museum of Natural History 1 (3): 75-164.

Osborn, H.F. 1929. Titanotheres of ancient Wyoming, Dakota, and Nebraska. United States Geological Survey Monographs 55: 1-894.

Peterson, O.A. 1919. Report upon the material discovered in the upper Eocene of the Uinta Basin by Earl Douglas in the years 1908-1909, and by O.A. Peterson in 1912. Annals of Carnegie Museum 12 (2-4): 40-168.

Prothero, D. 2005. The evolution of North American rhinoceroses. Cambridge: Cambridge University Press.

Prothero, D.R., E. Manning, and C.B. Hanson. 1986. The phylogeny of the Rhinocerotoidea (Mammalia, Perissodactyla). Zoological Journal of the Linnean Society 87 (4): 341-366.

Qi, T. 1987. The Middle Eocene Arshanto fauna (Mammalia) of Inner Mongolia. Annals of Carnegie Museum 56: 1-73.

Qiu, Z.X., and B.Y. Wang. 2007. Paracerathere fossils of China. Palaeontologia Sinica (New Series C) 29: 1-396.

Radinsky, L. 1963. Origin and early evolution of North American Tapiroidea. Bulletin of the Peabody Museum of Natural History 17: 1-106.

Radinsky, L.B. 1965a. Evolution of the tapiroid skeleton from Heptodon to Tapirus. Bulletin of the Museum of Comparative Zoology 134 (3): 69-106.

Radinsky, L.B. 1965b. Early Tertiary Tapiroidea of Asia. Bulletin of the American Museum of Natural History 129 (2): 181-263.

Radinsky, L.B. 1966. The families of the Rhinocerotoidea (Mammalia, Perissodactyla). Journal of Mammalogy 47 (4): 631-639

Radinsky, L.B. 1967a. A review of the rhinocerotoid family Hyracodontidae (Perissodactyla). Bulletin of the American Museum of Natural History 136 (1): 1-45.

Radinsky, L.B. 1967b. Hyrachyus, Chasmotherium, and the early evolution of helatetid tapiroids. American Museum Novitates 2313: 1-23.

Savage, D., D. Russell, and P. Louis. 1966. Ceratomorpha and Ancylopoda (Perissodactyla) from the Lower Eocene Paris Basin, France. University of California Publications on Geological Science 66: $1-38$.
Schoch, R.M. 1984. Two unusual specimens of Helaletes in the Yale Peabody Museum collections, and some comments on the ancestry of the Tapiridae (Perissodactyla, Mammalia). Postilla 193: 1-20.

Sisson, S., J.D. Grossman, and R. Getty. 1975. The anatomy of the domestic animals, 5th ed. Philadelphia: W.B. Saunders Company.

Steiner, C.C., and O.A. Ryder. 2011. Molecular phylogeny and evolution of the Perissodactyla. Zoological Journal of the Linnean Society 163 (4): 1289-1303.

Stilson, K.T., S.S.B. Hopkins, and E.B. Davis. 2016. Osteopathology in Rhinocerotidae from 50 million years to the present. Plos One 11 (2): e0160793.

Tougard, C., T. Delefosse, C. Hanni, and C. Montgelard. 2001. Phylogenetic relationships of the five extant rhinoceros species (Rhinocerotidae, Perissodactyla) based on mitochondrial cytochrome $b$ and $12 S$ rRNA genes. Molecular Phylogenetics and Evolution 19 (1): 34-44.

Troxell, E.L. 1922. The genus Hyrachyus and its subgroups. American Journal of Science (series 5) 4 (19): 38-49.

Wang, Y., et al. 2011. Early Eocene perissodactyls (Mammalia) from the upper Nomogen Formation of the Erlian Basin, Nei Mongol, China. Vertebrata PalAsiatica 49 (1): 123-140.

Wang, H.B., B. Bai, J. Meng, and Y.Q. Wang. 2016. Earliest known unequivocal rhinocerotoid sheds new light on the origin of giant rhinos and phylogeny of early rhinocerotoids. Scientific Reports 6: 39607.

Wible, J.R. 2003. On the cranial osteology of the short-tailed opposum Monodelphis brevicaudata (Didelphidae, Marsupialia). Annals of the Carnegie Museum 72: 137-202.

Wood, H.E. 1927. Some early Tertiary rhinoceroses and hyracodonts. Bulletins of American Paleontology 13 (50): 5-105.

Wood, H.E. 1934. Revision of the Hyrachyidae. Bulletin of the American Museum of Natural History 67 (5): 181-295.

Wood, A.R., R.M. Bebej, C.L. Manz, D.L. Begun, and P.D. Gingerich. 2011. Postcranial functional morphology of Hyracotherium (Equidae, Perissodactyla) and locomotion in the earliest horses. Journal of Mammalian Evolution 18 (1): 1-32.

Zhang, Z.Q., and R. Yang. 2016. Morphology and taxonomy of Gazella (Bovidae, Artiodactyla) from the Late Miocene Bahe Formation, Lantian, Shaanxi Province, China. Vertebrata PalAsiatica 54 (1): $1-20$. 


\section{APPENDIX 1}

List of the Postcranial Anatomical Terms

On the left are the terms used here; on the right are the references and/or Nomina Anatomica Veterinaria (NAV) equivalents.

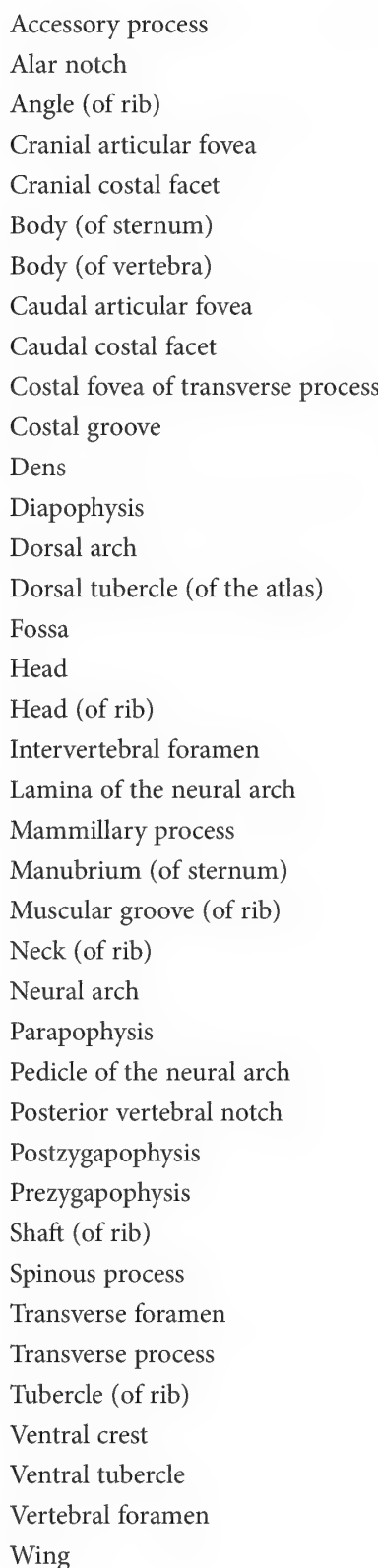

\section{Axial Skeleton}

Processus accessorius (NAV)

Incisura alaris (NAV)

Angulus costae (NAV)

Fovea articularis cranialis (NAV)

Fovea costalis cranialis (NAV)

Corpus sterni (NAV)

Corpus vertebrae (NAV)

Fovea articularis caudalis (NAV)

Fovea costalis caudalis (NAV)

Fovea costalis processus transversi (NAV)

Sulcus costae (NAV)

(NAV)

(Flower, 1885) $=$ Tuberculum dorsale (NAV)

Arcus dorsalis (NAV)

Tuberculum dorsale (NAV)

Extremitas caudalis [Fossa vertebrae] (NAV)

Extremitas cranialis [Caput vertebrae] (NAV)

Caput costae (NAV)

Foramen intervertebrale (NAV)

Lamina arcus vertebrae (NAV)

Processus mamillaris (NAV)

Manubrium sterni (NAV)

(Qiu et Wang, 2007)

Collum costae (NAV)

(Flower, 1885) $=$ Arcus vertebrae (NAV)

(Flower, 1885) $=$ Tuberculum ventrale (NAV)

Pediculus arcus vertebrae (NAV)

Incisura vertebralis caudalis (NAV)

(Flower, 1885) $=$ Processus articularis caudalis (NAV)

(Flower, 1885) $=$ Processus articularis cranialis (NAV)

Corpus costae (NAV)

Processus spinosus (NAV)

Foramen transversarium (NAV)

Processus transversus (NAV)

Tuberculum costae (NAV)

Crista ventralis (NAV)

Tuberculum ventral (NAV)

Foramen vertebrale (NAV)

Ala atlantis (NAV) 
Acromion

Anconeal process

Anterior angle

Anterior border

Articular fovea (of radius)

Bicipital groove

Capitulum

Carpal articular surface

Coracoid process

Cuneiform

Deltoid tuberosity

Dorsal border

Glenoid cavity

Greater tubercle

Head (of humerus)

Head (of radius)

Humeral condyle

Infraspinous fossa

Interosseous space (of the forearm)

Lateral epicondyle

Lateral coronoid process

Lesser tubercle

Lunar

Magnum

Medial coronoid process

Medial epicondyle

Medal styloid process

Metacarpal I-V

Neck (of radius)

Neck (of scapula)

Neck (of humerus)

Olecranon

Olecranon fossa

Pisiform

Radial tuberosity

Posterior angle

Posterior border

Radial fossa

Shaft (of humerus)

Scapular notch

Scaphoid

Spine

Styloid process

Supraspinous fossa

Supinator ridge

Supratrochlear foramen

Trapezoid
Bones of The Thoracic Limb

(NAV)

Processus anconeus (NAV)

Angulus cranialis (NAV)

Margo cranialis (NAV)

Fovea capitis radii (NAV)

(Flower, 1885) $=$ Sulcus intertubercularis $(\mathrm{NAV})$

Capitulum humeri (NAV)

Facies articularis carpea (NAV)

Processus coracoideus (NAV)

(Flower, 1885) = Os carpi ulnare [Os triquetrum] (NAV)

Tuberositas deltoidea (NAV)

Margo dorsalis (NAV)

Cavitas glenoidalis (NAV)

Tuberculum majus (NAV)

Caput humeri (NAV)

Caput radii (NAV)

Condylus humeri (NAV)

Fossa infraspinata (NAV)

Spatium interosseum antebrachii (NAV)

Epicondylus lateralis (NAV)

Processus coronoideus lateralis (NAV)

Tuberculum minus (NAV)

(Flower, 1885) = Os carpi intermedium [Os lunatum] (NAV)

(Flower, 1885) $=$ Os carpale III [Os capitatum] (NAV)

Processus coronoideus medialis (NAV)

Epicondylus medialis (NAV)

Processus styloideus medialis (NAV)

Ossa metacarpalia I-V (NAV)

Collum radii (NAV)

Collum scapulae (NAV)

Collum humeri (NAV)

(NAV)

Fossa olecrani (NAV)

(Flower, 1885) = Os carpi accessorium [Os pisiforme] (NAV)

Tuberositas radii (NAV)

Angulus caudalis (NAV)

Margo caudalis (NAV)

Fossa radialis (NAV)

Corpus humeri

Incisura scapulae (NAV)

(Flower, 1885) = Os carpi radiale [Os scaphoideum] (NAV)

Spina scapulae (NAV)

Processus styloideus (NAV)

Fossa supraspinata (NAV)

(Flower, 1885) $=$ Crista supracondylaris lateralis (NAV)

Foramen supratrochleare (NAV)

(Flower, 1885) = Os carpi II [Os trapezoideum] (NAV) 
Trapezium

Trochlea

Trochlear notch

Tuber of spine

Unciform

Acetabulum

Acetabular notch

Articular surface (of patella)

Anterior part (of greater trochanter)

Arcuate line

Astragalus

Apex (of patella)

Base (of patella)

Body (of ilium)

Body (of ischium)

Body (of pubis)

Calcaneus

Calcaneal tuber

Central intercondyloid area

Coxal tuberosity

Cuboid

Ectocuneiform

Entocuneiform

Extensor fossa

Extensor sulcus

Trochlea (of femoral)

Fovea (of femur)

Gluteal surface

Greater ischiatic notch

Greater trochanter

Head (of femur)

Head (of fibula)

Iliac rest

Intercondyloid fossa

Intercondyloid eminence

Intertrochanteric ridge

Ischiatic spine

Ischiatic arch

Ischiatic table

Ischiatic tuberosity

Lateral condyle

Lateral epicondyle

Lateral malleolus

Lessor ischiatic notch

Lessor trochanter

\author{
(Flower, 1885) = Os carpi I [Os trapezium] (NAV) \\ Trochlea humeri (NAV) \\ Incisura trochlearis (NAV) \\ Tuber spinae scapulae (NAV) \\ (Flower, 1885) = Os carpi IV [Os hamatum] (NAV)
}

Bones of the Pelvic Limb

(NAV)

Incisura acetabuli (NAV)

Facies articularis (NAV)

Pars cranialis (NAV)

Linea arcuata (NAV)

(Flower, 1885) $=$ Talus (NAV)

Apex patellae (NAV)

Basis patellae (NAV)

Corpus ossis ilii (NAV)

Corpus ossis ischii (NAV)

Corpus ossis pubis (NAV)

(NAV)

Tuber calcanei (NAV)

Area intercondylaris centralis (NAV)

Tuber coxae (NAV)

(Flower, 1885) = Os tarsale IV [Os cuboideum] (NAV)

(Flower, 1885) $=$ Os tarsale III [Os cuneiforme laterale] (NAV)

(Flower, 1885) = Os tarsale I [Os cuneiforme mediale] (NAV)

Fossa extensoria (NAV)

Sulcus extensorius (NAV)

Trochlea ossis femoris (NAV)

Fovea capitis (NAV)

Facies glutea (NAV)

Incisura ischiadica major (NAV)

Trochanter major (NAV)

Caput ossis femoris (NAV)

Caput fibulae (NAV)

Crista iliaca (NAV)

Fossa intercondylaris (NAV)

Eminentia intercondylaris (NAV)

Crista intertrochanterica (NAV)

Spina ischiadica (NAV)

Arcus ischiadicus (NAV)

Tabula ossis ischii (NAV)

Tuber ischiadicm (NAV)

Condylus lateralis (NAV)

Epicondylus lateralis (NAV)

Malleolus lateralis (NAV)

Incisura ischiadica minor (NAV)

Trochanter minor (NAV) 
Medial condyle

Medial epicondyle

Medial malleolus

Mesocuneiform

Metatarsal I-V

Navicular

Neck (of femur)

Neck (of astragalus)

Obturator foramen

Pelvic symphysis

Posterior part (of greater trochanter)

Pubis symphysis

Sacral tuberosity

Sacropelvic surface

Shaft (of femur)

Shaft (of fibula)

Shaft (of tibia)

Supracondyloid fossa

Sustentacular process

Third trochanter

Tibial tuberosity

Trochlea

Trochanteric fossa

Wing (of ilium)
Condylus medialis (NAV)

Epicondylus medialis (NAV)

Malleolus medialis (NAV)

(Flower, 1885) = Os tarsale II [Os cuneiforme intermedium] (NAV)

Ossa metatarsalia I-V (NAV)

(Flower, 1885) $=$ Os tarsi centrale [Os naviculare] (NAV)

Collum ossis femoris (NAV)

Collum tali (NAV)

Foramen obturatum (NAV)

Symphysis pelvina (NAV)

Pars caudalis (NAV)

Symphysis pubica (NAV)

Tuber sacrale (NAV)

Facies sacropelvina (NAV)

Corpus ossis femoris (NAV)

Corpus fibulae (NAV)

Corpus tibiae (NAV)

Fossa supracondylaris (NAV)

Sustentaculum tali (NAV)

Trochanter tertius (NAV)

Tuberositas tibiae (NAV)

Trochlea tali (NAV)

Fossa trochanterica (NAV)

Ala ossis ilii (NAV) 


\title{
Scientific Publications of the American Museum of Natural History
}

AMERICAN MUSEUM NOVITATES

BULletin of the American Museum of Natural History

anthropological Papers of the American museum of Natural History

\author{
Publications CommitTee \\ ROBERT S. VOSS, CHAIR \\ BOARD OF EDITORS \\ Jin Meng, PALEONTOlogy \\ LORENZO PRENDINI, INVERTEBRATE ZOOLOGY \\ ROBERT S. VOSS, VerTebrate ZOOLOGY \\ Peter M. Whiteley, Anthropology \\ MANAGING EDITOR \\ MARY KNIGHT
}

Submission procedures can be found at http://research.amnh.org/scipubs

All issues of Novitates and Bulletin are available on the web (http://digitallibrary. amnh.org/dspace). Order printed copies on the web from:

http://shop.amnh.org/a701/shop-by-category/books/scientific-publications.html or via standard mail from:

American Museum of Natural History-Scientific Publications

Central Park West at 79th Street

New York, NY 10024

(2) This paper meets the requirements of ANSI/NISO Z39.48-1992 (permanence of paper). 